\title{
SIGNIFICADOS E INTERPRETACIONES DE LA INFORMACIÓN DESDE EL USUARIO
}
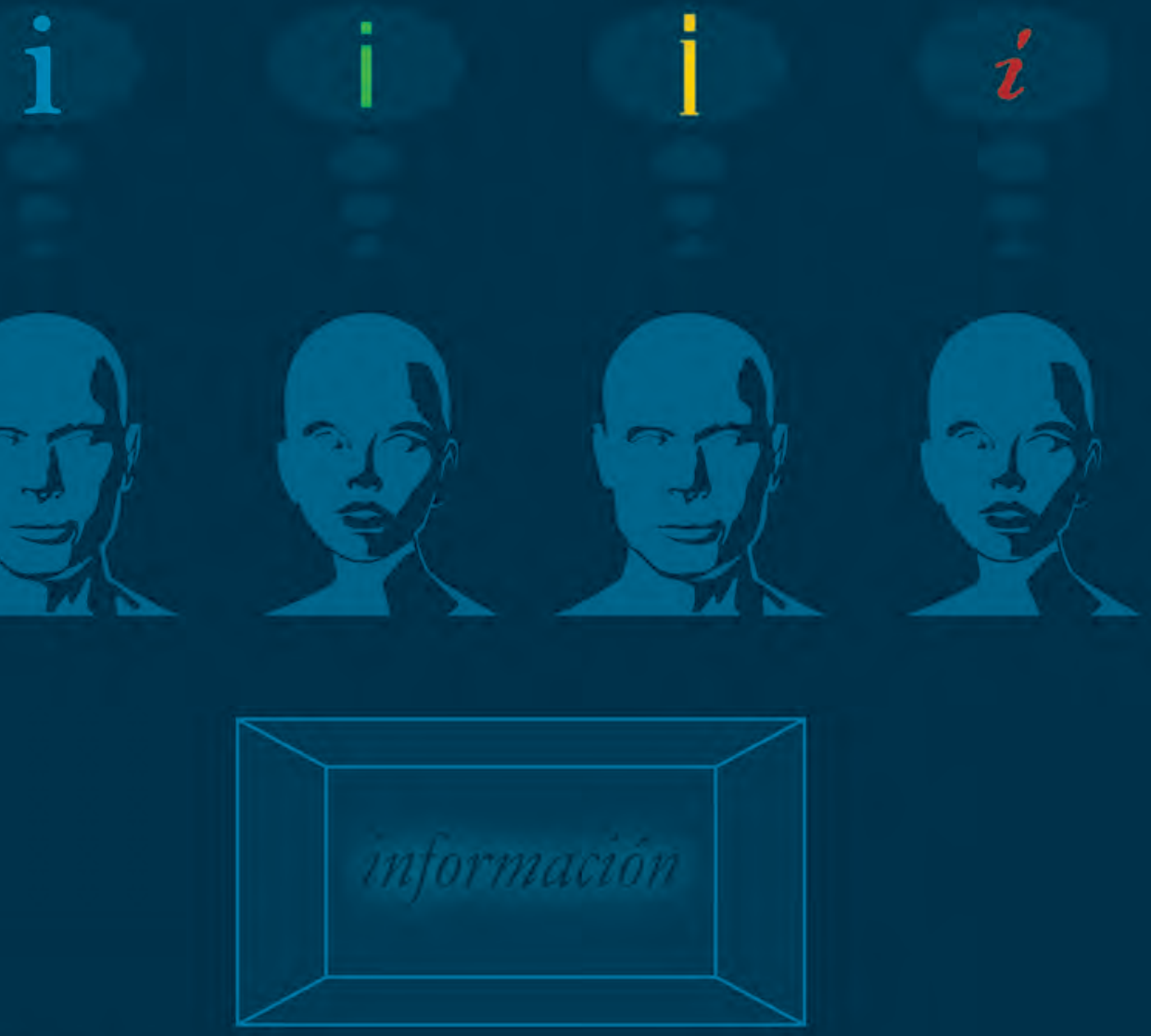

Coordinadora

Patricia Hernández Salazar 


\section{La presente obra está bajo una licencia de:}

\section{http://creativecommons.org/licenses/by-nc-sa/3.0/deed.es MX}

\section{Atribución-No Comercial-Licenciamiento Reciproco 3.0 Unported}

Eres libre de:

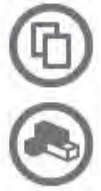

copiar, distribuir y comunicar públicamente la obra

hacer obras derivadas

Bajo las condiciones siguientes:

Atribución - Debes reconocer la autoría de la obra en los términos

especificados por el propio autor o licenciante.

No comercial - No puedes utilizar esta obra para fines comerciales.

Licenciamiento Recíproco - Si alteras, transformas o creas una obra a

partir de esta obra, solo podrás distribuir la obra resultante bajo una licencia

igual a ésta.

\section{Esto es un resumen fácilmente legible del: texto legal (de la licencia completa)}

En los casos que sea usada la presente obra, deben respetarse los términos especificados en esta licencia.
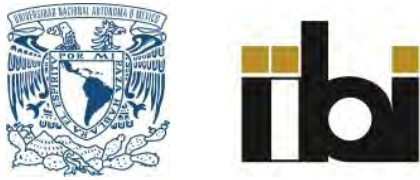
Significados e interpretaciones de la información desde el usuario 


\section{COLECCIÓN}

USO DE LA INFORMACIÓN, PROCESOS Y MEDIOS

Instituto de Investigaciones Bibliotecológicas y de la Información 


\section{Significados e interpretaciones de la información desde el usuario}

Coordinadora

\section{Patricia Hernández Salazar}

\section{Universidad Nacional Autónoma de México 2017}




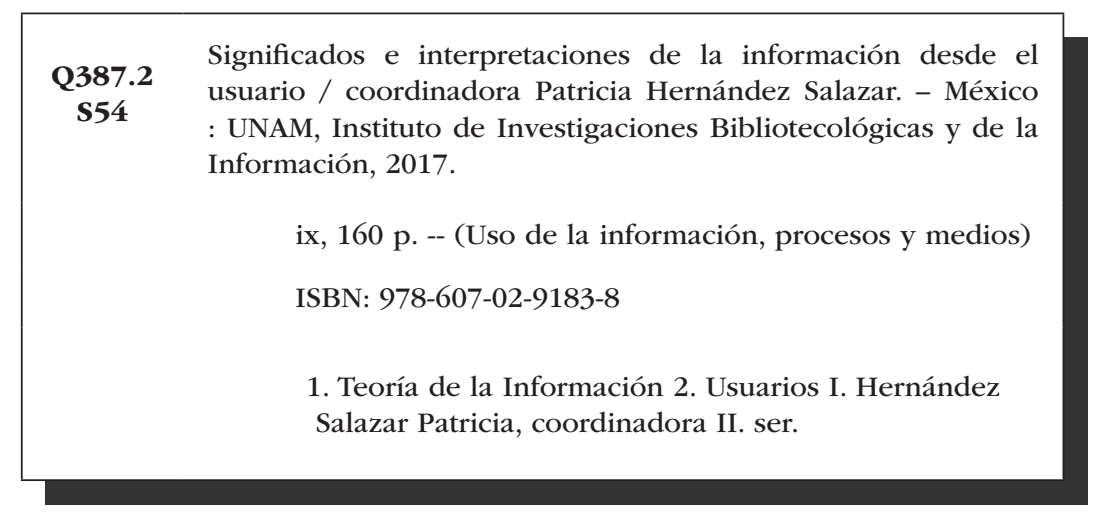

Diseño de portada: Mercedes Torres Serratos

Primera edición, 2017

DR (C) UNIVERSIDAD NACIONAL AUTÓNOMA DE MÉXICO

Ciudad Universitaria, 04510, Ciudad de México

Impreso y hecho en México

ISBN: 978-607-02-9183-8

Publicación dictaminada 


\section{Tabla de contenido}

Presentación ............................

Patricia Hernández Salazar

LA INFORMACIÓN Y SUS TRANSFORMACIONES: ¿QUÉ SIGNIFICA

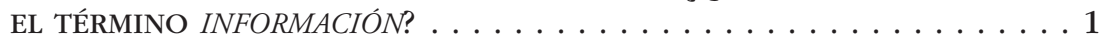

Víctor Manuel Solís-Macías

EL CONCEPTO DE INFORMACIÓN DESDE UNA ÓPTICA DE LA

FILOSOFÍA DE LA BIBLIOTECOLOGÍA Y LOS ESTUDIOS

DE LA INFORMACIÓN . . . . . . . . . . . . . . . . . . . . . . . . . . 29

Miguel Ángel Rendón Rojas

EL SENTIDO DE LA INFORMACIÓN: UN ENFOQUE CENTRADO

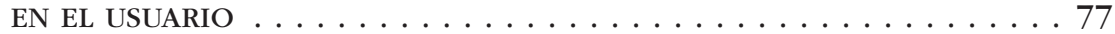

Patricia Hernández Salazar

LA INFORMACIÓN DESDE LA PERSPECTIVA DE COMUNIDADES

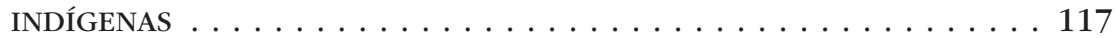

César Augusto Ramírez Velázquez

EL PAPEL DE LA ALFABETIZACIÓN INFORMATIVA PARA LA

INTERPRETACIÓN DE LA INFORMACIÓN . . . . . . . . . . . . . . . 127

Andrés Fernández Ramos 


\section{Presentación}

T a consolidación de cualquier disciplina requiere generar marcos teóricos que permitan a las comunidades epistémicas comunicarse en forma unívoca. Esto resulta complicado cuando los términos dejan de ser elementos que conforman un fenómeno y se convierten en el fenómeno a estudiar; un claro ejemplo es el término información.

Existe una gran cantidad de autores y estudios de diversas disciplinas humanísticas (filosofía, geografía, bibliotecología, estudios y ciencias de la información), sociales (comunicación, psicología, pedagogía, sociología) y aplicadas (informática) que han generado aproximaciones conceptuales y otras que se han comprometido con definiciones puntuales. Cada disciplina lo ha hecho a partir de sus propios objetos de estudio y campos fenoménicos, lo que determina su esencia, características y objetivo.

Lo anterior nos muestra que el tema ha sido tratado anteriormente, ¿qué ofrece este libro de novedoso? La aportación de esta obra es abordar la delimitación conceptual de 
La Infodiversidad y el uso ético del conocimiento...

información desde dos maneras de construcción de conocimiento: la interdisciplina y la intradisciplina. Además, está centrada en las dimensiones humanista y social del término, es decir, vinculada directamente con un sujeto, ya sea en un plano individual o como parte de una comunidad. Mirarlo como un ente social en relación con otros sujetos implica situarlo dentro de un contexto o entorno específico. Esto permitió averiguar si la práctica social modifica sus apreciaciones, si existe un cambio al transitar de un plano individual a uno social, y de un contexto a otro.

De este planteamiento surgieron las siguientes preguntas: ¿cómo se transforma la información en los sujetos? ¿Varía el concepto de información de acuerdo con sus aspectos ontológicos? ¿Qué sentido le da el individuo a la información? ¿Cómo la significa? ¿Está implicada la representación del mundo del sujeto en la interpretación de la información? ¿Cambia el sentido que un sujeto le da a la información cuando se ubica como ente social? ¿Los sujetos con las habilidades necesarias para explotar eficientemente los recursos informativos interpretan sus contenidos de manera diferente?

Para dar respuesta a estas interrogantes, el objetivo de la obra es precisar el sentido de la información a partir de los significados, transformaciones, apreciaciones e interpretaciones que los sujetos le confieren.

El acercamiento interdisciplinario se evidencia por la inclusión de las aportaciones de especialistas de la psicología y la filosofía. La primera, mediante el análisis de las transformaciones que se realizan en el cerebro de los sujetos ante la exposición a nueva información; se tratan procesos como la percepción, la memoria, la aprehensión y la asimilación para incorporarla como nuevo conocimiento. En cuanto a la segunda, ésta se encarga de examinar diversos 
aspectos del término, histórico, ontológico y etimológico, su gnoseología y su construcción lingüística.

Es posible apreciar la intradisciplina con la participación de estudiosos de la bibliotecología y ciencias de la información que trabajan en tres líneas de investigación: sentido de la información con un enfoque centrado en el usuario (cognitivo); estudio de comunidades indígenas, y alfabetización informativa.

Resulta interesante reconocer que existen diferencias y semejanzas en las definiciones de información desde diversas disciplinas y áreas de investigación dentro de la propia bibliotecología y estudios de la información. Vale rescatar los elementos comunes: cambio, transformación, estructura de conocimientos, construcción de ideas, representaciones lingüísticas, significados, interpretaciones, contexto, comunicación, y uso efectivo de la información mediante procesos mentales.

Es importante resaltar que Significados e interpretaciones de la información desde el usuario es producto del intercambio de saberes y reflexiones de los participantes del seminario de investigación Uso de la Información: Procesos y Medios: Víctor Manuel Solís-Macías, Miguel Ángel Rendón Rojas, César Augusto Ramírez Velázquez y Andrés Fernández Ramos. Vaya mi agradecimiento por su inestimable contribución al seminario y a este libro. 


\title{
La información y sus transformaciones: ¿qué significa el término información?
}

\author{
VÍCTOR MANUEL SOLÍS-MACÍAS
}

Universidad Nacional Autónoma de México

¿CÓMO PODEMOS DEFINIR Y DESCRIBIR LA INFORMACIÓN?

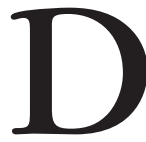
efinir con claridad y rigor el concepto de información es una tarea tan elusiva como necesaria. Este término tiene un problema, y es que lo utilizamos tan frecuentemente, en contextos tan heterogéneos y de maneras tan diferentes, que imaginamos que lo conocemos cuando en realidad no es así. Empezaremos considerando cuánto nos acercan los diccionarios a ese fin y a continuación ofreceremos una definición que inicialmente puede parecer poco intuitiva; pero una vez explicada y ejemplificada, nos dará las bases para desarrollar este capítulo.

Los diccionarios - supuestas autoridades que ocasionalmente ofuscan más que aclaran- definen así la información: el de la Real Academia Española, en la primera de ocho acepciones - que es por lo menos elegantemente breve- dice que es la "acción y efecto de informar". No obstante, dicha propuesta incurre en circularidad por incluir en la definición aquello que intenta definir. Borges ilustra 
esta incorrección en "Las Kenningar", cuando cita a pie de página la "segunda regla menor de la definición": Definitum in definitione ingredi non debet (lo definido no debe entrar en la definición) (1936: 372), a la cual califica de "risueña infracción"; mas infracción al fin.

La mayoría de las restantes definiciones no corren con mejor suerte. Por ejemplo, en Definición $A B C$, una ambiciosa descripción indica: "La información es un conjunto de datos con significado que estructura el pensamiento de los seres vivos, especialmente, del ser humano." A primera vista, esta definición no incita objeciones; empero, nos compromete a aceptar por lo menos tres nociones cuestionables. La primera, que la información invariablemente posee significado. La segunda, más polémica, que su efecto causal e invariable es la estructuración del pensamiento; la función primordial de la información no es "estructurar el pensamiento", independientemente de lo que eso signifique. La tercera, especulativa, sugiere que la información estructura el pensamiento de los seres vivos. ¿De todos ellos, o prudentemente convendría limitarla a los seres vivos multicelulares, a los vertebrados, o sólo a los mamíferos?

Afortunadamente, definiciones-de nos ofrece esto: "La información es un conjunto de datos organizados acerca de algún suceso, hecho o fenómeno, que en su contexto tiene un significado determinado, cuyo fin es reducir la incertidumbre o incrementar el conocimiento sobre algo." Nuestra única objeción es que el inicio de la definición puede mejorar, o preferiblemente extirparse; bastan las nueve palabras finales para describir con concisión y rigor el concepto que nos ocupa.

En inglés el problema tampoco queda resuelto. Por ejemplo, el Diccionario de Oxford indica vagamente que la información consiste en "[...] hechos que comunicamos o 
aprendemos sobre algo o alguien." Igualmente, el MerriamWebster, afiliado a la Encyclopædia Britannica, sugiere en su primera acepción que información es la "[...] comunicación o recepción de conocimiento o inteligencia”. En otras palabras, intenta definir el concepto como un intercambio de conocimiento. Naturalmente el problema no queda resuelto, puesto que únicamente sustituyen un concepto por otro, yendo de "información" a "intercambio de conocimiento", y resta por definir qué entienden por éste último.

Al seguir la estrategia de definir conceptos en forma reversible, la mayoría de los diccionarios nos pone en peligro de caer en regresiones interminables, en este caso sugiriendo que la información implica conocimiento. Empero, consultando la definición de conocimiento, encontramos que éste revierte a la noción de información, o bien con comprensión, posesión de habilidades o con "tener conciencia" de algo. En suma, la mayoría de las definiciones de información son - paradójicamente- poco informativas, desorganizadas, o circulares. No obstante, si alguien intrépidamente lograra llegar a la cuarta acepción de la segunda definición de información en Merriam-Webster leería: "[...] cantidad que mide la incertidumbre en el resultado de un experimento que está por realizarse.” Esto ya está más cercano a la realidad, aunque la enredan innecesariamente predicando que se aplica "a un experimento que está por realizarse." No es necesario en absoluto hablar de experimentos, realizados o por realizarse, para definir la información. Inopinadamente, la definición más apropiada y concisa proviene del Diccionario de negocios. Éste indica que la información consiste en datos que: "[...] pueden conducir a un incremento en la comprensión y a una reducción de la incertidumbre.”

¿Cuál es entonces la definición de información que proponemos? De manera tan breve como poco intuitiva 
- como ya advertimos-, ésta indica: la información es reducción de incertidumbre y aumento del conocimiento. Esta noción es abordada en dos de las definiciones comentadas anteriormente. Ahora la explicaremos y ejemplificaremos. En primer lugar, aclaremos que por incertidumbre nos referimos al concepto de incertidumbre probabilística, es decir, a la posibilidad de elegir uno de varios eventos posibles. Otra acepción alternativa de este concepto describe la incertidumbre como sensaciones de duda, perplejidad, o vacilación, mismas que no se aplican en este caso.

¿Cómo puedo aumentar conocimiento y reducir incertidumbre? Eso ocurre, por ejemplo, cuando somos presentados a personas que previamente no nos conocían. Al decir nuestro nombre transmitimos información en dos formas; la primera es obvia, la segunda no. Cuando decimos nuestro nombre, aumentamos el conocimiento del receptor. Lo que es menos evidente es que ipso facto de decir nuestro nombre también eliminamos incertidumbre, puesto que implícitamente descartamos todas las posibilidades restantes, es decir, todos los nombres imaginables, desde la A hasta la Z.

Imaginen que les revelan el resultado de tres juegos de azar: lanzar un volado, rodar un dado y extraer una carta de una baraja. Nuestro conocimiento aumenta cuando nos informan que el resultado del volado fue "águila", el del dado "seis", y el de la carta "reina de corazones". Lo que no es obvio, pero sí muy informativo, es estimar cuánta incertidumbre se redujo en cada evento. Al saber que salió "águila" descartamos exactamente un medio de incertidumbre (50\%).

Con el dado descartamos cinco sextos (83\%) de incertidumbre, correspondiente a los eventos que no resultaron (del 1 al 5). Finalmente, con la baraja descartamos la mayor proporción de incertidumbre (98\%), ya que en cuanto supi- 
mos que salió la reina de corazones eliminamos las 51 posibilidades restantes. Conocer los resultados nos dio nuevos conocimientos (águila, seis, y reina de corazones), e igualmente fue muy informativo cuando consideramos cuánta incertidumbre quedó eliminada en cada evento: 50\%, 83\% y $98 \%$.

¿CÓMO TRANSFORMAMOS LA INFORMACIÓN?

Desde que la información llega a nuestro organismo es sometida a una variedad de transformaciones. A continuación detallamos algunos de estos procesos.

\section{Transformaciones sensoriales}

Antes del surgimiento de los métodos experimentales que utilizamos para investigar la sensopercepción, varios pensadores prominentes ya habían advertido la enorme distancia que media, por una parte, entre los datos que arriban a nuestros sentidos $y$, por otra, la riqueza de detalle con la cual interpretamos dicha información. Por ejemplo, Schopenhauer (1813) delinea esa conexión en su tesis doctoral en la universidad de Jena. Más adelante, el polímata von Helmholtz (1867) propone la teoría de las inferencias inconscientes. Ésta sugiere que, sin tener consciencia de ello, habitualmente interpretamos cantidades limitadas de datos sensoriales a partir de los cuales formulamos con regularidad - mas no invariablemente - interpretaciones plausibles y organizadas que fundamentamos en nuestro conocimiento previo. La influencia de von Helmholtz dista mucho de ser exclusivamente histórica. Hay numerosos tratamientos modernos de la noción de inferencias inconscientes, como 
por ejemplo la elaboración bayesiana de este concepto, así como numerosos estudios contemporáneos sobre el mismo (v. gr., Geisler y Kersten, 2002; Hatfield, 2002; Hilbert, 2005; Meyering, 1989; Pellicano y Burr; Westheimer, 2008).

Más recientemente, al tratar sobre la relación entre cognición y categorización, Harnad (2005) indica: somos organismos sensoriomotrices. Los órganos de los sentidos tienen la función de llevar a cabo las primeras transformaciones de la información. Éstas consisten en transformar diversas modalidades de energía física a un lenguaje único: el lenguaje electroquímico del sistema nervioso. Así, la visión recodifica la energía electromagnética de la luz; la audición lo hace con los patrones acústicos; el olfato y el gusto transforman señales químicas, mientras que las diversas variedades del tacto - el sentido somatosensorial- procesan señales de presión, temperatura, dolor y propriocepción. Un aspecto fundamental de nuestros sensoreceptores es que por su propia naturaleza hacen que todas las transformaciones que realizan estén organizadas (ver apartado sobre categorización). ¿Y cómo organizan los sensoreceptores dichas transformaciones? En parte por su propia arquitectura, la cual determina y estructura cómo detectamos los estímulos medioambientales.

Los umbrales, rangos detectables de energía. Por principio, todo organismo posee limitaciones acerca del rango de energías físicas que puede detectar, denominados umbrales. En el caso de la visión cromática, el ojo humano percibe un intervalo aproximado de longitud de onda entre 400 y $700 \mathrm{~nm}$ (nanómetros: $1 x 10^{-9} \mathrm{~m}$.), desde el violeta hasta el rojo (Bohren y Clothiaux, 2006). Mientras que el ojo humano no suele detectar ultravioleta, ciertos insectos y aves diurnas como las abejas (Apis mellifera) y los periquitos australianos (Melopsittacus undulatus) pueden hacerlo, ya 
que su sistema visual capta esas longitudes de onda. El oído humano normal puede discriminar un rango de frecuencias que va desde 20 hasta $20,000 \mathrm{~Hz}$, en tanto que el rango de intensidad perceptible abarca desde 0 hasta $130 \mathrm{~dB}$ (Gelfand, 1990; Katz, 2002).

Determinantes estructurales de la percepción. Aparte de la forma en que los umbrales demarcan la captación de información, la arquitectura y fisiología de cada sensoreceptor igualmente determinan y delimitan qué magnitudes y cualidades vamos a procesar. En el caso de la visión, la retina contiene dos clases de fotoreceptores, conos y bastones. Los primeros nos dan mayor agudeza visual, así como la visión cromática (Rowe, 2002; Solomon y Lennie, 2007). Los segundos poseen una mayor sensibilidad y nos dan la capacidad de visión escotópica, capaz de operar en condiciones de baja iluminación (Marc, Anderson, Jones, Sigulinsky y Lauritzen, 2014).

En el caso de la audición la cóclea transforma patrones de presión en experiencias auditivas. De manera análoga a los fotoreceptores es diferencialmente sensible, en este caso a diferentes rangos de frecuencia, siendo más receptiva a frecuencias altas cerca de la base y a frecuencias bajas en el ápice. Ese arreglo respecto a frecuencias es preservado por las diversas estructuras que conducen los impulsos auditivos hasta los centros especializados del cerebro en un arreglo denominado mapas tonotópicos (Formisano, Kim, Di Salle, van de Moortele, Ugurbil, y Göbel, 2003; Shera, Guinan, Jr., y Oxenham, 2002; Stakhovskaya, Sridhar, Bonham, y Leake, 2007). Como ejemplo final citaremos la organización espacial del sentido del gusto, ya que los receptores a las diversas dimensiones del sabor también se ubican diferencialmente en la superficie de la lengua (Chandrashekar, Hoon, Ryba y Zuker, 2006; Scott, 2005). 
Significados e interpretaciones de la información desde el usuario

En suma, la totalidad de nuestras experiencias perceptuales está mediada por la naturaleza y características de respuesta de nuestros órganos sensoreceptores y las diversas transformaciones que éstos realizan sobre los datos que nos proporciona la información medioambiental.

\section{Atención selectiva}

Una segunda forma de transformar la información consiste en atenderla selectivamente, filtrando sólo algunos de los muchos estímulos que impactan nuestros sentidos. Justo en este instante y mientras lees, pon atención en tu postura corporal y responde las siguientes preguntas: ¿cuál es tu posición corporal? ¿Estás sentada, de pie, o reclinada? ¿Cómo tienes las piernas, cruzadas, paralelas o en alguna otra posición? ¿Cómo están colocados tus brazos? ¿Tienes alguna sensación corporal como tensión muscular, fatiga, hambre o sueño? Mediante la atención selectiva decidimos qué aspectos del medio ambiente - interno y externo- procesamos con mayor detalle y cuáles dejar fuera de nuestra vigilancia. La atención consiste en atender sólo algunos aspectos de la información y descartar los demás.

Otra descripción de atención señala que es la asignación de recursos limitados de procesamiento, ya que es imposible atender simultáneamente a todos los estímulos medioambientales (Anderson, 2004; Kinchla, Solís-Macías y Hoffman, 1983). Incluso los estímulos más sencillos nos permiten ilustrar este principio. La Figura 1 ilustra la articulación alternativa figura-fondo. La figura puede ser selectivamente interpretada como un par de perfiles o como una copa; no obstante, no podemos pensar en ambas simultáneamente. Obviamente podemos ver ambas imágenes a la vez, pero 
no podemos atender paralelamente al significado de cada estímulo.

Figura 1.

Ejemplo clásico de organización figura-fondo

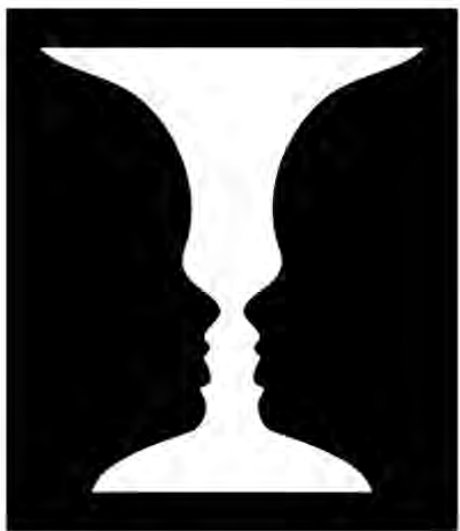

\section{Memoria}

La memoria es un proceso cognoscitivo que sustenta nuestra existencia. El primero en estudiarla experimentalmente fue Hermann Ebbinghaus (1885). Los procesos de la memoria son propicios para ilustrar diversas transformaciones de la información. Esto se debe a que nuestra memoria realiza múltiples transformaciones a lo largo de sus operaciones esenciales: (1) codificación, (2) registro (almacenamiento) y (3) recuperación. Al hablar de memoria aludimos a los procesos y estructuras que realizan estas operaciones. La memoria empieza a operar cuando se recibe información, sea de los sensoreceptores o de operaciones que realizamos internamente. Por codificación entendemos la recepción de información, así como todo cambio en el formato de representación de la misma. El registro es la permanencia de 
la información en nuestra memoria. Dicha permanencia va desde fracciones de segundo hasta el resto de nuestra vida. Finalmente, la recuperación es el proceso de reactivar la información para su utilización, y adopta diversas formas. Recuperamos información explícitamente al activar el recuerdo del nombre de una persona, y también al activar el reconocimiento de una melodía que nos agrada. Los procesos anteriores son formas de memoria declarativa. Otra clase de memoria es la de procedimientos; consiste en conductas motoras que pueden ser sencillas, como vestirnos; ser relativamente más complicadas como manejar un automóvil, o poseer un avanzado grado de refinamiento, como la interpretación musical por parte de un virtuoso.

¿Cómo transforma la información nuestra memoria? Lo hace, por ejemplo, cuando escuchamos una palabra y la convertimos en una representación visual. Al escuchar "mesa" podemos evocar la imagen mental de cualquier mesa particular, hecha de materiales específicos y que posee dimensiones y atributos (visuales, táctiles, etcétera) que activamos en nuestra memoria. En este ejemplo, el paso de la representación auditiva inicial de "mesa" a su representación mental posterior en modalidad visual ejemplifica una transformación mental.

Otro tanto sucede entre las etapas de registro y recuperación. Supongamos que una persona estudia anatomía para presentar un examen. Para hacerlo, aprende visualmente diversas estructuras anatómicas. Supongamos que el examen fuera verbal y se pidiera a la examinada especificar la localización de cierto órgano con respecto a otras estructuras, $v$. gr., "¿qué estructura se localiza por debajo del hipotálamo anterior y sobre la hipófisis?" En este caso, la transformación requerida consiste en cambiar la información de un código visual a uno verbal y responder "quiasma óptico". 
Lo mismo sucede en una prueba de conocimientos musicales cuando se nos pide identificar una melodía, su autor, o cualquier otro dato relevante. La transformación consiste en reconocer auditivamente el fragmento y en evocar a partir de éste la información verbal correspondiente.

Acostumbramos realizar estas transformaciones en forma automática, sin reparar siquiera en su enorme complejidad, como tampoco en los procesos que utilizamos. Cuando visitamos lugares desconocidos solemos pedir orientación para visitar algún punto de interés. Quien nos guíe nos va a dar una serie de explicaciones verbales, $v$. gr., "camine tres cuadras, al llegar al semáforo verá un banco, de vuelta a la derecha, siga directo dos cuadras más, dé vuelta a la izquierda y ahí está el lugar." Las personas no suelen tener problemas para transformar estas secuencias verbales en un mapa visual interno que guíe su recorrido. Para hacerlo realizan una compleja serie de transformaciones a partir de descripciones discretas que generan un mapa mental continuo que los lleve a su objetivo.

Estas instancias ilustran transformaciones de la información. Por ejemplo, al cambiar de una modalidad sensorial a otra como en los exámenes de anatomía o música que citamos. En el caso del mapa mental transformamos direcciones discretas en una representación continua. Sin entrar en detalles, una variable discreta tiene valores enteros, y una continua puede tomar valores tan fragmentarios como nos convenga. La proporción de águilas y soles que resulta de lanzar 10 volados es una variable discreta. Pueden registrarse siete águilas y tres soles, pero nunca 6.77 soles y 3.23 águilas. En contraste, el tiempo requerido para realizar un proceso es una variable continua, puesto que tiene sentido fraccionarlo tanto como sea necesario, y reportar que el tiempo de reacción ante un estímulo es de 7 segs., de 7.5 
segs., o de 757 msgs. (milésimas de segundo o milisegundos). En el ejemplo de la dirección, cada descripción verbal es discreta y su representación visual interna es continua.

Haga ahora el siguiente ejercicio: evoque tan rápidamente como le sea posible el rostro de una persona que le parezca muy atractiva, y en cuanto lo logre responda las siguientes preguntas: ¿requirió mucho tiempo para responder? ¿Imaginó el rostro deseado, o inesperadamente evocó - por ejemplo_ la imagen de un mueble? ¿Se siente muy agotada por hacer el ejercicio? Obviamente no tuvo el menor problema para hacerlo, y podría pensar que éste es trivial; pero no es así. Entre la petición de evocar ese rostro y lo que hizo de manera tan aparentemente sencilla hubo una serie de procesos cognoscitivos que le permitieron responder con facilidad. Por contraste, considere las dificultades que afrontan ciertos pacientes neurológicos y advertirá la complejidad de estas tareas. Esto ocurre en quienes sufren prosopagnosia, una clase de agnosia visual caracterizada por la incapacidad de reconocer rostros humanos, inclusive el de la propia persona que padece esta condición (Grüter, Grüter y Carbon, 2008).

Advierta que pude haberle pedido que manipulara cualquier otra imagen, como el contorno geográfico de México, el plano de su casa o cualquier otra imagen visual conocida. De cualquier forma, hubiera generado su respuesta con la misma facilidad, ya que nuestra memoria realiza éstas y muchas otras transformaciones de manera automática, en forma prácticamente instantánea y sin esfuerzo aparente. 
TRANSFORMACIONES QUE REORGANIZAN E INCREMENTAN LA INFORMACIÓN

En esta sección abordaremos dos procesos que no sólo son activados en respuesta a ciertas transformaciones de la información; además, su activación tiene efectos a más largo plazo que las descritas anteriormente y pueden conducir a reorganizaciones más perseverantes y profundas de nuestro conocimiento. Éstos son: (1) el léxico mental y (2) la categorización.

\section{El léxico mental (LM)}

Este concepto, introducido por Oldfield (1966), se refiere a una especie de diccionario mental que reside en nuestra memoria a largo plazo. El LM contiene información acerca de todas las palabras que conocemos, e incluye, entre otros, datos sobre $i$ ) significado, $i$ i) sintaxis, y $i$ ii) fonología de las palabras. Más activamente que un léxico físico, el LM describe cómo codificamos, activamos, almacenamos y recuperamos las palabras, y no está organizado alfabéticamente. La analogía nominal con un léxico fue hecha meramente con intenciones descriptivas.

Una propiedad del LM es que su contenido se actualiza a lo largo de toda nuestra vida, puesto que acumulamos nuevos vocablos y significados gracias a nuestras experiencias lingüísticas. Por ejemplo, un estudio canadiense (2008) exploró el crecimiento exponencial del vocabulario de las personas entre los 18 meses y los 17 años de edad. En promedio, se producen menos de 100 palabras a los 18 meses, a los seis años ya se producen más de 10,000; a los 17 ese promedio se acerca a 100,000. En su punto más productivo, 
los niños incorporan en promedio más de ocho palabras diariamente (Bloom, 2000).

La Figura 2 ejemplifica una posible representación del conocimiento sobre el concepto de adverbio y sirve para ejemplificar cómo podemos ir incorporando nueva información lingüística a la que ya poseemos.

Figura 2.

Descripción gráfica del concepto de adverbio. llustra cómo acrecentamos nuestro conocimiento de ese concepto y lo vinculamos con otros

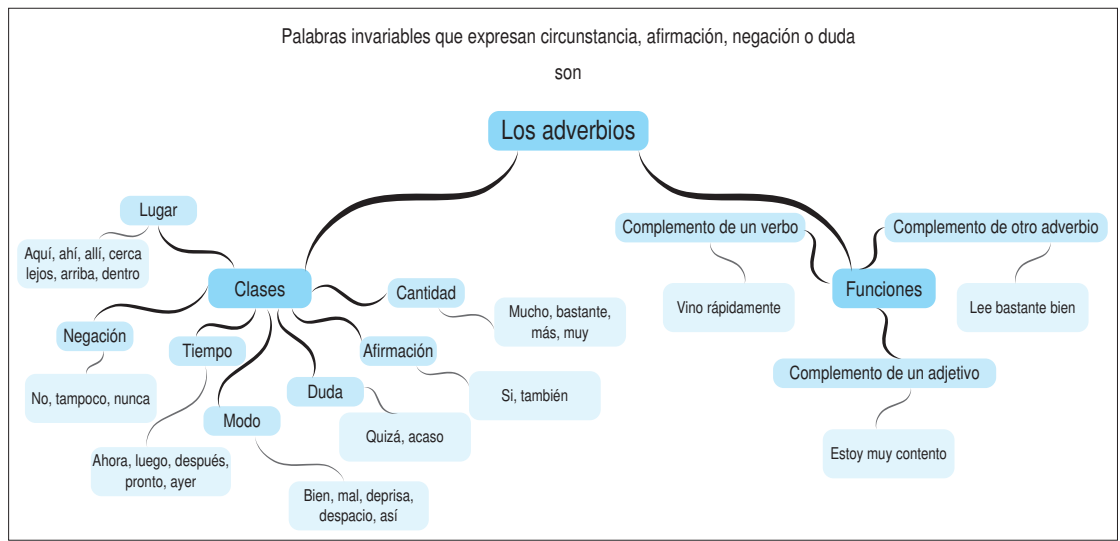

Fuente: elaboración propia.

La tarea experimental que se utiliza más frecuentemente para explorar el LM es la verificación lexicográfica. Ésta consiste en presentar una serie de estímulos verbales, y pedir a los participantes que decidan tan rápidamente como puedan si cada uno de esos estímulos es, o no, una palabra válida. Los participantes responden oprimiendo una de dos teclas que indican su decisión de "verdadero" o "falso". La variable dependiente que registramos es el tiempo de reacción, medido en msgs (milésimas de segundo).

Dependiendo de los objetivos de un experimento, el número, secuencia y naturaleza de los estímulos puede variar 
considerablemente. No obstante, un factor común de estos estudios es que se utiliza una proporción de palabras verdaderas y otra de falsas, estudiando el patrón de latencias resultante para hipotetizar qué factores causaron el patrón observado, v. gr., Solís-Macías (2011).

La investigación sobre el LM es muy activa; numerosos estudios exploran una rica variedad de interrogantes como - por ejemplo- qué áreas de la corteza cerebral responden a la estimulación visual rápida (Lochy, Van Belle y Rossion, 2015); si los lectores jóvenes disponen de acceso rápido al LM o éste se desarrolla con la experiencia y maduración (Perea, Jiménez y Gomez, 2015). Argyriou, Byfield y Kita (2015), analizan cómo el hemisferio derecho procesa semánticamente las metáforas, y Zhu, Gold, Chang, Wang, y Juan (2015) examinan qué regiones frontales del cerebro determinan la velocidad de respuesta.

La investigación sobre el LM amplía nuestra comprensión sobre cómo éste se estructura y refina mediante la experiencia. Dos preguntas cruciales sobre el lenguaje y el LM son: ¿cómo se relacionan nuestros pensamientos con las palabras que utilizamos para expresarlos? Y a su vez, ¿cómo buscamos esas palabras en nuestra mente para comunicar eficientemente nuestros pensamientos? El LM debe poseer un alto grado de organización que nos permita expresarnos de manera adecuada, rápida y con mínimo error. Esto es importante, puesto que este capítulo considera la influencia de la búsqueda de información sobre su representación y sus transformaciones.

El LM es crucial para el manejo del lenguaje. Gell-Mann (1994), Gell-Mann y Park (1997) y Kirby (1999) caracterizan al lenguaje como un sistema adaptativo complejo (sIC, por sus siglas en inglés), e indican que esa adaptación se logra por un proceso de auto-organización y selección. Dooley 
(1997) sugiere que todo SIC funciona y evoluciona gracias a tres principios esenciales: (1) su orden es emergente; la organización de un SIC no está predeterminada, sino que emerge por la experiencia. (2) la bistoria del sistema es irreversible. Entre los registros más permanentes de nuestra memoria están los del LM. Evidentemente, en ocasiones podremos olvidar temporalmente alguna palabra conocida; el ejemplo más ilustre es el fenómeno de tener la información "en la punta de la lengua" (PdeL). Ocurre cuando intentamos recordar una palabra y nuestros intentos iniciales fracasan. Al describirlo, William James (1890) señala que es un estado de "leve tortura" por alusión a la irritación que causa no poder nombrar algo que solemos designar con familiaridad. No obstante, PdeL no ilustra una falla del LM, sino un fallo temporal de la memoria. En este sentido, Tulving y Pearlstone (1966) diferenciaron entre dos estados alternativos de la información en memoria. Uno es la disponibilidad, y describe el hecho de tener información potencialmente utilizable. Otro es la accesibilidad, e indica que la información no sólo está disponible, sino que tenemos acceso directo a ella. PdeL ilustra una incapacidad temporal de acceder a nuestra memoria, si bien la información sigue disponible. (3) El futuro del SIC es a menudo imprevisible. Esta propiedad amplía la primera, ya que además de un orden no preestablecido, tampoco se fija de antemano el curso de desarrollo de nuestro sic.

En las instancias iniciales que propusimos - perceptuales, atencionales y mnemónicas - vimos cómo se transforma la información al codificarla, seleccionarla y registrarla. A partir del LM, abordamos procesos aún más dinámicos y perseverantes, puesto que ya no sólo aluden a transformaciones de la información, sino a formas acumulativas de 
La información y sus transformaciones...

crecimiento y (re)organización que emergen como consecuencia de manipular nuestros contenidos mentales.

\section{Categorización}

Junto con el LM, la categorización es otra instancia de transformaciones de la información que opera a largo plazo y reorganiza significativamente los contenidos mentales. Al categorizar agrupamos conceptos con base en dos cualidades. Primera, los miembros de una categoría comparten entre sí varios atributos en común y guardan cierta similitud entre ellos. Segunda, el conjunto de rasgos que designa pertenencia dentro de una categoría a su vez la diferencia de otras (Rosch, 1978). La categorización organiza conceptos. Éstos son los vehículos del pensamiento, puesto que representan simbólicamente nuestro conocimiento y derivan de experiencias directas con instancias específicas (Bruner, Goodnow, y Austin, 1956; Love, 2003). Una diferencia importante entre categorías y conceptos es que éstas representan clases de objetos en el medio ambiente, en tanto que los conceptos son las representaciones mentales de tales clases (Margolis, 1994).

Aristóteles hizo la contribución inicial en este campo. En

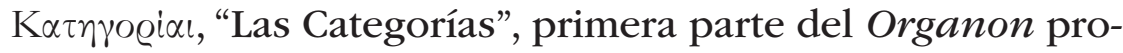
pone una taxonomía compuesta por diez praedicamenta, conjunto de diez criterios para clasificar lo que existe, y sirven para enumerar qué puede fungir como sujeto o predicado de una proposición lógica (Barnes, 1984; 1995). Las Categorías de Aristóteles es la única obra estudiada y analizada en forma ininterrumpida desde su surgimiento, en el siglo III antes de nuestra era, hasta nuestros días.

Funciones de la categorización: (1) Reduce la complejidad, al responder genéricamente a una categoría, $v$. gr., 
agrupamos bajo el rubro "fruta" o "emoción" todas las diferentes instancias de esas clases (Principio de economía cognoscitiva, Rosch, 1978). (2) Organiza el conocimiento al establecer taxonomías jerárquicas. Esto es, incorporamos categorías menores dentro de otras más inclusivas, $v$. gr., gato $\rightarrow$ mamífero $\rightarrow$ vertebrado $\rightarrow$ animal $\rightarrow$ ser vivo (Dimensión de inclusividad, Rosch, 1978; Sloutsky, 2003). (3) Agiliza tomar decisiones. Conocer una categoría nos permite responder a nuevas instancias. Si bien nunca antes habíamos visto un perro específico, nuestro conocimiento categórico nos ayuda a identificar nuevos ejemplares y elegir cursos de acción (acariciar, evadir, etcétera). (4). Permite formular inferencias predictivas. En un interesante experimento Gelman y Markman (1986) presentaron tercias de conceptos, $v$., gr., flamenco, cuervo y murciélago, e informaron a los participantes que el flamenco: "tiene un arco aórtico derecho". Del murciélago dijeron: "tiene un arco aórtico izquierdo"; enseguida preguntaron: ¿qué tipo de arco aórtico tiene el cuervo? A pesar de parecerse más en color y talla al murciélago, casi el $90 \%$ de los participantes respondieron correctamente que - como el flamenco- el cuervo también lo tiene del lado derecho. Otro aspecto interesante de este estudio fue encontrar que los niños de cuatro años ya responden con base en estas inferencias casi el $70 \%$ de las veces; es decir, la habilidad de inferir a partir de categorías se manifiesta tempranamente. Esto significa que, al formular inferencias, en ocasiones obviamos información perceptual, en este ejemplo similitudes en color y talla, y que la propiedad en cuestión es por entero inobservable.

Los trabajos recientes de investigación sobre categorización estudian, entre otros, los campos de música, lenguaje y acción (Fitch y Martins, 2014), la lectura eficiente, mediante análisis neurofuncional por fMRI (Graves, Binderb, Desaic, 
Humphries, Stengel, y Seidenberg, 2014), la relación entre predicción y resultados en el control cognoscitivo adaptativo (Schiffer, Waszak, y Yeung, en prensa), mientras Bartelet, Ansari, Vaessen, y Blomert (2014) abordan las dificultades en el manejo de las matemáticas a nivel primario.

Una división evidente entre categorías distingue entre naturales $(v . g r ., a v e) \mathrm{y}$ artificiales (v.gr., avión), Kalénine, Peyrin, Pichat, Segebarth, Bonthoux, y Baciu, (2009); Medin, Lynch y Solomon (2000). La investigación experimental revela que el tiempo que requiere responder ante ambos tipos de categorías es comparable, VanRullen y Thorpe (2001).

Dos propiedades de las categorías lograron escapar el escrutinio aristotélico y han sido recientemente descubiertas. La primera es la representatividad (typicality); la segunda, que las categorías tienen bordes difusos (fuzzy boundaries). Vigorosos programas de investigación cognoscitiva experimental, así como investigaciones filosóficas en el siglo Xx informaron sobre la existencia de estas características, que describiremos a continuación.

Las categorías que manejamos mentalmente se ubican en un continuo de representatividad. Esto significa que: (1) todas las instancias de una categoría se ubican en un gradiente, y que: (2) toda categoría tiene instancias más representativas que otras, es decir, hay instancias que son "mejores" ejemplos de una categoría que otras. Piense tan rápidamente como pueda en ejemplos de la categoría "aves". Es más probable que haya pensado en "águila" o "canario" que en "kiwi" o "ñandú". La propiedad de representatividad se ve experimentalmente confirmada por el hecho de que no sólo citamos algunas instancias con mayor frecuencia; asimismo, el tiempo de reacción para verificar lexicográficamente una proposición es más rápido para instancias representativas que para las menos representativas. 
Bordes difusos. Desde que se formuló la concepción aristotélica de categoría se supuso que cada una definía su pertenencia sin ambigüedades. Es decir, además de suponer que toda categoría podría ser definida con claridad - esto es, carente de ambigüedades_-, se añadía que éstas fueran mutuamente excluyentes y exhaustivas. Por ejemplo, las definiciones de "número par" y "número non" deberían bastar no sólo para distinguir entre ambas clases de número, sino también para agotar el universo de posibilidades. ${ }^{1}$

No obstante, numerosas investigaciones han modificado la visión tradicional respecto a estos dos aspectos. Primero, la supuesta equivalencia de membresía, según la cual cualquier instancia representa tan adecuadamente a una categoría como cualquier otra. Segundo, que la membresía en una categoría es definitiva y excluyente.

Esto implica que los miembros menos representativos en ocasiones se consideran instancias de categorías adyacentes; por ejemplo, ¿qué es un aguacate, o una aceituna; fruta o verdura? Experimentos sobre el tema revelan que indistintamente lo clasificamos como instancias de alguna de las dos categorías. Estudios en diversos campos de investigación examinan esta propiedad del pensamiento humano. Fitting, Wedell y Allen (2005) analizaron la memoria para ubicaciones espaciales, y Keskin, Ilhan y Özkan (2010) aplican lógica difusa al proceso de elección de proveedores. McCloskey y Glucksberg (1978) estuvieron entre los primeros en demostrar experimentalmente los bordes difusos en psicología. En un interesante artículo, Hey (2001) discute un problema tan profundo como fundamental en biología: cómo definir el concepto de especie. De manera interesante, la solución que propone Hey consiste en manifestar: "en

1 Éste es un ejemplo ilustrativo; no se abunda precisando que tratamos de números naturales, positivos, enteros, etcétera. 
nuestras mentes y en nuestro lenguaje, las especies son categorías" (énfasis añadido, p. 327). En la percepción de emociones, Russell y Bullock, M. (1986), así como Russell y Fehr (1994) aplican el concepto de bordes difusos a la percepción de expresiones faciales emocionales.

En "Funes el memorioso" Borges dice: "Pensar es olvidar diferencias, es generalizar, abstraer. En el abarrotado mundo de Funes no había sino detalles, casi inmediatos" (1944: 490). Esta descripción atañe a un personaje ficticio; la inmensa mayoría de los seres humanos reducimos convenientemente una infinidad de singularidades gracias a la categorización. Empero, sí ha habido al menos una persona real con una incapacidad similar a la de Funes para abstraer y categorizar. Se trata de "S", cuyo nombre era Solomon Shereshevsky, el mnemonista cuyas hazañas fueron descritas en la obra de Luria La mente de un mnemonista (1968). Por una parte, " $S$ " tenía memoria fotográfica perfecta; por otra, igualmente tenía una incapacidad casi absoluta de conceptualizar información abstracta, llegando al extremo de tener dificultades ocasionales para leer, ya que las palabras escritas le evocaban sensaciones que lo distraían. Esto se debía a que, además, " $S$ " no sólo tenía sinestesia múltiple sino muy acentuada, ya que veía sonidos en color, el tacto le provocaba sensaciones de sabor, etcétera. En resumen, si bien muchas personas desearían tener una memoria "perfecta", el caso de " $S$ " ilustra el alto costo de esa supuesta perfección.

\section{CONCLUSIONES}

Este capítulo describe de manera sistemática la forma en que la información es sometida a una diversidad de transformaciones. Éstas ocurren desde (1) la percepción, que es 
la llegada de información a nuestros sensoreceptores, pasando por (2) la atención selectiva, y (3) la memoria, hasta llegar a procesos más duraderos y que organizan internamente la información que poseemos. Dichos procesos son (4) el léxico mental y (5) la categorización. Ambos nos permiten realizar operaciones sumamente complejas que guían nuestro comportamiento en diversas situaciones, e ilustran las diversas y complejas formas en las cuales no sólo transformamos sino que reestructuramos la información.

\section{BIBLIOGRAFÍA}

Aitchison, J. (2003). Words in the Mind: An Introduction to the Mental Lexicon. Malden, MA: Blackwell.

Anderson, J. R. (2004). Cognitive psychology and its implications (6th ed.) [United States of America]: Worth Publishers.

Argyriou, P., Byfield, P. \& Kita, S. (2015). Semantics is crucial for the right-hemisphere involvement in metaphor processing: Evidence from mouth asymmetry during speaking. Laterality: Asymmetries of Body, Brain and Cognition, 20(2), 191-210. doi: 10.1080/1357650X.2014.951654

Barnes, J. (Ed.) (1984). The Complete Works of Aristotle. The Revised Oxford Translation. Bollingen series LXXI, 2. Princeton: Princeton University Press.

. (Ed.) (1995). Aristotle. Categories. The Complete Works of Aristotle, 2 vols. (pp. 3-24) Transl. J. L. Ackrill. Princeton: Princeton University Press,

Bartelet D., Ansari D., Vaessen A., \& Blomert L. (2014). Cognitive subtypes of mathematics learning difficulties in primary education. Research in Developmental Disabilities, 35(3), 657-670. doi:10.1016/j.ridd.2013.12.010 
Bloom, P. (2000). How children learn the meanings of words. Cambridge: MIT Press.

Bohren, C. F., \& Clothiaux, E. E. (2006). Fundamentals of Atmospheric Radiation: An Introduction with 400 Problems. Weinheim: Wiley-VCH Verlag GmbH \& Co. KGaA.

Borges, J. L. (1936). Historia de la eternidad. Obras completas, Vol. 1. Buenos Aires: Emecé Editores. . (1944). Ficciones. Obras completas, Vol. 1. Buenos Aires: Emecé Editores.

Bruner, J. S., Goodnow, J. J., \& Austin, G. A. (1956). A study of thinking. New York: Wiley.

Chandrashekar, J., Hoon, M. A., N. J. P. Ryba \& Zuker, C. S. (2006). The receptors and cells for mammalian taste. Nature, 444, 288294. doi:10.1038/nature05401

Contemporary Lingüistic Analysis (5th Custom Edition for $U$ of A). (2008). Toronto, ON: Pearson Custom Publishing.

Dooley, K. J. (1997). A complex adaptive systems model of organization change. Nonlinear Dynamics, Psychology, and Life Sciences, 1(1), 69-97. doi: 10.1023/A:1022375910940

Ebbinghaus, H. (1885). Über das Gedächtnis: Untersuchungen zur experimentellen Psychologie. Leipzig: Duncker \& Humblot.

Elman, J. L. (2004). An Alternative view of the mental lexicon. Trends in Cognitive Science, 8(7), 301-306. doi: 10.1016/j. tics.2004.05.003

Estes, W. K. (1975), Handbook of Learning and Cognitive Processes vol. $V$. Hillsdale: Lawrence Erlbaum Associates.

Fitch W. T. \& Martins M. D. (2014). Hierarchical processing in music, language, and action: Lashley revisited. The Year in Cognitive Neuroscience. Annals of the New York Academy of Sciences, 1316, 87-104. doi: 10.1111/nyas.12406 
Significados e interpretaciones de la información desde el usuario

Fitting, S., Wedell, D. H., \& Allen, G. L. (2005) Spatial Information Theory. Lecture Notes in Computer Science, 3693, 459-474.

Formisano, E., Kim, D. S., Di Salle, F., van de Moortele, P. F., Ugurbil, K., \& Göbel. R. (2003). Mirror-Symmetric Tonotopic Maps in Human Primary Auditory Cortex. Neuron, 4O(4), 859-869.

Geisler, W. S., \& Kersten, D. (2002). Illusions, perception and Bayes. Nature neuroscience, 5(6), 508-510. doi: 10.1038/nn0602-508

Gelfand, S A. (1990). Hearing: An introduction to psychological and physiological acoustics. 2nd edition. New York and Basel: Marcel Dekker, Inc.

Gell-Mann, M. (1994). The Quark and the Jaguar. New York: Freeman \& Co.

Gell-Mann, M., \& Park, D. (1997). The Quark and the Jaguar: Adventures in the simple and the complex. American Journal of Physics, 65(164), 164-165. http://dx.doi.org/10.1119/1.1860

Graves, W. W., Binderb, J. R., Desaic, R. H., Humphries, C., Stengel, B. C. \& Seidenberg, M. S. (2014). Anatomy is strategy: Skilled reading differences associated with structural connectivity differences in the reading network. Brain and Language, 133, 1-13. doi:10.1016/j.bandl.2014.03.005

Grüter, T., Grüter, M., \& Carbon, C. C. (2008). Neural and genetic foundations of face recognition and prosopagnosia. Journal of Neuropsychology, 2(1), 79-97. doi: 10.1348/174866407X231001. PMID 19334306

Harnad, S. (2005). To Cognize is to Categorize: Cognition is Categorization. En H. Cohen \& Lefebvre C., (Eds.) Handbook on Categorization. Amsterdam: Elsevier.

Hatfield, G. (2002). Perception as Unconscious Inference. En D. Heyer \& R. Mausfeld (Eds.) Perception and the Physical World: Psychological and Philosophical Issue in Perception. New York: John Wiley \& Sons, Ltd. 
Helmholtz, H. L. F. von. (1867). Handbuch der physiologischen Optik 3. Leipzig: Voss.

Hey, J. (2001). The mind of the species problem. Trends in Ecology E Evolution, 16(7), 326-329.

Hilbert, D. (2005). Color constancy \& the Complexity of Color. Philosophical topics, 33(1), 141-158.

James, W. (1890). The Principles of Psychology, Cambridge, MA: Harvard University Press [1981. Originally published in 1890].

Kalénine, S., Peyrin, C., Pichat, C., Segebarth, C., Bonthoux, F., \& Baciu, M. (2009). The sensory-motor specificity of taxonomic and thematic conceptual relations: A behavioral and fMRI study. NeuroImage, 44, 1152-1162.

Katz, Jack (2002). Handbook of Clinical Audiology (5th ed.). Philadelphia: Lippincott Williams \& Wilkins.

Keskin, G. A., Ilhan, S. \& Özkan, C. (2010). The Fuzzy ART algorithm: A categorization method for supplier evaluation and selection. Expert systems with applications, 37, 1235-1240.

Kinchla, R. A., Solís-Macías, V. M. \& Hoffman, J. (1983). Attending to different levels of structure in a visual image. Perception $\varepsilon$ Psychophysics, 33(1), 1-10. doi: 10.3758/BF03205860

Kirby, S. (1999). Function, selection and innateness. Oxford: Oxford University Press.

Lochy, A., Van Belle, G. \& Rossion, B. (2015). A robust index of lexical representation in the left occipito-temporal cortex as evidenced by EEG responses to fast periodic visual stimulation. Neuropsychologia, 66, 18-31. doi: http://dx.doi.org/10.1016/j. neuropsychologia.2014.11.007

Love, B. C. (2003). Concept learning. En L. Nadel (Ed.), Encyclopaedia of cognitive science (Vol. 1, pp. 646-652). London: Nature Publishing Group. doi: 10.1002/0470018860.s00499 
Luria, A. R. (1968). The Mind of a Mnemonist. A Little Book about a Vast Memory. New York: Basic Books.

Marc, R. E.; Anderson, J. R.; Jones, B. W.; Sigulinsky, C. L.; \& Lauritzen, J. S. (2014). The AII amacrine cell connectome: a dense network hub. Frontiers in Neural Circuits, 8: 104. doi: 10.3389/ fncir.2014.00104

Margolis, E. (1994). A reassessment of the shift from the classical theory of concepts to prototype theory. Cognition, 51, 73-89.

McCloskey, M. E., \& Glucksberg, S. (1978). Natural categories: Well defined or fuzzy sets? Memory \& Cognition, 6(4), 462-472.

Medin, D. L., Lynch, J., \& Solomon, H. (2000). Are there kinds of concepts? Annual Review of Psychology, 51, 121-147.

Meyering, T. C. (1989). Helmholtz's Theory of Unconscious Inferences. Historical Roots of Cognitive Science. The Rise of a Cognitive Theory of Perception from Antiquity to the Nineteenth Century. Synthese Library, 208, 181-208. doi 10.1007/978-94009-2423-9_10

Neisser, U. (1967). Cognitive Psychology. New York: Appleton-Century-Crofts.

Oldfield, R. C. (1966). Things, words and the brain. Quarterly Journal of Experimental Psychology, 18, 340-353. doi: $10.1080 / 14640746608400052$

Pellicano, E. \& Burr, D. (2012). When the world becomes 'too real': a Bayesian explanation of autistic perception. Trends in cognitive sciences, 16(10), 504-510.

Perea, .M, Jiménez, M. \& Gomez, P. (2015) Do young readers have fast access to abstract lexical representations? Evidence from masked priming. Journal of Experimental Child Psychology, 129, 140-147. doi:10.1016/j.jecp.2014.09.005 


\section{La información y sus transformaciones...}

Rosch, E. (1978). Principles of Categorization. En E. Margolis \& S. Laurence (Eds.), Concepts: Core Readings (pp. 189-206). Cambridge: MIT Press.

Rowe, M. H. (2002). Trichromatic color vision in primates. News in Physiological Sciences, 17(3), 93-98.

Russell, J. \& Bullock, M. (1986). Fuzzy concepts and the perception of emotion in facial expressions. Social Cognition, 4, 309-341.

Russell, J. \& Fehr, B. (1994) Fuzzy concepts in a fuzzy hierarchy: varieties of anger. Journal of Personality and Social Psychology, 67, 186-205.

Schiffer, A. M. Waszak, F., y Yeung N. (En prensa). The role of prediction and outcomes in adaptive cognitive control. Journal of Physiology-Paris. doi:10.1016/j.jphysparis.2015.02.001

Schopenhauer, A. (1813). Über die vierfache Wurzel des Satzes vom zureichenden Grunde. (1974) On the Fourfold Root of the Principle of Sufficient Reason. Open Court Publishing Co.

Scott, K., (2005). Taste Recognition: Food for Thought, Neuron, 48, (3), 455-464.

Shera, C. A., Guinan, Jr., J. J. \& Oxenham, A. J. (2002) Revised estimates of human cochlear tuning from otoacoustic and behavioral measurements. Proceedings of the National Academy of Sciences of the United States of America, 99(5), 3318-3323. doi:10.1073/pnas.032675099

Sloutsky, V. M. (2003). The role of similarity in the development of categorization. Trends in Cognitive Sciences, 7(6), 246-251. doi:10.1016/S1364-6613(03)00109-8

Solís-Macías, V. M. (2011). Investigación del léxico mental mediante tareas de reconocimiento visual. Archivos de Neurociencias, 16(4), 179-185.

Solomon, S. G., \& Lennie, P. (2007). The machinery of colour vision. Nature Reviews Neuroscience, 8, 276-286. doi: 10.1038/nrn2094 
Significados e interpretaciones de la información desde el usuario

Stakhovskaya, O., Sridhar, D., Bonham, B. H. \& Leake, P. A. (2007). Frequency Map for the Human Cochlear Spiral Ganglion: Implications for Cochlear Implants. Journal for the Association for Research in Otolaryngology, 8, (2), 220-233. doi: 10.1007/ s10162-007-0076-9

Tulving y Pearlstone (1966). Availability versus accessibility of information in memory for words. Journal of Verbal Learning and Verbal Behaviour, 5(4), 381-391. doi: 10.1016/S00225371(66)80048-8

VanRullen R. \& Thorpe S. J. (2001). Is it a bird? Is it a plane? Ultrarapid visual categorisation of natural and artifactual objects. Perception, 30(6), 655-668.

Westheimer, G. (2008). Was Helmholtz a Bayesian? A review. Perception, 37, 642-650. doi: 10.1068/p5973

Zhu, Z., Gold, B. T., Chang, C. F., Wang, S. \& Juan, C. H. (2015). Left middle temporal and inferior frontal regions contribute to speed of lexical decision: A TMS study. Brain and Cognition, 93, 11-17. doi: 10.1016/j.bandc.2014.11.002

\section{Direcciones electrónicas}

http://www.archive.org/details/AristotleOrganon

http://www.businessdictionary.com/definition/information.html

http://www.definicionabc.com/tecnologia/informacion.php

http://www.definiciones-e.com/Definicion/de/informacion.php

http://lema.rae.es/drae/?val=informacion (edición electrónica 22, 2012)

http://www.merriam-webster.com/dictionary/knowledge

http://www.oxforddictionaries.com/definition/english/information 
El concepto de información desde una óptica de la filosofía de la bibliotecología y los estudios de la información

\author{
Miguel Ángel Rendón Rojas \\ Universidad Nacional Autónoma de México
}

Veo bien este o aquel caballo pero no la "cabalidad". Antístenes. Siglo IV a. C.

$$
T=F . D
$$

(Trabajo es igual a fuerza por distancia)

Trabajo es el conjunto de actividades para la producción de bienes y servicios.

\footnotetext{
1 presente trabajo tiene ante sí una tarea compleja y se puede decir poco novedosa: el análisis de un concepto tan general y escurridizo como el de información. Como ya es sabido, uno de los conceptos centrales dentro del aparato teórico de la bibliotecología y estudios de la información es precisamente el de información. Aunque simultáneamente dicho concepto también juega un papel importante en otras disciplinas o ramas del saber humano, como la cibernética, la inteligencia artificial, las telecomunicaciones, la computación, la genética, la lógica, la física, el periodismo, la ciencia de la comunicación, la ciencia de la información, la psicología, la pedagogía, a lo cual se puede
} 
agregar un largo etcétera. Por ello, no es de extrañar que exista una gran cantidad de trabajos que versan sobre esa problemática. Desde tesis doctorales (Capurro, 1978); trabajos donde su estudio se convierte en toda una línea de investigación como problemática filosófica (Floridi, 2011), pasando, por supuesto, por trabajos fundacionales (Shannon y Weaver, 1949; Bar- Hillel y Carnap, 1953; Rapaport, 1970); los que rastrean el concepto de información en el mundo físico (Stonier, 1996; Landauer, 1996), o su relación con la entropía (Bérut et al., 2012), con la Lógica (Voishvillo, 1976; Ruiz Calleja, 2008) o, ya en el terreno de la ciencia de la información, la comunicación o lenguaje, sólo por nombrar algunos, en estricto orden alfabético (Machlup, 1983; Machlup y Mansfiel, 1983; Israel y Perry, 1990; Capurro, 2001; Capurro y Hjørland 2003; Pérez-Moontoro Gutiérrez, 2007); o los que intentan seguir su evolución histórica o elaborar una bibliografía sobre el tema (Peters, 1988; Qvortrup, 1993). Incluso, el autor de estas líneas no pudo sustraerse al reto de reflexionar sobre la información cuando iniciaba sus trabajos sobre la fundamentación de la bibliotecología (Rendón Rojas, 1995).

Así pues, ante la gran cantidad de nociones sobre información consideramos que nuestro objetivo en este trabajo no es proporcionar una enésima definición de información que se agregue a la ya vasta lista, sino tratar de clarificar esa idea tan general, pero específicamente en el campo que nos compete: el informativo documental.

PRIMER PROBLEMA. LA INDEFINICIÓN DE LA INFORMACIÓN

Al iniciar el análisis del concepto que nos ocupa, nos enfrentamos a la paradoja de que si queremos explicar en 
qué consiste la idea de información debemos proporcionar información sobre ella, es decir, se necesita dar información sobre lo que es la información. Pero en este caso la nueva noción que se introdujo se debe definir, por lo que ahora se exige proporcionar información sobre la información de información. Sin embargo, en ese nuevo caso aparece una nueva noción de información que es necesario aclarar, y así es indispensable dar información sobre la información sobre la información de la información; de este modo, el proceso se repite ad infinitum. O por el contrario, si no se quiere ver ese proceso como una secuencia lineal, entonces caemos en una auto-aplicación de la información a sí misma, por lo que queda indefinida.

Sin embargo, esta situación no es exclusiva de la bibliotecología; la ciencia informativa documental no es la única ciencia que descansa en una categoría primitiva indefinida. Podemos encontrar otros conceptos igualmente importantes para su ciencia, como lo es la información para la bibliotecología, que tampoco son definidos de manera estricta. Como ejemplo de esos conceptos podemos encontrar los de punto, recta y plano en geometría; o los conceptos de conjunto o función en matemáticas, los cuales se explican a través de sinónimos o para su comprensión se apela a la intuición. ${ }^{1}$ Es cierto que ese acercamiento intuitivo y la au-

1 Euclides empieza su célebre obra Elementos con algunas definiciones iniciales: "1. Un punto es lo que no tiene partes. 2 . Una línea es una longitud sin anchura [...] 5. Una superficie es lo que sólo tiene longitud y anchura". (Euclides, 1991: 189-191). Cantor, creador de la teoría intuitiva de conjuntos, introduce como definición inicial que un conjunto es cualquier colección $\mathrm{C}$ de objetos determinados $\mathrm{y}$ bien distintos $\mathrm{x}$ de nuestra percepción o nuestro pensamiento (que se denominan elementos de $\mathrm{C}$ ), reunidos en un todo. (Huertas Sánchez y Manzano Arjona: 4). 
toinclusión condujeron al descubrimiento de paradojas, ${ }^{2}$ lo que obligó construir sistemas formales que las bloquearan, como la teoría de tipos de Russell aparecida en el primer volumen de sus Principia Mathematica en 1910 (Russell y Whitehead, 1981) o la teoría axiomática de conjuntos propuesta por Zermelo en 1908 y refinada más tarde por Fraenkel en 1922, Skolem en 1923 y von Newman en $1925^{3}$ (Huertas Sánchez y Manzano Arjona: 6).

\section{ACERCAMIENTO LINGÜÍSTICO Y ETIMOLÓGICO}

Así pues, independientemente de esa primera dificultad, nos acercaremos a esclarecer el contenido de la categoría información teniéndola presente, buscando tal vez sinónimos, pero no como evasión del problema; no proporcionamos esos sinónimos al inicio de nuestro análisis sino que aparecerán al final, sólo después de haber desmenuzado ese concepto y aclarado su contenido.

Parece que la tarea inmediata que se presenta es el análisis lingüístico y etimológico de la palabra. Como ya se ha

2 En la teoría intuitiva de conjuntos se descubrieron paradojas cuyo origen es la autoinclusión. Si llamamos conjuntos propios a los que no se incluyen a sí mismos (el conjunto de todos los perros no es un perro) y conjuntos impropios a los que se incluyen a sí mismos (el conjunto de todos los conjuntos es un conjunto), entonces si formamos el conjunto $\mathrm{H}$ compuesto por todos los conjuntos propios, ¿ese conjunto es propio o impropio? Si H es propio entonces es elemento de sí mismo, por lo que es impropio; si $\mathrm{H}$ es impropio, entonces no es elemento de sí mismo, por lo que es propio. De este modo obtenemos una contradicción: $\mathrm{H}$ es conjunto propio si y sólo si es conjunto impropio y $\mathrm{H}$ es conjunto impropio si y sólo si es propio. Si se desea construir un catálogo que incluya a todos los catálogos que no se incluyen a sí mismos ¿ese catálogo se debe o no contener en él?

3 No existe propiamente una solución a ese tipo de paradojas sino más bien se evade su aparición prohibiendo la autoinclusión. 
hecho notar cada vez que se aborda la categoría de información descubrimos que el término que se utiliza para denotarla tiene su origen en el latín, formado por in, forma y tio.

De acuerdo con el diccionario, in (no confundir con el prefijo in que indica privación o negación: inmaduro, inmoral, inconsciente, inestable, etcétera) tiene varias connotaciones. Como preposición de acusativo indica el término de un movimiento real o figurado: 1. Lugar — con idea de penetración-: a, en, dentro de; —con idea de dirección-: hacia, a. 2. Tiempo: hasta; paso de un estado a otro: en. 3. División: en; distribución: a, por. 4. Finalidad; para, en vista de. 5. Resultado: en. 6. Objeto de un sentimiento: para, por, en favor de. 7. Modo: según, de acuerdo con, a manera de. Relación: en cuanto a. Como preposición de ablativo, sin idea de movimiento: 1. Situación: en, entre, con. 2. Tiempo: en, durante. 3. Relación: en cuanto a, a propósito de.

Por su parte forma es un término eminentemente filosó-

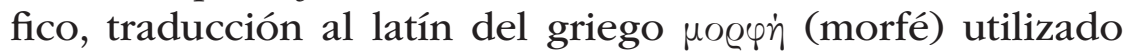
principalmente por Aristóteles: Metafísica 999b16, 1015a5, 1017b25 entre otros muchos pasajes. Para Aristóteles los entes están compuestos de dos principios metafísicos in-

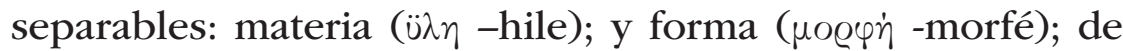
ahí que a su doctrina se le llame hilemorfismo. La materia primera es un principio indeterminado (in-forme) que necesita a la forma para que se delimite, con lo cual surge un sustrato determinado: madera, mármol, arcilla, metal, etcétera, que es la materia segunda. Esta materia es apta para recibir cualquier forma. De esta manera, es formada a su

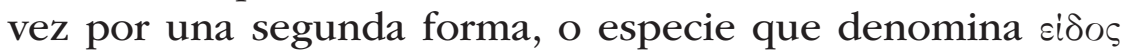
- eidos-. Por ejemplo, el metal puede ser una espada, un anillo, una bandeja. En otras palabras, la forma hace que las cosas sean lo que son, conforma la materia en algo. 
Finalmente la terminación tio denota acción, proceso, estado.

De esta manera informatio significa llegar o estar en la forma, que algo está formado, tiene forma.

Capurro (2008) nos proporciona algunos autores que utilizaron el término información y nosotros seguimos y ahondamos esas pistas. Así, por ejemplo, encontramos que Virgilio, en concordancia con ese sentido de "llegar o estar formado", en su Eneida utiliza el término informatum para expresar que los cíclopes elaboran con sus manos, dan forma un rayo para Zeus:

ferrum exercebant vasto Cyclopes in antro Brontesque Steropesque et nudus membra Pyragmon. his informatum manibus iam parte polita fulmen erat, toto genitor quae plurima caelo (Vergili, 1969: 426 [el subrayado es nuestro]). ${ }^{4}$

El anterior uso del término informatum es para designar un hecho de carácter ontológico: construir, hacer un objeto, darle forma a una materia. En cambio Cicerón, en su obra De natura deorum, le da otro uso, y la emplea con una connotación gnoseológica:

Quae est enim gens aut quod genus hominum, quod non habeat sine doctrina anticipationem quandam deorum? Quam appellat

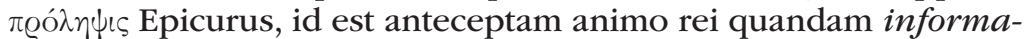
tionem, sine qua nec intellegi quicquam nec quaeri nec disputari possit (Cicero, 1967: 43)

4 "El hierro trabajaban los cíclopes en su vasta guarida, / Brontes y Estéropes y Piragmón con el cuerpo desnudo. / Ocupados estaban en terminar [dar forma: M. A. R], / en parte ya pulido, / un rayo de los muchos que lanza el padre por todo el cielo." Virgilio, La Eneida. 1969: 426.

5 "¿Qué tribu o qué género de hombres hay que no posea, sin haber sido enseñados, una preconcepción de los dioses? Aquello que Epicuro llama prólepsis, esto es, una especie de imagen mental preconcebida sobre las cosas, sin la cual nada puede ser entendido, investigado o discutido." 
El concepto de información desde una óptica de la filosofía...

Más tarde, en los albores de la filosofía medieval de Occidente, en los siglos IV-V d. C. en la patrística, San Agustín, dentro de una visión neoplatónica, refuerza ese uso gnoseológico. Podemos encontrar en su tratado Sobre la Trinidad toda una serie de pasajes donde emplea el término informatio o sus derivados con esa connotación, lo que nos permite ir entendiendo cómo se fue fijando esa noción como una forma - eidos - en el pensamiento: "Secundum hanc notitiam cogitatio nostra informatur [...]" (San Agustín,1956, De Trinitate. VIII, 5, 7). ${ }^{6}$

Aquí el pensamiento es el que "es formado" por la noticia. No está del todo claro si la noticia es "información" y por eso forma al pensamiento, o es como los Cíclopes en Virgilio que formaban el rayo de Zeus, que sin ser rayos forjan el rayo, como una especie de causa eficiente. Aunque sí podemos afirmar que la noticia no puede ser una causa formal, un eidos que forma al pensamiento, porque es un hecho empírico.

Más adelante podemos leer: "imaginatio corporis quae in memoria est, et inde informatio cum ad eam convertitur acies cogitantis [...]" (San Agustín, 1956: 610-611, De Trinitate, $\mathrm{XI})^{7}$

En el anterior texto encontramos una distinción interesante. La simple imagen que se encuentra en la memoria no es todavía información; se convierte en ella hasta cuando es objeto del pensamiento. Adelantándonos algunos siglos en la historia de la filosofía, podríamos decir que la ideas primeras o impresiones de las cosas en los sentidos de las que hablarán los empiristas no eran para San Agustín información, sino hasta que se convirtieran en ideas segundas.

6 "Nuestro pensamiento es informado según esta noticia [...]"

7 "[... la imagen del cuerpo que está en la memoria, la información que surge al convertirse a ella la mirada del pensamiento [...]" 
Aunque al hablar de la percepción en el caso concreto de la visión explica que no es otra cosa que el sentido formado por el objeto que se percibe, es decir, es obra del cuerpo que se ve:

Ipsaque visio quid aliud, quam sensus ex ea re quae sentitur informatus, apparet? [...] tamen ex corpore quod videtur gignitur visio, id est, sensus ipse formatur; ut iam non tantum sensus qui etiam in tenebris esse integer potest, dum est incolumitas oculorum, sed etiam sensus informatus sit, quae visio vocatur [...] Quocirca ex visibili et vidente gignitur visio, ita sane ut ex vidente sit sensus oculorum, et aspicientis atque intuentis intentio: illa tamen informatio sensus, quae visio dicitur, a solo imprimatur corpore quod videtur, id est, a re aliqua visibili. (San Agustín, 1956, De Trinitate, XI, 2, 3)

O en otra parte: "[...] fides ista communis est: non sicut aliqua corporis forma communis est ad vídendum omnium oculis quibus praesto est; ex ipsa quippe una omnium cernentium quodam modo informatur aspectus". (San Agustín, 1956, De Trinitate)

Esas mismas ideas las encontramos en: "Deinde in ipso animo, ab iis quae extrinsecus sensa sunt velut introducta inventa est altera trinitas, ubi apparerent eadem tria unius esse substantiae, imaginatio corporis quae in memoria est,

8 "¿Qué es la visión sino el sentido informado por el objeto que se percibe? [...] no obstante, la visión es engendrada por el cuerpo que se ve; es decir, es informado el sentido; y no tan sólo el sentido que puede subsistir íntegro en la obscuridad si los ojos permanecen incólumes, sino el sentido informado, lo que se llama visión. [...] En consecuencia, la visión es engendrada por un objeto visible y un sujeto que ve: al sujeto pertenecen el sentido de la vista y la atención con que mira y contempla; la información del sentido que se llama visión, obra es del cuerpo que se ve, es decir, del objeto visible."

9 "Fe común no como es la forma de algún cuerpo común a cuantos la miran, pues la pupila de todos los espectadores es informada por dicha imagen." 
et inde informatio cum ad eam convertitur acies cogitantis [...]" (San Agustín,1956, De Trinitate, Xv, 4, 6: 838-839) ${ }^{10}$

Aunque en la Ciudad de Dios San Agustín también le otorga al término informatio el sentido ontológico de causa formal: "Inde est civitatis "sanctae, quae in sanctis Angelis sursum est, et origo, et informatio, et beatitudo." (San Agustín, 1958, De Civitas Dei, XI, 24: 757) ${ }^{11}$

Se reconoce de manera general que la caída de Imperio Romano de Occidente en el siglo $\mathrm{v}$ marca el inicio de lo que se conoce como la Edad Media que duraría mil años. Después de un periodo de destrucción y devastación por la invasión de los bárbaros, la cultura logró encontrar refugio en los monasterios e iglesias, para luego resurgir bajo una apariencia religiosa. Debido a que la sociedad medieval estaba regida por el cristianismo y éste, a su vez, era una religión cuyas ideas centrales estaban escritas en su libro sagrado, la Biblia, entonces esa sociedad giraba en torno a la palabra, a sus interpretaciones, a su estudio. Es por eso que no es de extrañar que los principales logros en sus investigaciones se realizaran en el campo del lenguaje: lógica, retórica, dialéctica, gramática, filosofía del lenguaje. El concepto que nos preocupa - la información- encontró lugar en esa esfera, y lo podemos rastrear entre la semiótica, la teoría del conocimiento y la filosofía del lenguaje.

Los filósofos de la Edad Media reconocían la existencia de dos tipos de lenguaje, el interno (mental) y el externo (oral y escrito). El lenguaje externo está constituido por signos; el lenguaje oral, por voces. El proceso a través del

10 "Luego descubrimos en el alma otra trinidad introducida por las cosas que se experimentaron en la periferia, y en ella aparecen tres realidades de una misma esencia: la imagen (imaginatio) del cuerpo existente en la memoria, la forma (informatio) que resulta cuando a ella se convierta la mirada interior del pensamiento [...]"

11 "De ella toma la ciudad santa, que tiene su morada arriba, en los ángeles santos, su origen, su forma y su felicidad." 
cual una voz adquiere significado lo denominaron "imposición". Gracias a la imposición, las voces representan "intenciones del alma" o del intelecto; esto es, representan formas del pensamiento: conceptos, juicios, raciocinios, así como ideas, nociones, elementos, operaciones o relaciones lógicas -cuantificadores (todos, algunos); conectores (y, o, no, si... entonces, si sólo si); functores $f(x) \times$ es $\mathrm{f}$; predicados $P^{\mathrm{n}}\left(x 1, \ldots x_{\mathrm{n}}\right) \mathrm{x} 1, . . \mathrm{x}_{\mathrm{n}}$ tienen la propiedad o están en la relación $\mathrm{P}$ - Sin embargo, si las intenciones del alma no se limitan sólo a esas realidades lógicas, intelectuales, contenidos de conciencia, sino existen además otras "intenciones del alma”, como estados anímicos -emociones, sentimientos, deseos, pasiones, valores o creencias-, entonces existen signos que también designan ese otro tipo de "intenciones del alma"; y por consecuencia, puede haber no sólo lenguajes objetivos sino expresivos. Así pues, las voces significan intenciones del alma y posteriormente esas intenciones del alma representan a las cosas. De esta manera la significación se realiza presentando la forma de algo al entendimiento. (Beuchot, 1991: 15-28)

Considero que precisamente en ese vocablo resaltado se centra el contenido de lo que llamamos información. La forma, entendida filosóficamente, es su origen y clave para entenderla, lo que Aristóteles denominó como $\mu \circ \varrho \varphi \dot{n}$ (morfé), ciঠos (eidos), y su expresión latina correspondiente se tradujo como forma, especie, género, entendiendo por forma aquello que hace a una cosa ser lo que es y, por eso, esa forma en el entendimiento puede representarla.

Por su parte Santo Tomás, cuando analiza el problema del conocimiento, principalmente en Summa Theologiae I, q 79; 84-89, expresa que el conocimiento intelectual de la realidad material, esto es, el captar sus formas, se lleva a cabo debido a que el sujeto utiliza su capacidad intelectual 
que es de naturaleza inmaterial, y de cierta manera convierte al objeto también en algo inmaterial, lo que le permite asimilarlo; por supuesto, no en su entidad física, sino en su forma inmaterial. Las formas están presentes en las cosas, pero no son inteligibles en acto, sólo en potencia, por lo que se requiere de la acción del entendimiento agente para que esas formas se conviertan en inteligibles en acto, en ideas, especies o géneros.

En este momento encontramos una idea importante en la dialéctica de la aparición de la información: las cosas ya no son las que forman al intelecto, sino éste tiene una participación activa en la construcción de esas formas; ya no como formas ontológicas, sino como formas gnoseológicas.

En la filosofía de la Edad Moderna el centro de atención se dirigió al análisis del conocimiento. Los racionalistas reconocen la existencia de ideas innatas en el entendimiento, por lo que se pierde esa relación de las formas externas que llegan al intelecto y éste se forma ya sea por acción inmediata de esas formas o por la propia actividad del entendimiento. Por su parte, los empiristas afirman que el origen del conocimiento es la experiencia; los sentidos proporcionan el material con el que conocemos. De esta manera Locke (2003) y Hume (2007) al analizar los contenidos de conciencia encuentran que las ideas son de dos clases de acuerdo a la cercanía que tengan con la sensación; son ideas simples, derivadas de la sensación y reflexión (Locke) o impresiones si son copias inmediatas de una sensación (Hume); o ideas complejas que surgen por la combinación de ideas simples (Locke), o simplemente ideas si son una copia de las impresiones, es decir, una copia menos vívida de la sensación (Hume). Al romper con la metafísica los empiristas rompen con la noción de forma y con ello se desconectan de la on- 
tología, dejando solamente el aspecto gnoseológico y comunicativo de las ideas.

SEGUNDO PROBLEMA. El ESTATUS ONTOLÓGICO DE LA INFORMACIÓN

Desde la Antigüedad surgió la interrogante del estatus ontológico de los universales, que traducido al lenguaje contemporáneo corresponde al estatus ontológico de la información. En la Edad Media fue un problema que se discutió de manera álgida ya que las repercusiones de las posibles soluciones que se proporcionaban tocaban puntos no sólo filosóficos, ontológicos, gnoseológicos, lingüísticos, sino teológicos, y dado el carácter de la sociedad en esa época, ese hecho era muy delicado. Curiosamente en el pensamiento contemporáneo la discusión sobre los universales resurge en la controversia entre los realistas (Frege, Husserl, Popper) y los filósofos posmodernos que niegan toda función de representación del lenguaje ya sea porque toda realidad es un texto sin un referente externo (Foucault, Vattimo, Derrida) o porque el lenguaje no representa significados sino es sólo un instrumento que nos indica cómo usar las cosas (Segundo Wittgenstein, Austin, Searle).

Proporcionaremos una descripción sumaria del problema de los universales en la Edad Media porque de su planteamiento y solución sacaremos conclusiones que consideramos válidas en la discusión contemporánea.

El análisis del estatus ontológico de los universales en la Edad Media surge a partir de la traducción que realizó Boecio del griego al latín de la obra Isagoge de Porfirio. Al inicio podemos leer: "Así, pues, sobre los géneros y las especies declinaré hablar tanto de si subsisten o son puros 
El concepto de información desde una óptica de la filosofía...

y simples pensamientos, como de si son subsistentes corpóreos o incorpóreos, como también de si están separados o si son subsistentes en las cosas corpóreas sensibles y dependen de ellas [...]" (Porfirio, 2003: 3)

Ya hemos dicho que las voces significaban intenciones del alma, contenidos de conciencia; en el texto citado aparecen como géneros y especies. Porfirio evade el problema de responder cómo existían esas realidades mentales, cuál era su fundamento ontológico y su relación con las palabras que las mencionaban, por lo que los filósofos medievales se plantearon esa pregunta y trataron de responderla. Casi ocho siglos después, el problema continúa intrigando a los filósofos y así, por ejemplo, Foucault ya no en el siglo XI o XII, sino en el siglo XX se ocupará de discernir la relación entre las "palabras y las cosas".

Una de las soluciones planteadas al problema de los universales es el llamado realismo exagerado de marcada tendencia platónica. Para algunos como Guillermo de Champeaux (1070-1121) los universales son res - cosas, entidades metafísicas que subsisten en sí mismas-. En nuestro caso, se tomaría a la información como algo que existe independientemente de las cosas singulares, de los sujetos y de las palabras. Frege, filósofo, matemático y lógico alemán, creador de la lógica matemática contemporánea, reconoce la existencia de lo "objetivo no real", esto es, de aquello que existe independientemente de la conciencia, pero a diferencia de lo objetivo real que puede percibirse por los sentidos, no es una realidad empírica, y al mismo tiempo se reconoce como independiente de las ideas o sensaciones privadas de cada individuo; aunque también se le identifica como contenido de conciencia presente en muchos sujetos. En uno de sus textos Frege escribe: 
Debe admitirse un tercer reino. Lo que pertenece a él coincide con las representaciones en que no puede ser percibido por los sentidos, pero con las cosas en que no necesita portador a cuyos contenidos de conciencia pertenezca. Así, p. ej., el pensamiento que expresamos en el teorema de Pitágoras es atemporalmente verdadero, verdadero independientemente de que alguien lo tome por verdadero. (Frege, 1984: 69-70)

De esta manera tenemos que los pensamientos pertenecen a ese reino, por tanto existen de manera objetiva, independientemente de los sujetos. Éstos pueden aprehenderse, asimilarse, estar presentes en los sujetos y comunicarse entre ellos.

Semejante posición conlleva serias consecuencias metafísicas. En primer lugar postular una realidad supra sensorial cuya existencia es difícil de comprobar, no se sabe bien a bien cómo existe, cuál es su origen, no podemos hablar de ubicación por ser inmaterial, ni explicar cómo se relaciona con el mundo físico. Ese tercer reino existe $a b$ aeterno y con un número infinito de ideas, ideas sobre las ideas, e ideas sobre las ideas de las ideas, así ad infinitum.

En segundo lugar también es difícil explicar la aparición y desaparición de ideas según el tiempo y las culturas. Pareciera que esas ideas y sus relaciones ya existen y sólo esperan ser nombradas por alguien para develarse. Así, conceptos, ideas, nociones que se empezaron a utilizar sólo en el siglo XXI como "textear", smartphone, ipod, ipad, Facebook, Twitter, "ontología” no en el sentido clásico filosófico del estudio del ser, sino con el significado propio asignado en el campo de la información documental, estuvieron esperando ser nombrados para darse a conocer a la humanidad durante milenios, porque de acuerdo con esa idea de la información como algo ideal subsistente, independiente de los sujetos, ya preexistían en ese mundo metafísico de lo objetivo no real. 
El concepto de información desde una óptica de la filosofía...

Lo mismo acontece con conceptos científicos que denotan un descubrimiento que merece ser comunicado. Partículas subatómicas que antes eran desconocidas y al ser descubiertas se nombran y se describen, como por ejemplo el Bosón de Higgs; o en su momento el ADN como contenedor y trasmisor de las características de los seres vivos; o los nuevos organismos que se encuentran, se les pone un nombre y clasifican de acuerdo a sus categorías taxonómicas, como el simpático "olinguito", ${ }^{12}$ y un largo etcétera.

Asimismo parece contradecir los hechos la afirmación de que J. K. Rowling al introducir la noción de no-mago nacido de padres no-magos, en su mundo mágico de Harry Potter, designados con el término muggle, estrictamente hablando no fue inventora de esa idea, porque la muggleidad ya existía antes que ella naciera.

De esta manera caemos en ese mundo de las formas puras y debemos aceptar, hasta caer en el absurdo, que la smartphoneidad, la ipodiedad, la ipadiedad, la Facebookiedad, la Twitteriedad, la Bosón de Higgsiedad, la ADNiedad, la Bassaricyon nebliniedad, y todo lo que puede ser nombrado preexisten. Es más, lo que no se me ocurre aún pero lo pensaré algún día está ahí, en ese reino de lo objetivo no real.

Otro fenómeno también difícil de explicar a partir de esa tesis cuasi platónica es el hecho de que algunas nociones se han abandonado porque, aunque poseían un sentido, eran informativas, estaban lejos de tener un correlato en la

12 Por ejemplo el 15 de agosto de 2013 se publicó en la revista Zookeys la identificación, por científicos del Instituto Smithsoniano, de un mamífero carnívoro nativo de las selvas de Colombia y Ecuador como especie independiente. $C f$. http://smithsonianscience.si.edu/2013/08/olinguito/ Era la primera especie carnívora identificada en el continente americano en 35 años; se denominó "olinguito", su nombre científico: Bassaricyon neblina, y le asoció la siguiente información taxonómica: Reino: Animalia; Filo: Chordata (vertebrados); Clase: Mammalia (mamíferos); Orden: Carnivora (carnívoros); Familia: Procyonidae (incluye mapaches y coatíes); Género: Bassaricyon; Especie: Bassaricyon neblina. 
realidad. En este caso se encuentran por ejemplo "flojisto" (substancia que poseían los cuerpos y era la causa de la combustión); "éter" (substancia que llenaba el espacio exterior a la Tierra); "piedra filosofal" (substancia que tenía la capacidad de convertir los metales en oro); "mundo sublunar" - finito, imperfecto, cambiante- y "mundo supra lunar" - infinito, perfecto, sin cambios - en la cosmología de Aristóteles; "elementos" —los cuatro elementos clásicos que ahora se tratan como mezclas: aire, tierra, compuesto agua o proceso: fuego-; "la generación espontánea"; "planeta menor" o "planetoide", incluso el mismo concepto de "planeta" se transformó; "tiempo" y "espacio" en el sentido newtoniano como realidades absolutas, entre otras muchas. Todas esas ideas existen en el topos uranos, pero no son modelos o formas de objetos, o lo eran pero en determinado momento se consideró que ya no debían serlo. ${ }^{13}$

En tercer lugar, una crítica que siempre se le ha hecho a esa teoría platónica del mundo de las ideas es la necesidad de la superposición de ideas, es decir, las ideas con mayor contenido incluyen a las de menor contenido. Esto se ve claro en las categorías taxonómicas. Por ejemplo el filo contiene al reino; la clase al filo y al reino; la orden, a la clase, al filo y al reino; la familia, al orden, a la clase, al filo y al reino; el género, a la familia, al orden, a la clase, al filo y al reino; la especie, al género, a la familia, al orden, a la clase, al filo y al reino. De esta manera, la idea de "mexicanos" me indica que son de la especie Homo sapiens, pero al mismo tiempo que son del género Homo, pertenecen a la familia de Homínidos; a la orden de los Primates, a la clase de los

13 Por ejemplo la idea de "planeta" se ejemplificaba en el objeto denominado Plutón, pero después se dudó de que lo fuera y se le llamó planetoide, para finalmente por una convención, por votación en el Congreso de la Unión Astronómica Internacional en 2006, se le consideró un "planeta enano" o "plutoide". 
El concepto de información desde una óptica de la filosofía...

mamíferos y al reino animal. ¿Es una sumatoria de ideas? ¿Cómo entender con entes objetivos la generalización y limitación de conceptos?

Observamos que nuestro problema de comprender lo que es la información lejos de aclararse se hace mucho más complejo al adoptar una solución semejante al realismo exagerado de la Edad Media, por lo que buscaremos otra alternativa.

La otra solución al problema de los universales en la Edad Media, contraria al realismo exagerado, es el nominalismo de Roscelino de Compiègne (1050-1120), según el cual los universales no poseen ningún correlato semántico ni se refieren a ninguna res — cosa-, sino son simples flatus vocis (viento de voz), ya que todo lo que existe son objetos individuales y separados (discretos).

En nuestra época encontramos posiciones semejantes que desechan lo universal y van más allá, incluso llegan a negar la misma realidad. Así Nietzsche escribe: "No hay exactamente hechos, sino sólo interpretaciones. No podemos determinar ningún factum 'en sí' [por lo que] el mundo es interpretable de distintas maneras, no tiene un sentido detrás de sí, sino incontables sentidos". (Nietzche, 2004: 170)

De la misma manera Derrida afirma que il n'y a pas de bors-texte (no hay nada fuera del texto), ni referentes ni significados trascendentes, ni vida real, ni naturaleza, sólo queda el texto:

[...] la ausencia del referente o del significado trascendental. No hay fuera del-texto [...] Lo que hemos intentado demostrar [...] es que dentro de lo que se llama la vida real [...], y detrás de ella, nunca ha habido otra cosa que escritura; [...] el presente absoluto, la naturaleza, lo que nombran las palabras "madre real", etc., se han sustraído desde el comienzo, jamás han existido; que lo que abre el sentido y el lenguaje, es esa escritura como desaparición de la presencia natural. (Derrida, 1986: 202-203) 
En otra obra Derrida obtiene la conclusión que se deriva de esa primacía del texto: "[...] ningún elemento puede funcionar como signo sin remitir a otro elemento [...] Este encadenamiento, este tejido, es el texto que sólo se produce en la transformación de otro texto. No hay nada [...] simplemente presente o ausente. No hay [...] más que diferencias y trazas de trazas". (Derrida, 1975: 393)

De esta manera se crea lo que se ha denominado una pensée de citation donde la fundamentación de un discurso descansa en otros discursos, y éstos a su vez en otros, conformando de esta manera una concatenación interdiscursiva de la que ya no es posible salir.

Si no existe un referente objetivo y el significado es el uso, entonces se deja abierta la puerta no sólo a la innovación en las interpretaciones, sino a la negación de un límite a éstas, con lo cual se rompe la posibilidad de una comunidad general, apareciendo sólo comunidades particulares que "juegan el mismo juego del lenguaje”. Pero, ¿cómo pueden comunicarse diferentes comunidades? ¿Cuál es el fundamento de una posible traducción entre los diferentes lenguajes? ¿El diálogo intercultural y los derechos humanos universales son imposibles? Nos parece que el nominalismo tampoco responde adecuadamente al problema de los universales y con ello no nos ayuda a aclarar la naturaleza del concepto de "información".

Existe una tercera posición frente a este problema que es conocida como realismo moderado, y es el que seguimos para la comprensión de lo que es la información. Dentro de esta propuesta se distinguían los universales ante rem, in re, y post rem.

Es necesario no olvidar el contexto ideológico en esa época, el hecho que la religión permeaba toda la sociedad y cultura del Medievo. Teniendo eso presente, descubrimos 
que, en primer lugar, los filósofos medievales aceptaban que los universales existían ante rem -antes de la cosa, no como entidades metafísicas platónicas en un mundo de las ideas, sino como ideas en la mente de Dios-. Ahora bien, el presuponer la existencia de Dios como garante de los universales o de la información como modelo de las cosas es salir del marco de este análisis y adentrarnos en discusiones ajenas a nuestro objetivo tocando cuestiones de teología natural o incluso cuestiones de fe. Simplemente haremos la observación de que los mismos problemas que identificamos al analizar el realismo exagerado los encontramos en esa presunta existencia ante rem en la mente divina. Aunque claro, siempre se puede encontrar la solución a esos problemas aduciendo a la infinitud de Dios y a la imposibilidad de comprenderlo totalmente. Pero para nuestro estudio, que pretende limitarse en los marcos de la ciencia y epistemología, desechamos esa posibilidad, al menos dentro de esos campos.

En segundo lugar, también se reconocían los universales in re -en la cosa-. Efectivamente desde el punto de vista ontológico, lo que existe en la realidad son individuos, objetos singulares, cada uno de los cuales posee características, propiedades, cualidades, relaciones particulares. Sucede que algunos objetos coinciden en que comparten algunas de esas características. Gracias a esa coincidencia el intelecto los identifica, distingue y agrupa. Así pues la objetividad de los universales (información) reside en esas características, cualidades o relaciones realmente presentes en los objetos. Es por ello que los medievales afirmaban que los universales existían in re - en la cosa-, pero no formalmente - es decir, no como forma acabada de universal, ya que entonces habría una sobreposición de formas, el universal en sí y el objeto singular en sí-, sino que exis- 
ten fundamentalmente, esto es, son la base para elaborar conceptos universales. Además nosotros añadimos que esos universales in re no son esencias totalmente establecidas, identificables, inmutables que yacen en los objetos esperando ser captadas. De acuerdo a la tarea intelectual específica que alguien pretende realizar es que se establecen los criterios para elaborar los conceptos, las ideas, la información. Ante un mismo objeto diferentes especialistas se fijarán en distintas características de ese objeto para abstraerlo como concepto, esto es, para construir información a partir de él. Por lo que no podemos hablar de una esencia de ese objeto. Así por ejemplo ante un libro el lingüista centrará su atención en aspectos gramaticales (morfología, sintaxis) y semánticos del texto; el historiador en la relevancia que tuvo en el devenir de una sociedad; el crítico del arte en sus aspectos estéticos; el bibliotecólogo en sus elementos descriptivos que permiten organizarlo dentro de una colección para recuperarlo y ofrecerlo al lector que lo requiera; el economista, como una mercancía que posee valor de cambio, etcétera. De esta manera, no podemos afirmar de modo contundente qué es un libro o cualquier otra cosa. Todo depende del aspecto que deseamos resaltar debido al interés que tenemos en él.

De lo anterior se desprende que estamos uniendo el aspecto pragmático con el ontológico. En efecto, la información se construye y se nombra arbitrariamente, nace en un juego social, pero no un juego arbitrario totalmente, tiene sus fundamentos en el modo de ser de las cosas. Gracias a esa interrelación de la pragmática con lo ontológico podemos comprender cómo pudo ser que Plutón, de ser un planeta con todas sus prerrogativas, pasó a planetoide y después, por una simple votación, a un planeta menor. 
El concepto de información desde una óptica de la filosofía...

De la misma manera con ese fundamento ontológico de los universales podemos comprender la "informatividad" de ideas sin referentes, la información de algo que no existe. Esas ideas fueron construidas sobre la base de ciertas características de objetos reales pero descontextualizadas, extrapoladas, trasformadas, yuxtapuestas que se conforman en un nuevo objeto imaginario.

Finalmente en tercer lugar se consideraban los universales post rem - después de la cosa que existían en la mente humana "formados" por el acto intelectivo tomando como base las características in re-. Esas ideas son las que identificamos con la información, con la debida adaptación por supuesto porque los filósofos escolásticos tenían en mente sólo los universales y nosotros los expandimos a todas las intenciones del alma. Al mismo tiempo esos universales son nombrados por la imposición de las voces con términos lingüísticos, con símbolos, que se unen a ellos y en una relación semiótica conducen a ellos.

Así pues, terminamos nuestro recorrido, que empieza con las cosas, sigue con las ideas en el intelecto humano (información) y concluye con los signos, para después realizar el camino inverso, de los signos llegamos a las ideas y de éstas a las cosas. Concordamos con la idea de que la función significativa de los signos se origina a partir de su uso en un juego dentro de lo que Wittgenstein denominó una forma de vida. (Wittgenstein, 1999: 15) Sin embargo, como ya indicamos, ese juego toma en cuenta características reales de los objetos, además de que una de las reglas de ese juego establece que ya instituido el vínculo de ese signo con esa idea, cada vez que se utilice ese signo, se recrea dicho vínculo. 
Significados e interpretaciones de la información desde el usuario

TERCER PROBLEMA.

LA INFORMACIÓN COMO ENTE MATERIAL

A partir de la segunda mitad del siglo pasado, debido al auge de las tecnologías de la información y comunicación, a la creación de la teoría matemática de la comunicación de Shannon y Weaver, así como al desarrollo de la cibernética, se ha venido planteando la idea sobre la naturaleza física de la información. En 1948 el creador de la cibernética escribía: "la información es información, no materia o energía. Ningún materialismo que no admita esto puede sobrevivir hoy". (Wiener, 1961: 132)

Rolf Landauer escribe sobre la naturaleza física de la información (1996) y formula el principio que lleva su nombre (1961), el cual establece una relación entre energía e información y afirma que existe una cantidad mínima de energía requerida para borrar un bit de información. Su forma matemática tiene la forma de: $k T \ln 2$, donde $\mathrm{k}$ es la constante de Boltzmann (aproximadamente 1.38×10-23 J/K -joule por grados kelvin-), T es la temperatura del circuito en grados kelvin, y $\ln 2$ es el logaritmo natural de 2 (aproximadamente 0.69315). (Landauer, 1961)

Por su parte Stonier admite que la información es una propiedad básica del universo de la misma forma que lo son la materia y la energía. Así como la energía se define en términos de su capacidad para realizar el trabajo, la información se define en términos de su capacidad para organizar un sistema, entendiendo por "organización" la existencia de un patrón no aleatorio de las partículas, campos de energía u otras subunidades que componen el sistema. (Stonier, 1996: 135-136) Además, si recordamos que la entropía es el desorden en un sistema, entonces una simple deducción 
lógica establece la relación inversa entre información y entropía.

Incluso Stonier proporciona la expresión matemática de esa relación en una ecuación así como la relación numérica de la conversión de la energía en información. Su razonamiento es el siguiente: si el aumento de entropía conlleva a una pérdida de organización, o sea a una pérdida de información, entonces debe haber una relación precisa entre entropía e información. Para encontrar esa relación parte de las propuestas de Erwin Schrödinger (1944), quien utilizó la ecuación de Boltzmann, para el cual, según Schrödinger, $\mathrm{S}=\mathrm{k} \log (\mathrm{D})$, donde $\mathrm{S}$ es entropía, $\mathrm{k}$ es la constante de Boltzmann y D es "una medida cuantitativa del desorden atómico del cuerpo en cuestión". Ahora bien, si D es una medida del desorden, es lógico pensar que su recíproco $1 / \mathrm{D}$ sea una medida del orden. Por consiguiente, la entropía negativa es una medida del orden y se puede definir como $-\mathrm{S}=\mathrm{k} \log$ (1/D). Pero como D es desorden y $1 / \mathrm{D}$ es su contrario, es decir, orden, entonces se puede escribir que or $=1 / \mathrm{D}$, donde Or es una medida del orden del sistema, por lo que $-\mathrm{S}=$ $\mathrm{k} \log$ (Or).

Además, prosigue Stoiner, el contenido de información de un sistema (I) es una función del orden: I = f (Or); es más, la información y la organización se encuentran directa y linealmente relacionadas, por lo que la expresión $\mathrm{I}=\mathrm{f}$ (Or) puede escribirse como I = c (Or), donde c es una constante.

Sustituyendo en la ecuación $-\mathrm{S}=\mathrm{k} \log (\mathrm{Or})$ y despejando I, se puede derivar la relación entre la información y la entropía:

$$
I=c e^{-s / k}
$$


Finalmente, la constante c es igual a la información de un sistema cuando su entropía absoluta es cero. Por lo tanto, la ecuación toma la forma:

$$
\mathrm{I}=\left(\mathrm{I}_{0}\right) \mathrm{e}^{-\mathrm{S} / \mathrm{k}}
$$

Donde $\mathrm{I}_{0}$ es la información del Sistema cuando $\mathrm{S}=0$.

Por otro lado, la conversión de energía a información tiene la relación de $1 \mathrm{~J} /{ }^{\circ} \mathrm{K}=10^{23}$ bits (aproximadamente). (Stonier, 1996; 2007)

Otra de las teorías más conocidas, y que se ufana de establecer mediante una fórmula que expresa magnitudes numéricas lo que es la información, es la Teoría Matemática de la Comunicación, generalmente llamada Teoría Matemática de la Información de C. E. Shannon y W. Weaver, hecho que entusiasmó sobremanera a los científicos y pensadores de tendencia positivista. Por ejemplo Rapaport escribió que: "La noción de la cantidad de información es una Gran Idea [sic] en la ciencia, similar a la definición de 'cantidad de materia' [...] 'cantidad de energía' [...] o 'cantidad de entropía'.” (Rapaport, 1970)

Nacida dentro del campo de la ingeniería de las telecomunicaciones, la Teoría Matemática de la Comunicación se origina como una exigencia para explicar y predecir la cantidad de mensajes que un sistema es capaz de emitir. La cantidad de información de un mensaje, tan aclamada por algunos, resultó ser una relación de probabilidad del número de mensajes en el repertorio de la fuente con base en la cantidad de señales de las que dispone, o más bien dicho, una función de la improbabilidad de que ocurra el mensaje. De esta manera, paradójicamente, esta teoría de la información concluye que la cantidad de información en el mensaje no es lo que se está diciendo, sino lo que se podría decir. 
La fórmula de lo que para algunos representa la definición exacta de lo que es la información por estar establecida como una expresión matemática consiste en lo siguiente:

La cantidad de información $\mathrm{H}$ de una fuente que cuenta con $n$ signos que pueden ser no equiprobables es igual a menos la probabilidad de aparición de la señal 1 por el logaritmo de su aparición, menos la probabilidad de aparición de la señal 2 por el logaritmo de su aparición... menos la probabilidad de aparición de la señal $\mathrm{n}$ por el logaritmo de su aparición, esto es: $H=-P(1) \log (P(1))-P(2) \log (P(2))$ - .. - $P(n) \log (P(n))$, donde $P(i)$ es la probabilidad de aparición de la señal $i$.

Lo anterior equivale a que la cantidad de información $(\mathrm{H})$ es igual a menos la sumatoria de todas las probabilidades de aparición de las señales del 1 a $n$ por su respectivo logaritmo:

$$
H=-\sum_{i=1}^{n} p(i) \log (p(i))
$$

Pero si la fuente contiene $n$ signos equiprobables, entonces la fórmula de la cantidad de información toma la siguiente expresión:

$$
H=-\sum_{i=1}^{n} P(i) \log P(i)=-n\left(\frac{1}{n} \log \left(\frac{1}{n}\right)\right)=-\log \left(\frac{1}{n}\right)
$$

Ahora bien, muchos tomaron la anterior fórmula como la "definición de información", lo que ocasionó muchas críticas y malentendidos. Por ejemplo Bar-Hillel expresa que la confusión no es sólo el resultado de una terminología poco afortunada, sino conectar el concepto de "cantidad de infor- 
mación" con el de proceso de selección de señales, dejando a un lado el aspecto semántico de los enunciados. (Bar-Hillel, 1964: 285-287) Por lo que Bar-Hillel prefiere no hablar de "Teoría de la Información", ni siquiera de una "Teoría de Transmisión de Información", sino de una "Teoría de Transmisión de Señales" o, mejor aún, de una "Teoría de la Codificación”. (Bar-Hillel, 1964: 288, 296)

Sin embargo, podemos calificar como injusta esa crítica ya que los mismos autores advirtieron sobre el uso específico que se asignaba a la palabra "información". Así por ejemplo podemos leer en la introducción del apartado que escribió Weaver en el mencionado libro Teoría Matemática de la Comunicación:

La palabra información, en esta teoría, se utiliza en un sentido especial que no debe confundirse con su uso ordinario. En particular, información no debe ser confundido con el significado. De hecho, dos mensajes, uno de los cuales esté muy cargado de significado y el otro sea puro sinsentido, pueden ser exactamente equivalentes, desde el presente punto de vista, en cuanto a la información. Esto es sin duda lo que Shannon quiso decir cuando afirma que "los aspectos semánticos de la comunicación son irrelevantes para los aspectos de ingeniería". (Shannon y Weaver, 1949: 8)

Y en otra parte de esa introducción Weaver llama a su teoría "Teoría Matemática de los Aspectos de Ingeniería de la Comunicación”, muy lejos de lo que la mayoría llama Teoría Matemática de la Información. (Shannon y Weaver, 1949: 6)

Más adelante, en ese mismo libro, pero ahora Shannon en la introducción de su capítulo explica:

El problema fundamental de la comunicación es el de reproducir un mensaje seleccionado de un punto a otro punto, ya sea exacta o aproximadamente. Con frecuencia los mensajes tienen un significado; es decir se refieren o se correlacionan con algún sistema en el que hay ciertas entidades físicas o conceptuales. 
El concepto de información desde una óptica de la filosofía...

Estos aspectos semánticos de la comunicación son irrelevantes para el problema de ingeniería. El aspecto importante es que el mensaje actual es uno seleccionado entre un conjunto de posibles mensajes. El sistema debe ser diseñado para funcionar para cada posible selección, no sólo la que será realmente elegida, sino la que se desconoce en el momento de su diseño. (Shannon y Weaver, 1949: 31)

Ya hemos indicado que esa Teoría Matemática de la Comunicación de Shannon y Weaver es una teoría sintáctica de la información en cuanto su estudio se centra en los signos y las relaciones que existen entre ellos independientemente de su significado, uso o interpretación. (Rendón Rojas, 2005: 152)

Es una teoría que es válida en el contexto de la tecnología de la información y de la comunicación, en un mundo físico y de objetos. No es casualidad que el concepto de información que se maneja en esta teoría y otras como las propuestas por Stonier o Landauer, que conciben a la información como algo físico, tiene estrecha relación con el de "entropía” y la segunda ley de la Termodinámica. Ya lo constatamos con la propuesta de Stonier; por su parte Weaver también resalta esa relación inversa entropía-desorden; información-orden (Shannon y Weaver, 1949: 12-13). Es más, al proporcionar los antecedentes teóricos de su propuesta, Weaver menciona a Ludwig Boltzmann y sus trabajos en física estadística (1894) de donde relaciona la entropía con la falta de información; a Leo Szilard (Zsch. F. Phys. Vol. 53, 1925), quien amplió esta idea para una discusión general de la información en la física, y John von Neumann (Math Foundation of Quantum Mechanics. Berlín, 1932, cap. V), quien trató la información en la mecánica cuántica y la física de partículas. Por parte de los ingenieros menciona las ideas desarrolladas H. Nyquist y R. V. L. Hartley (Shannon y Weaver, 1949: 3). 
Este último autor que cita Weaver proporciona la clave del porqué su preocupación por entender la información de manera objetiva: si se estudia la transmisión de señales a través de máquinas "[...]es deseable, por tanto, eliminar los factores psicológicos involucrados y establecer la medida de información en términos de cantidades puramente físicas". (Hartley, 1928: 536)

Al mismo tiempo es necesario tener presente que para todos los que conciben la información como algo físico, la entienden no como mensaje, contenido, significado, sino como señales. Stonier escribe que es importante diferenciar entre el concepto de "información" y el concepto de "mensaje". Para muchos no existe información hasta que se tiene un mensaje. Lo anterior noción de información se encuentra en contraposición con lo que él entiende por "información". La información es la materia prima que cuando es procesada puede producir un mensaje. Y agrega que no importa si esta materia prima se compone de las letras de un alfabeto escrito, los nucleótidos de una cadena de ADN, los átomos que componen un cristal, o patrones de radiación electromagnética. Se convierten en un mensaje sólo después de que la materia prima (información) ha sido procesada. Tras la recepción de un mensaje, éste una vez más debe ser procesado por el receptor para que el mensaje adquiera significado. Y concluye: "[...] sin esta diferenciación precisa entre información, mensaje y significado no puede haber teoría de la información. Sin esta diferenciación se hace imposible cuantificar el contenido de información de un sistema”. (Stonier, 1996: 136)

Ahora bien, ya comentamos la crítica que Bar-Hillel realiza sobre la teoría de Shannon y Weaver, quien la califica de una teoría de trasmisión de señales que no toma en cuenta el aspecto semántico. Para resarcir ese defecto, propone 
junto con Carnap una Teoría Semántica de la Información. (Bar-Hillel y Carnap, 1953) Dicha teoría la construyen sobre la base de la lógica inductiva de probabilidades, la cual a su vez trabaja sobre la lógica de enunciados. ${ }^{14}$ Así pues, en un sistema de la lógica de enunciados, cualquier fórmula $Q$ está formada por un número $\mathrm{n}$ de proposiciones atómicas. Es posible formar un conjunto de disyunciones en las que en cada disyunto aparecen todas las combinaciones posibles de esas proposiciones atómicas con sus negaciones, pero nunca se repite una proposición, ni tampoco aparece ella y su negación al mismo tiempo. Por ejemplo, si la fórmula $Q$ está formada por una proposición atómica $\mathrm{p}$, entonces se obtiene el conjunto de dos disyunciones $\{\mathrm{p}, \neg \mathrm{p}\}$ (cada disyunción tiene un solo disyunto); si la fórmula $Q$ tiene dos proposiciones atómicas, p y q, entonces el conjunto de disyunciones estará formado por cuatro elementos, sus disyunciones serán: $\{\mathrm{pq}, \mathrm{p} \neg \mathrm{q}, \neg \mathrm{pq}, \neg \mathrm{p} \neg \mathrm{q}\}$. En general el número de disyunciones de cualquier fórmula $Q$ es $2^{\text {n }}$, donde n es el número de proposiciones atómicas que contiene $Q$; y el número de disyuntos de cada una de esas disyunciones es n. Así por ejemplo si $Q$ tiene cinco proposiciones atómicas, entonces el número de disyunciones es igual a $2^{5}$, esto es 32 disyunciones cada una con cinco disyuntos.

A cada disyunción de ese conjunto lo llaman elemento de contenido; y al conjunto de todos los elementos de contenido que $Q$ lógicamente implica es el CONTENIDo de $Q$ -Cont. $(Q)$. Es posible demostrar lógicamente que toda tautología (verdad universal tipo $\mathrm{p} \neg \mathrm{p}-\mathrm{p}$ o no $\mathrm{p}$ ) no implica ningún elemento de contenido; y una contradicción (falso

14 Esta lógica cuenta con su alfabeto y reglas para formar fórmulas bien formadas (fbf). Los principales símbolos son: $\mathrm{p}, \mathrm{q}, \mathrm{r}, \mathrm{p}_{1}, \mathrm{q}_{1}, \mathrm{r}_{1}, \ldots \mathrm{p}_{\mathrm{n}}, \mathrm{q}_{\mathrm{n}}, \mathrm{r}_{\mathrm{n}}$ para representar proposiciones atómicas; $\neg$ para la negación -no, \& para la conjunción $-\mathrm{y} ; \mathrm{v}$ para la disyunción $-\mathrm{o}$. Si $A$ y $B$ son fbf, entonces $\neg A-$ no A; $A \& B-\mathrm{A}$ y $\mathrm{B} ; A v B-\mathrm{A}$ o $\mathrm{B}$ son fbf. 
universalmente como $\mathrm{p} \& \neg \mathrm{p}-\mathrm{p}$ y no $\mathrm{p}$ ) implica a todos los elementos de contenido. Carnap y Bar-Hillel proponen precisamente esa idea de "contenido de $Q$ " Cont.( $Q)$ como base para explicar desde el punto de vista semántico lo que es información de la proposición $Q$. Al mismo tiempo ponen al descubierto que existe una relación entre Cont. $(Q)$ y la probabilidad de $\neg Q$, por lo que es posible establecer la cantidad de información:

$$
\operatorname{Cont}(\mathrm{Q})=\operatorname{Prob} .(\neg \mathrm{Q})=1-\operatorname{Prob} \cdot(\mathrm{Q})
$$

Eso queda claro en los casos de las tautologías y contradicciones. La probabilidad de que aparezca una negación de la tautología es 0 , mientras que la probabilidad de la negación de una contradicción es 1 . Así pues la cantidad de información se encuentra entre 0 y 1.

Más adelante Bar-Hillel y Carnap, utilizando como instrumento de cálculo los logaritmos, proporcionan una segunda fórmula para calcular la cantidad de información:

$$
\text { Infor. }(Q)=\log \left(\frac{1}{\text { Prob. }(Q)}\right)=-\log (\text { Prob. }(Q))
$$

Sin embargo, esa concepción semántica de información también deja mucho que desear, ya que su idea de semántica se restringe a una función que relaciona las proposiciones con los valores de verdad (verdadero y falso) independientemente del significado o sentido de esas proposiciones. 
El concepto de información desde una óptica de la filosofía...

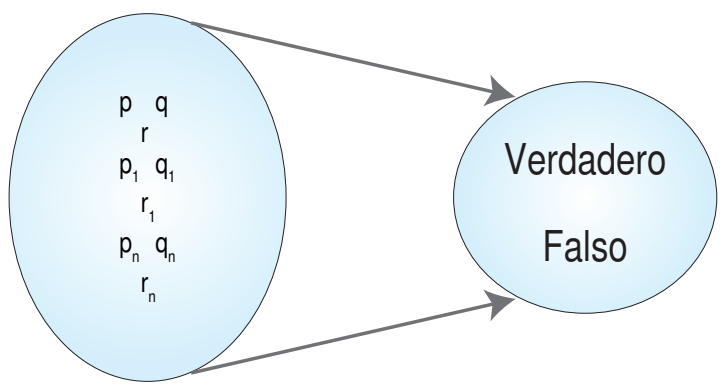

De esta manera, para toda $\mathrm{p}_{\mathrm{n}}$, donde $\mathrm{p}_{\mathrm{n}}$ es una proposición: $f\left(\mathrm{p}_{\mathrm{n}}\right)=\{\mathrm{V}, \mathrm{F}\}$, por lo que la información de una proposición depende no de su significado sino de su forma lógica. Por ejemplo el enunciado p\&q (p y q) tiene la misma información que q\&p ( $\mathrm{q}$ y p), pero si p es "comió" y q es "murió", es obvio que "comió y murió" no tiene la misma información que "murió y comió".

No es difícil descubrir la similitud que existe entre esta noción semántica de información con la teoría matemática de trasmisión de señales y con la información entendida como anti-entropía. Todas ellas tienen en su centro de atención una realidad de objetos donde no hay sujetos; ya sea el mundo físico, natural (física, química, biología, etcétera) o artificial (tecnologías, cibernética); o un mundo formalizado lógicamente.

En todos estos casos se toman en cuenta más bien señales; fuerzas con determinadas dirección, velocidad y aceleración que se entrecruzan, ondas electromagnéticas de cierta amplitud y longitud que se salen de una fuente; partículas y corpúsculos que se mueven; moléculas que chocan entre sí; enlaces químicos que forman estructuras; nucleótidos que se secuencian; letras de un alfabeto que se combinan; formas lógicas de proposiciones que implican a otras; en 
una palabra, objetos que tienen una interrelación pero que no son "formas", a menos que sean captados por el intelecto, sino que se mueven sólo en la esfera acción-reacción, causa-efecto sin una teleología, intencionalidad, sentido. Un termostato que ante el calor abre o cierra un circuito, un sensor óptico que recibe o no determinadas ondas electromagnéticas, un circuito que reacciona ante el 1 o el 0 para dejar fluir la corriente, una cadena de nucleótidos que da lugar a un fenotipo, artefactos "inteligentes", desde bombas, edificios, teléfonos, ropa, lentes, programas informáticos, etcétera, pueden ser catalogados como objetos que tienen que ver con la información. Si a eso los físicos, ingenieros, tecnólogos le quieren llamar información no vamos a discutir sobre términos. Sin embargo, desde el punto de vista bibliotecológico, podemos afirmar que no son información tal como se le concibe en esa área.

INFORMACIÓN EN BIBLIOTECOLOGÍA. APARICIÓN DEL SUJETO

Existen tres factores fundamentales para entender lo que es información dentro de la bibliotecología: el sujeto, el lenguaje y la comunicación.

Si partimos de la idea de que una necesidad es, entre otras cosas, una carencia que surge a partir del modo de ser y su desarrollo de algo o alguien, y que sólo un objeto de la misma naturaleza que la necesidad puede solventar esa carencia (el alimento satisface una necesidad de alimentación, algo psicológico satisface una necesidad psicológica), entonces existe la posibilidad de vislumbrar lo que es la información al observar lo que satisface una necesidad de información. 
Es claro que cuando un usuario se acerca a una institución informativa documental, llámese biblioteca, archivo o centro de documentación, para satisfacer sus necesidades de información, no está buscando signos, señales, bases de datos, ni siquiera libros o documentos en sí mismos, sino lo hace por los estados anímicos a los que todos los artefactos mencionados lo pueden conducir través de sus contenidos: ideas, conceptos, significados, enunciados, teorías, raciocinios, prescripciones, normas, preguntas, incluso sentimientos, emociones.

A menos que la necesidad de información se encuentre ligada exclusivamente a un documento concreto (se necesita consultar ese documento y no una copia, facsimilar, otra edición, etcétera) el usuario se sentirá satisfecho independientemente del soporte, medio, presentación, edición, ejemplar, etcétera, que se le proporcione, siempre y cuando pueda acceder a la información que llene esa carencia informativa que tenía. Así pues, la información no se reduce a los datos.

Ahora bien, si la información no son los datos de forma pura, en sí, se le puede agregar un modificador a ese término y convertirlo en algo que sigue siendo dato pero ahora con una característica: interpretado. Así pues, es común encontrar la idea de que la información son "datos interpretados", cuestión de la que disiento, puesto que podemos separar espacial y temporalmente la información de los datos, aunque éstos sean interpretados, estudiados, trabajados o analizados. Es más correcto expresar que la información es el resultado de esa interpretación, estudio, trabajo, análisis de los datos. Decir que la información son datos interpretados es parecido, tomando prestada una comparación que puede parecer un poco tosca, afirmar que el "jugo de naranja" son naranjas exprimidas. Podemos distinguir clara- 
mente la existencia de esas naranjas exprimidas que siguen siendo naranjas, y por otro lado el jugo que salió de ellas. De la misma manera la información resulta de la interpretación de datos pero no se identifica con esos datos interpretados; existe la información y al mismo tiempo esos datos, como entes distintos que no se confunden.

Ahora bien, el ser humano con el lenguaje va otorgando sentido y significado a la realidad; construye su mundo, el mundo de la cultura y al mismo tiempo se autoconstruye culturizándose. La creación de su mundo cultural ocurre al dotar de sentido a la realidad a través de la información. Lo anterior significa que esa información no preexistía sino que es construida por el ser humano, aunque claro no arbitrariamente sino con base en la realidad a través de la abstracción. Lo que es arbitrario son los símbolos que se emplean para representar esos sentidos-información que se abstrajeron.

Así pues, el ser humano, como lo mencionara Cassirer, se relaciona con la realidad no de manera directa sino a través de un sistema simbólico. (Cassirer, 1999: 47; 1971: 57) De esta manera el símbolo no representa a una realidad metafísica ya existente ni tampoco tiene nada que ver con la realidad; es una conexión arbitraria que nace en el uso, en un juego del lenguaje, como diría Wittgenstein, o en la "imposición de las voces", como dirían los medievales, donde obtiene esa significatividad.

Un ejemplo claro y muy simple de que la señal o dato no tiene relación alguna con el significado al que lleva es el modelo del condicionamiento clásico de Pávlov. Como es sabido, el científico ruso, al estudiar la fisiología del sistema digestivo, realizaba experimentos con perros y notó que el animal empezaba a salivar no sólo cuando tenía su alimento frente a él, sino que lo hacía incluso sólo con la simple vista del asistente que lo alimentaba. Después asoció un sonido 
con el alimento y descubrió que con el tiempo el sonido llegaba a representar al alimento y con la sola aparición del estímulo sonoro el perro empezaba a salivar aunque la comida no estuviera presente. Es obvio que el sonido no tiene ninguna relación con la comida; ese "dato" no es "la información" sino que conlleva a ella. Por supuesto en modelos más complejos, el condicionamiento operante, la adquisición del lenguaje, o procesos culturales de otro nivel como la ciencia, el arte, la religión, la ideología, moral, filosofía, etcétera, ese proceso es mucho más complejo pero en esencia conserva esa característica inicial: es un proceso de simbolización.

Ya en otras ocasiones hemos mencionado que la información que le interesa a la bibliotecología es un ente ideal, abstracto, no material (puesto que puede estar en varios lugares a la vez), que existe como cualidad secundaria (no es substancia, eidos, objetivo no real) de los símbolos o datos y que surge a partir de la actividad del sujeto que interpreta y significa (es pragmática) (Rendón Rojas, 2005: 88-106). Por lo tanto, tal como concebimos la información en bibliotecología, sin sujeto no hay información.

Ahora bien, reconocer esa dependencia de la información con el sujeto, el transitar a un mundo ideal, del pensamiento, de la mente, nos puede llevar a un callejón sin salida como es la subjetividad, un mentalismo que se vuelve inaccesible para los demás. ¿Cómo es posible saber lo que otro tiene en su mente? Sin embargo, es posible escapar de ese mentalismo cerrado con ayuda de la comunicación, la comunidad y la praxis.

El hecho de que el sujeto pueda relacionarse con otro(s) sujeto(s), pueda comprenderlos y crear una comunidad nos indica que esa información ideal es compartida y podemos interactuar, coordinarnos como sociedad, hacer "historia", 
esto es existir como sociedad en el tiempo. La comunicación muestra que el flujo de esos contenidos informativos fluye y cuando un sujeto construye otra información a partir de los mismos símbolos (otra interpretación o mal entendido) siempre es posible identificarlo, justificarlo o rectificar.

Al mismo tiempo esa información ayuda a construir un mapa mental que regula la acción, no de manera mecánica (como una planta orientará sus hojas al sol en su crecimiento como respuesta a estímulos luminosos, el termostato de refrigerador abrirá o cerrará un circuito por la acción de la temperatura, o una lámpara se prenderá cuando unos fotones bombardeen una placa conectada a ella, por ejemplo), sino de manera intencional que permite, hablando de manera general "resolver rompecabezas", esto es, solucionar problemas, contestar preguntas, tomar decisiones, actuar para obtener resultados. De esta forma, si no compartiéramos esa información no habría comunicación, comunidad ni praxis.

El fundamento ontológico de esa intersubjetividad es la existencia de la realidad objetiva. No debemos olvidar que, en última instancia, el origen y fuente de la información es un mundo objetivo que vamos interpretando en nuestra relación con él y con los demás. Lo que he llamado proceso onto-antropológico (Rendón Rojas, 2012: 16), que parte de una posición realista hermenéutica dialéctica. (Rendón Rojas, 2013: 279-282)

\section{CONSIDERACIONES FINALES}

Para finalizar podemos decir que no existe una definición universal válida para todas las disciplinas de lo que es la información. Consideramos que existen esencialmente cua- 
tro campos de la realidad en donde se manifiesta un tipo de información específico en cada uno de ellas: el físico, el biológico, el psicológico y el tecnológico.

En el campo físico, desde nuestro punto de vista, aparece cierta realidad informativa, pero no la información como un ens in se, esto es, una entidad en sí, substancial, un objeto existente como una realidad independiente, una tercera realidad aparte de la materia y energía como lo afirmara Wiener, o incluso en lugar de ellas, ni como un paninformacionismo donde todo es información ( $c f r$. Floridi, 2008) o un info-computacionalismo donde el universo es un conjunto de procesos computacionales que se realizan sobre la base de estructuras informacionales (Dodig-Crnkovic, 2010: 106), sino una información a nivel sintáctico, sin el componente semántico que es esencial para nosotros y, por supuesto, sin el sujeto que construye ese componente. En este nivel lo que existe son los objetos materiales; ésa es su naturaleza, "ser materiales", pero que además, siguiendo a Aristóteles, tienen "una forma de ser" manifestada por características, cualidades, propiedades, atributos, relaciones, predicados, o, continuando con la postura aristotélica, los nueve accidentes de sus categorías: cantidad, cualidad, relación, lugar, tiempo, posición, posesión, acción, pasión. Esos objetos materiales con su determinado modo de ser, se pueden convertir en quantun de información (Carbonero, 2010), o como San Agustín diría, son capaces de informar los sentidos y el intelecto al interactuar con un sujeto. En el caso de que su presencia y acción se realice únicamente en un sistema físico, se comportan como información sintáctica, reaccionan o causan reacciones al combinarse entre ellos: fuerzas, movimientos, velocidades, direcciones, cargas, estructuras, etcétera. Surgen de esta manera los diferentes tipos de sistemas, movimientos, leyes que las ciencias estudian y donde 
los conceptos de entropía y anti-entropía juegan un papel preponderante.

En el campo de la biología ocurre un salto cualitativo en el que esas características físicas se combinan de tal manera que aparecen fenómenos biofísicos y sobre todo bioquímicos (cadena de nucleótidos) que son capaces de determinar la forma, organización y funcionamiento de un organismo, con la propiedad fundamental de que esas cadenas pueden ser copiadas y trasmitidas a nuevas generaciones. Sin embargo, la "codificación" y "lectura" que se hace de esa información genética continua siendo sintáctica, sin una intencionalidad ni conciencia, semejante a cómo las máquinas podían leer las tarjetas perforadas.

Por otra parte tenemos el nivel psicológico, el cual surge, de acuerdo con el psicólogo ruso Galperin, cuando representantes de una especie requieren resolver mediante su actividad problemas que se presentan no de manera uniforme, estereotipada, sino que siempre van cambiando en sus condiciones (por ejemplo, cazar una presa no siempre se da en el mismo escenario, sino en distintas circunstancias). De esta manera aparece lo ideal, porque se requiere tener un plan de acción que incluye una imagen del campo en donde se realiza; tomar en cuenta los elementos, así como las interrelaciones entre ellos, que intervienen en la actividad realizada para efectuar la tarea; los pasos necesarios a seguir para solucionar su problema; y un control para en caso de necesidad corregir su acción o su plan. Al conjunto de todos esos elementos Galperin lo denomina "actividad orientada" (Galperin, 2000: 7). Es decir, en determinada etapa de la evolución aparecen organismos que poseen un mapa mental, el cual se forja en su psíquica a partir de los quanta de información, los cuales, en un proceso neuronal, pasan de impulsos bioquímicos a fenómenos psicológicos. 
Esa copia ideal, por supuesto no fotográfica, de espejo, que implica pasividad del sujeto, sino construida con toda la dialéctica que se requiere para ello: de lo general-particular, el papel del contexto, de la visión particular del mundo, etcétera, es una representación ideal de la realidad. Y es en este momento que aparece la información que nos interesa. Esa actividad orientada está presente desde los animales, cuya conducta depende de ella hasta el ser humano con todo su mundo cultural, lenguaje, imaginarios colectivos, sistemas semióticos.

Finalmente tenemos el campo tecnológico, el cual regresa al campo físico porque los artefactos trabajan con información sintáctica. La información se "encapsula" en datos y de esta forma se introducen en las máquinas para su almacenamiento y procesamiento, lo que dado el amplio uso de artefactos que pueden realizar esas tareas, da lugar a lo que se conoce como mega data o big data. Puede parecer que las máquinas crean nuevas informaciones al combinar los datos a los que tienen acceso, pero no son más que eso, combinaciones de signos que necesitan ser interpretados para ser significativos.

Para descubrir la naturaleza bibliotecológica de la información, partimos de un principio que parece ser evidente, casi tautológico: si el análisis que realizamos de la información es desde la bibliotecología, entonces es obvio que nuestro enfoque debe centrarse en la visión bibliotecológica. Los físicos, biólogos, ingenieros, tecnólogos, tendrán su visión e incluso esgrimirán ecuaciones y entidades cuantitativas para explicar lo que es la información, pero no se pueden extrapolar a otros campos de conocimiento. Así como un físico explicará lo que es el trabajo mediante la fórmula $\mathrm{T}=\mathrm{FxD}$ (Trabajo es igual a fuerza por distancia), pero no por ello a un economista le parecería excepcional 
esa noción por ser presentada en forma cuantitativa y no la tomaría para aplicarla en su disciplina, sino que el economista defendería su concepto de trabajo como el conjunto de actividades para la producción de bienes y servicios. La fórmula de trabajo es válida en física pero no en economía y parecería absurdo comenzar una discusión para discernir qué concepto de trabajo es la correcta, ésa o la del economista. Lo mismo sucede con el concepto de información. Hay uno en telecomunicaciones, otro en computación, otro en física, en biología y otro en bibliotecología. No hay por qué extrapolar unos a otros campos ni discutir cuál es el mejor concepto. Aunque debemos reconocer que todos los enfoques se encuentran interrelacionados, y es importante desde la bibliotecología saber cómo y por qué la información en computación, telecomunicaciones o incluso la física se entiende de cierta manea, pero el diálogo con otros enfoques se debe realizar desde una posición originalmente bibliotecológica.

Así pues, desde esa posición hemos descubierto que etimológicamente la información está ligada a la noción de forma entendida filosóficamente, pero no metafísicamente. Lo anterior significa que la forma que da origen a la información es un modo de ser de un ente, que no existe de manera independiente, eterna y terminada. Por el contrario, la información se construye cada vez por un sujeto con base en las características objetivas de ese ente, no es una copia exacta de la realidad, sino la interpretación del sujeto porque él decide qué características elige para construirla. De esta manera, la información es un objeto ideal que en un primer momento se abstrae de la realidad o se compone a partir de ella aun cuando su modelo real no exista (Pegaso, Medusa, José Arcadio Buendía, etcétera) y se encuentra en el intelecto del sujeto. En un segundo momento, esa infor- 
mación ideal se objetiva en un documento, se asocia a un símbolo, y en un tercer momento se desobjetiva interpretando ese documento, decodificando ese símbolo para regresar a su estado ideal en el intelecto del sujeto que interpretó los símbolos.

Con respecto a las preguntas que se nos plantearon para analizar este tema, ¿qué sentido le da el individuo a la información? ¿Cómo la significa? ¿Está implicada la representación del mundo del sujeto en la interpretación de la información? Podemos contestar que, debido a que se trata de una información pragmática, esto es, su existencia está ligada necesariamente con el sujeto, cada sujeto interpreta los datos partiendo de lo que Gadamer denominó "horizonte hermenéutico" (Gadamer, 1999: 376-377), es decir, las tradiciones, visiones, creencias, conocimientos, valores, precomprensiones, en fin, cultura y biografía personal a partir de los cuales interpreta. Es semejante a los que otros pensadores, como Husserl (2008) o Habermas (1999), han denominado "mundo de vida"; o según Wittgenstein (1999: 15, 182) formas de vida que dan origen a un juego del lenguaje. Desde esta posición pragmática y tomando como punto de referencia el concepto de ser de Heidegger como "poder ser", "hacer su ser" es que he concebido el estudio de usuarios y la posibilidad de ofrecer la información requerida para satisfacer sus necesidades de información como un adentrarse al conocimiento del proyecto existencial de los usuarios (Rendón Rojas, 2005: 115) y ahora añadiría a su mundo de vida.

Por otro lado, ante la pregunta de si existen diferencias y semejanzas en el abordaje del proceso para identificar el sentido que le dan los sujetos a la información y un concepto de la misma, entre la bibliotecología, la psicología y la educación podemos decir que existe un común deno- 
minador aunque haya diferencias en sus objetivos. La información en bibliotecología está orientada a satisfacer necesidades de información que los usuarios le presentan al profesional de la información documental en una institución informativa documental. De acuerdo al proyecto existencial del usuario, será la intencionalidad de esa necesidad de información. Por su parte, la información en educación tiene como finalidad construir conocimiento, aunque la distinción tajante entre información y conocimiento es una idealización enfocada más a facilitar el análisis que un reflejo de la realidad ya que los seres humanos, como seres racionales no actúan utilizando sus capacidades de manera separada, sino como un todo. Si se obtiene una información, en cierta medida ya se tiene un conocimiento, conocimiento incipiente, que encuentra su justificación en el documento mismo y requiere de acciones adicionales -análisis, síntesis, verificación, demostración, valoración, relación con otras informaciones y conocimientos, asimilación en la elaboración de un discurso propio, aplicación-, para construir un conocimiento propio, nuevo y más justificado. Con respecto a estas dos esferas, es posible constatar que en ciertos momentos la información bibliotecológica y la educativa pueden coincidir. En toda institución educativa (escuela, universidad, instituto) la biblioteca o el sistema bibliotecario ocupan un lugar central en su organización. Por último, la información en psicología se produce para que el individuo se relacione con el medio ambiente (físico, social, psicológico) a través de percepciones, emociones, sentimientos, atención, memoria, aprendizaje, pensamiento, y se inserta en la dinámica de la personalidad. La relación de la psicología con la pedagogía también ya es conocida; todo pedagogo debe conocer las bases psicológicas de la educación y existe la psicología educativa, que investiga 
los procesos psicológicos que intervienen en el aprendizaje. Sólo restaría investigar más a fondo la relación de la bibliotecología con la psicología, que no dudamos que existe, ya que el proceso de significación empieza como un proceso neuropsicológico y su función es crear una imagen ideal de la realidad para interactuar con ella. Un primer acercamiento a esa problemática es la aplicación de la teoría de la Gestalt, que realicé para explicar la conformación de diferentes enfoques (construcción de diferentes informaciones) sobre una misma realidad (Rendón Rojas, 2013: 286-287).

Para terminar, a modo de síntesis apretada, podemos decir que lo que informa, es decir, la causa que origina la forma, son los objetos de la realidad. La información en sí es la presencia de esa forma en el intelecto, y de la cual nos percatamos de su objetividad a través de la intersubjetividad (comunicación, comunidad) y la praxis. Finalmente esa información ideal se asocia a una señal, un símbolo, un dato, que permite su objetivación en un soporte. Por último, gracias a la actividad de un sujeto que interpreta esos datos, se re-crea la información en su forma ideal.

\section{BIBLIOGRAFÍA}

Angulo Marcial, N. (1996). Información: una propuesta conceptual. Ciencias de la Información, 27(1), 190-195.

Bar-Hiller, Y. (1964). An Examination of Information Theory. En Language and Information (pp. 275-297). Jerusalem: Jerusalem Academic Press.

Bar-Hiller, Y., y Carnap, R. (1953). Semantic information. British Journal of Science, 4, 147-157. 
Bérut, A., Artak, A., Artyom, P., Ciliberto, S., Dillenschneider, R., y Lutz, E. (2012). Experimental verification of Landauer's principle linking information and thermodynamics. Nature, 483, 187-189.

Beuchot, M. (1991). La filosofía del lenguaje en la Edad Media. 2da edición. México: Universidad Nacional Autónoma de México.

Capurro, R., y Hjørland, B. (2003). The Concept of Information. Annual Review of Information Science and Technology (ARIST), 37, 343-411.

(1978). Information. Ein Beitrag zur etymologischen und ideengeschichtlichen Begründung des Informationsbegriffs. München: Saur.

(2001). On the Genealogy of Information. En K. Kornwachs, K. Jacoby (Eds.), Information. New questions to a multidisciplinary concept (pp. 259-270). Berlin: Akademie Verlag. Disponible en: http://www.capurro.de/cottinf.hbm.

. (2008). Presente, pasado y futuro de la noción de información. En: Actas del primer encuentro internacional de expertos en teorias de la información. Un enfoque interdisciplinar (pp. 1-26). León [España]: Universidad de León.

Carbonero, E. (2010). Informacionismo. En Glossarium BITri. Glosario de conceptos, metáforas, teorías y problemas en torno a la información (pp. 115-120) Coord.: José María Díaz Nafría, Mario Pérez-Montoro Gutiérrez, Francisco Salto Alemany. León: Universidad de León.

Cassirer, E. (1999). Antropología filosófica. México: FCE.

(1971). La filosofía de las formas simbólicas. México: FCE. $3 \mathrm{v}$.

Cicero (1967). De natura deorum. In 28 volumes. V. 19. Camridge, Massachusetts: Harvard University Press; London: William Heinemann LTD. Disponible en: https://archive.org/stream/denatu radeorumac00ciceuoft ${ }^{\#}$ page/44/mode/2up 
El concepto de información desde una óptica de la filosofía...

Derrida, J. (1975). La diseminación. Madrid: Fundamentos. (1986). Gramatología. México: Siglo XXI.

Dodig-Crnkovir, G. (2010). Info-computacionalismo. En Glossarium BITri. Glosario de conceptos, metáforas, teorías y problemas en torno a la información José María Díaz Nafría, Mario PérezMontoro Gutiérrez, Francisco Salto Alemany (Coord) (pp. 106107). León: Universidad de León.

Euclides (1991). Elementos. Madrid: Gredos.

Floridi, L. (2008). Information Ethics. Its Nature and Scope. En: Jeroen van den Hoven y John Wecker (Eds.). Information Technology and Moral Philosophy (pp. 40-65). Cambridge: Cambridge University Press.

. (2011). The philosophy of information. Oxford: Oxford University Press.

Frege, G. (1984). El pensamiento. En Investigaciones lógicas. Madrid: Tecnos.

Gadamer, H. G. (1999). Verdad y método 1. Salamanca: Sígueme.

Galperin, P. Y. (2000). Vvedenie v psijologuiu. (Introducción a la psicología) Moscú: Knizhnii dom Universitet.

Habermas, J. (1999). Teoría de la acción comunicativa, I. Racionalidad de la acción y racionalización social. Madrid: Taurus.

Hartley, R. V. L. (1928). Transmission of Information. Bell System Technical Journal, 7(3), 535-563.

Houser, L. (1988). A Conceptual Analysis of Information Science. Library and Information Science Research, 3, 3-35.

Huertas Sánchez, A. y Manzano Arjona, M. Teoría de Conjuntos. Disponible en: http://pendientedemigracion.ucm.es/info/pslogica/teoriaconjuntos.pdf.

Hume, D. (2007). Investigación sobre el conocimiento bumano. Investigación sobre los principios de la moral. Madrid: Tecnos. 
Husserl, E. (2008). La crisis de las ciencias europeas y la fenomenología trascendental. Buenos Aires: Prometeo Libros.

Israel, D., y Perry, J. (1990). What is information? En P. Hanson (Ed.), Information, language and cognition (pp. 1-19). Vancouver, BC: University of British Columbia Press.

Landauer, R. (1961). Irreversibility and Heat Generation in the Computing Process. IBM Journal, 183-191.

(1996). The physical nature of information. En Physics Letters A. 217. pp. 188-193.

Locke, J. (2003). Ensayo sobre el entendimiento humano. Barcelona: RBA Coleccionables.

Machlup, F., \& Mansfield, U. (1983). The Study of Information. Interdisciplinary Messages. New York: Wiley.

Machlup, F. (1983). Semantics quirks in studies of information. En Fritz Machlup y Una Mansfield (Eds.), The Study of Information. Interdisciplinary Messages (pp. 641-671). New York: Wiley.

Nietzsche, F. (2004). Fragmentos póstumos. Una selección. Madrid: ABADA Editores.

Pérez-Montoro Gutiérrez, M. (2007). The Phenomenon of Information. Maryland: Scarecrow Press.

Peters, J. D. (1988). Information: Notes toward a critical history. Journal of Communication Inquiry, 12, 10-24.

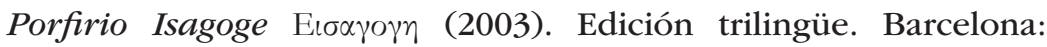
Anthropos. Disponible en: http://es.scribd.com/doc/62407693/ Porfirio-Isagoge-trilingue ${ }^{\#}$ scribd

Qvortrup, L. (1993). The controversy over the concept of information. An overview and a selected and annotated bibliography. Cybernetics \& Human Knowing, 1(4), 3-24. 
El concepto de información desde una óptica de la filosofía...

Rapaport, A. (1970). What is information? En Saracevic Tekfo (Comp. y Ed.) Introduction to information science (pp. 5-12). New York \& London: Bowker Company.

Rendón Rojas, M. A. (2005). Bases teóricas y filosóficas de la Bibliotecología. México: UNAM / CUIB.

. (1995). La información como ente ideal objetivizado. Investigación bibliotecológica: archivonomía, bibliotecología e información, 9(18), 17-24.

Rendón Rojas, M. A. et al. (2012). La manifestación dialéctica de los valores en el campo informativo documental. RICI: Revista Ibero-Americana de Ciencia de la Información, 5(2), 1-18.

. (2013) Reflexiones finales. En Miguel Ángel Rendón Rojas (Coord.), El objeto de estudio de la bibliotecología/documentación/ciencia de la información: propuestas, discusión, análisis y elementos comunes. (pp. 275-295). México: UNAM / Instituto de Investigaciones Bibliotecológicas y de la Información.

Ruiz Calleja, A. (2008). Información semántica e implicación lógica. Ágora. Papeles de Filosofía, 27(2), 101-114.

Russell, B., y Whitehead, A. N. (1981). Principia Mathematica. Madrid: Paraninfo.

San Agustín. (1956). Tratado sobre la Santísima Trinidad. En Obras de San Agustín. Edición Bilingüe. Tomo v. Madrid: Biblioteca de Autores Cristianos.

. (1958). La Ciudad de Dios. En Obras de San Agustín. Edición Bilingüe. Tomo XxvI. Madrid: Biblioteca de Autores Cristianos.

Santo Tomás. Summa Theologiae. En Corpus Thomisticum. S. Thomae de Aquino. Opera Omnia. Recognovit ac instruxit. Enrique Alarcón. Automato electrónico. Pompaelone ad Universitatis Studiorum Navarrensis aedes a MM A.D. Disponible en: http://www.corpusthomisticum.org/iopera.html 
Significados e interpretaciones de la información desde el usuario

Shannon, C. E. y Weaver, W. (1949). The mathematical theory of communication. Urbana, IL: University of Illinois Press.

Schrödinger, E. (1944). What is Life? Cambridge: University Press.

Stonier, T. (1996). Information as a basic property of the universe. Bio Systems, 38, 135-140.

. (2007). Información y entropía. Geotermia, 20(1), 54-64.

Todd, R. J. (1999). Back to our beginnings: information utilization, Bertram Brookes and the fundamental equation of information science. Information Processing and Management, 35, 851870.

Vergili, M. (1969). Aeneidos. Opera. ed. Roger A. B. Mynors. Oxonii. Disponible en: http://www.hs-augsburg.de/ harsch/Chronologia/Lsante01/Vergilius/ver_ae08.html

Virgilio. La Eneida [en línea], http://alerce.pntic.mec.es/rmarti41/ docum/eneida4.htm

Voishvillo, E. K. (1976). Semanticheskaia informatsia: Poniatiya ekstentsionalnoy i intentsionalnoy informatsiy. V Kibernetika $i$ sovremennoe nautchnoe poznanie. Moskvá: Nauka. pp. 165168. (Voishvillo, E. K. (1976). La información semántica: Concepto de la información extensional e intencional. En Cibernética y conocimiento científico contemporáneo (pp. 165-179). Moscú: Nauka.

Wiener, N. (1961). Cybernetics or control and communication in the animal and the machine. New York: MIT Press. 2a ed.

Wittgenstein, L. (1999). Investigaciones filosóficas. Barcelona: Ediciones Altaya. S. A. 
El sentido de la información: un enfoque centrado en el usuario

PATRICIA HeRnández SAlAZAR

Universidad Nacional Autónoma de México

INTRODUCCIÓN

U

n componente esencial de los fundamentos teóricos de diversas disciplinas, como la psicología, la informática, la comunicación, la bibliotecología y las ciencias de la información, es la información, por lo que existe una gran necesidad de delimitarla conceptualmente. Esta necesidad se vuelve acuciosa en las dos últimas, afirmación que se comprueba con la identificación de su objeto de estudio: la relación entre la información y el usuario. Se han generado definiciones de información basadas en diversas dimensiones; lo que interesa es distinguirla como detonante de significados e interpretaciones, y el sujeto en esta dimensión se ubica como el constructor de dichos significados desde su percepción y representación del mundo: sistemas de creencias, valores, principios, modelos del entorno, que se ven afectados por la incorporación de la información.

La tendencia de entender la información vinculada al usuario aparece al inicio de la década de los ochenta del si- 
glo pasado, y se denomina enfoque centrado en el usuario. La información no es sin el sujeto que la utiliza: su contenido existe hasta que alguien lo lee, analiza, sintetiza, asimila y lo incorpora a su acervo de conocimientos (Hernández Salazar, 2013).

Para sostener esta idea, el capítulo tiene por objetivo examinar los conceptos y definiciones de información a partir del enfoque centrado en el sujeto que la usa y el sentido que le da. El texto está conformado por dos grandes apartados: el primero se refiere a la delimitación conceptual de la información y el uso de información como el fenómeno en el que se enclavan la significación e interpretación de la misma por el sujeto; el segundo apartado se presenta en dos perspectivas de aprehensión e interpretación de significados: una el sujeto como ente individual y otra como sujeto social.

Cabe aclarar que el uso de la información se entiende como un proceso cognitivo de transformación, generado en el sujeto mediante la lectura, análisis y aprehensión de los contenidos de recursos primarios, y no como la explotación de recursos secundarios reflejado en el comportamiento en la búsqueda y recuperación de la información. La premisa es concebirlo como un proceso mental conformado por diferentes estadios cognitivos, como percepción, análisis, síntesis, aprehensión e interpretación, que permiten construir su sentido.

\section{DELIMITACIÓN CONCEPTUAL DE LA INFORMACIÓN}

Una etapa esencial de este trabajo es analizar las definiciones de información que se han generado de acuerdo con la tendencia centrada en el usuario. Se abordan tres perspec- 
tivas: el enfoque cognitivo, el sense-making y la toma de decisiones.

\section{Enfoque cognitivo}

En un afán por crear los fundamentos de las ciencias de la información, varios estudiosos se dan a la tarea de establecer definiciones de información, tomando como sustento teórico el cognoscitivismo o enfoque cognitivo, el cual plantea que se debe considerar el acervo de conocimientos que un sujeto posee al momento de incorporar lo contenido en un recurso informativo.

Uno de los precursores más citados cuando se trata de definir la información en este campo disciplinar es B. C. Brookes, quien al inicio de la década de los setenta empezó a delimitar una ecuación que mostrara la relación entre la información y el sujeto, y que culmina con la llamada Ecuación Fundamental. En una serie de cuatro artículos plantea la fundamentación teórica de la disciplina, cuyo elemento primordial es precisamente la información. En el primero explica los aspectos filosóficos que tomó como base, el esquema ontológico del conocimiento humano de Karl Popper, conformado por tres mundos:

Mundo 1. El mundo físico, el cosmos en el cual la Tierra, aunque vital para nosotros, no es más que una insignificante mota en la inmensidad del universo de la radiación y la materia.

Mundo 2. El mundo del conocimiento subjetivo humano o "estados mentales".

Mundo 3. El mundo del conocimiento objetivo, los productos de la mente humana registrados en lenguajes, las artes, las ciencias, las tecnologías - en todos los artefactos humanos que han sido almacenados o diseminados alrededor de la Tierra. (Brookes, 1980: 121) 
Su referente principal para desarrollar su ecuación son los Mundos 2 y 3; el 2 porque son los estados mentales humanos básicos para el 3, los productos de la mente humana no existen sin el mundo del conocimiento subjetivo humano.

Relaciona la información con la estructura de conocimiento de los sujetos, y su ecuación fundamental quedó de la siguiente manera:

Donde:

$$
\mathrm{K}[\mathrm{S}]+\Delta \mathrm{I}=\mathrm{K}[\mathrm{S}+\Delta \mathrm{S}]
$$

$\mathrm{K}[\mathrm{S}]=$ Estructura de conocimiento

$\Delta \mathrm{I}=$ Información (efecto de modificación)

$\mathrm{K}[\mathrm{S}+\Delta \mathrm{S}]=$ Nueva estructura modificada por la información Fuente: Brookes, B.C. (1980: 128).

Es evidente que la información se subordina al usuario, específicamente a su estructura de conocimiento, y la explicación de la ecuación es bastante clara. Un individuo posee una estructura de conocimiento ( $\mathrm{K}[\mathrm{S}]$ ), la cual, al ser expuesta (o sumada) a una información que es entendida e interpretada por un sujeto, modifica o transforma su estructura de conocimiento $(K[S+\Delta S])$. Esto se refleja en el símbolo de la información asociado a la estructura $(\Delta S)$. Es decisión del sujeto exponerse a la información, toda vez expuesto su acervo cognitivo cambiará.

Considera que la información y el conocimiento son entidades de la misma clase, en el sentido de que ambas son definidas a partir del acervo de conocimientos de los sujetos. La definición de información depende del conocimiento; el conocimiento es una estructura de conceptos enlazada por sus relaciones, y la información es una pequeña parte del conocimiento (Brookes, 1980: 131). Se evidencia que la información depende de su aprehensión, asimilación y aco- 
modo en el acervo cognitivo de un sujeto. Considera como un factor importante el entorno y el efecto que ejerce en la relación información-sujeto, "En la vida diaria dependemos grandemente de la información absorbida de nuestro entorno." (Brookes, 1980: 131). Genera cuatro tipos contrarios de información:

Verbal y no verbal. Además del conocimiento objetivo (verbal, lingüístico) existe un conocimiento subjetivo, asociado con la percepción de los sujetos, que no siempre tiene expresiones observables u objetivas. Vincula esta clasificación con que la información puede ser potencial y está en cualquier parte, y que no siempre estamos conscientes de todos los recursos de información que ayudarían a resolver un problema.

Objetiva y subjetiva. De acuerdo con los mundos de Popper, existe conocimiento objetivo y subjetivo; si la información y el conocimiento son interdependientes, entonces existe información objetiva y subjetiva. La objetiva corresponde a la materialidad de los productos de la mente humana, y la subjetiva a la significación que tanto el generador de la información como el receptor le dan. Esta tipología no se sostiene; la información como producto de la mente humana y representación del conocimiento objetivo es esencialmente objetiva, tangible; el significado y la interpretación de sus contenidos dependen de los usuarios; no es que haya información subjetiva: lo subjetivo es su transformación en las mentes humanas.

Si bien la información es un elemento fundamental para la ecuación, Brookes no la define puntualmente, es decir, no establece su esencia, sólo la caracteriza como parte del conocimiento.

Otro estudioso de la ciencia de la información y del tema ha sido N. J. Belkin, quien apoya la idea de Brookes en 
el sentido de que la consolidación de la disciplina precisaba la definición de su elemento primigenio, la información, siempre vista desde el usuario, concretamente de su acervo cognitivo. Él sí la define como "[...] datos estructurados los cuales actúan para transformar un estado de conocimiento o estructura de conocimiento" (Belkin, 1975: 53); los datos son "[...] símbolos físicos que de alguna forma representan un mensaje." (Belkin, 1975: 54)

Puntualiza que "[...] el cambio de la estructura de conocimiento indica la adquisición de la información, o una asimilación más efectiva de la información." (Belkin, 1975: 54)

Entiende este proceso de asimilación como una matriz algebraica, en la que la información representa los valores, y el estado de conocimiento las variables, las cuales cambiarán de acuerdo con los valores que otorgue la información. Si bien la transformación es un asunto individual, las representaciones pueden ser compartidas, socializadas:

[...] los seres humanos se construyen internamente, con representaciones estructuradas del mundo y de ellos; que la estructura básica de estas representaciones es común al menos a las sociedades; que el comportamiento depende de esta representación; que lo común en lo cognitivo y lo común en las experiencias permiten la comunicación; que el significado de la comunicación cambia la representación; y que la estructura del conocimiento objetivo organizado está basada en los mismos principios que el conocimiento interno subjetivo. (Belkin, 1975: 56)

Es posible apreciar que refuerza la idea de la clasificación del conocimiento en objetivo y subjetivo; de suyo, el conocimiento es subjetivo pues es un proceso/producto privativo del ser humano que se realiza/genera al interior del cerebro, y su representación, manifestación y percepción por el otro es absolutamente subjetiva. No es válida la afirmación de que el producto de la mente humana es el co- 
nocimiento objetivo. En realidad, estaríamos hablando de información, de acuerdo con la propia definición de Belkin.

La acepción de información está vinculada a un sujeto, y su posible relación con otros se basa en los siguientes aspectos fundamentales:

a) La información deberá ser requerida o necesitada.

b) El efecto de la información en un sujeto estará representado por un cambio en el estado de conocimiento o en su representación del mundo, es decir, eventualmente será observable. (Belkin, 1975)

Y lo observable se circunscribe a:

a) Las diferencias en las respuestas de cada individuo a los mismos datos.

b) Las diferencias de respuesta de un mismo individuo a los mismos datos en diversos momentos y circunstancias (entendidas como contextos).

c) Las diferencias de respuesta del mismo individuo a los mismos datos presentados en formas variadas (nos referiremos aquí a los tipos de recursos de información: primarias, secundarias y terciarias).

De lo anterior se rescatan varios elementos que conforman el sentido de la información:

- La importancia de las representaciones del mundo (estructuras cognitivas) de los sujetos para delimitar su concepto.

- Las representaciones cognitivas reflejan las experiencias del ser humano. 
- Las representaciones son personales, pero compartidas con otros sujetos; mediante éstas se establece la comunicación y le dan un carácter de común.

En un estudio posterior, Belkin (1977) relaciona el significado de la información y los modelos de estado de conocimiento con la lingüística. Esto apuntala la propuesta de comunicación de representaciones (lo comunal), y la introducción de lo lingüístico le permite vincular tres elementos: el contenido de la información de los textos (ya no es sólo la estructura); el significado de este contenido; y el estado de conocimiento del usuario. Aumenta dos elementos a su definición de información: el contenido (los datos estructurados representan o poseen un contenido), y el significado, que resulta del lenguaje de lo sintáctico y lo semántico.

En esta perspectiva incorpora en el proceso a la memoria. El sujeto recibe la nueva información de los contenidos de un texto, la retrotrae de su entramado conceptual, mediante la memoria, busca si existe un significado y, en caso que no, se lo concede de acuerdo con la cadena de sentidos que ya posee (visión del mundo), la transforma, la acomoda en su cadena conceptual, lo que se conoce como interpretación y la comunica nuevamente ya transformada. Los aspectos lingüísticos crean los conceptos; sin lenguaje no hay conceptos, ni interacción social mediante estos conceptos expresados verbalmente, principios ya abordados por Vygotsky en su obra Pensamiento y lenguaje, publicada en 1934.

En la década de los ochenta, Belkin, Oddy y Brookes (1982) crean una forma asociativa para analizar y representar los textos. Miden la coocurrencia de las palabras que $a$ priori un especialista o indizador ha elegido como claves en algún campo de conocimiento; las comparan con las que eligen los sujetos cuando pretenden cubrir una necesidad 
de información para determinar si las considera al buscarla. Con este estudio, se critica la forma en que se diseñaban los sistemas de recuperación de información (SRI), al casar los términos de búsqueda con los términos integrados arbitrariamente en las bases de datos. Derivado de estos estudios, se establece el diseño de los sistemas de búsqueda y recuperación de información centrados en el usuario. Deben basarse en las necesidades de información de los sujetos, a las que Belkin en 1980 denominó Estados Irregulares de Conocimiento (ASK, por sus siglas en inglés: Anomalous State of Knowledge), propuesta que se ha seguido hasta nuestros días.

Crea un modelo para diseñar SRI, denominado Sistema Cognitivo de Comunicación para la Recuperación de Información. El modelo está conformado por dos grandes partes, dispuestas de lado derecho e izquierdo. El lado derecho representa a:

[...] un generador, como el autor, decide comunicar por alguna razón y para determinada audiencia algún aspecto de su estado de conocimiento o "imagen" del mundo. Lo que el autor conoce acerca de este tópico es modificado por sus creencias, intenciones, valores, etc., y específicamente por el conocimiento de la audiencia meta y el contexto de comunicación. (Belkin, 1980: 135)

Y el izquierdo a:

[...] un usuario quien decide investigar o usar alguna parte de su estado de conocimiento o imagen, [...] el usuario percibe que hay una anomalía en su estado de conocimiento con respecto al problema que enfrenta. Esta percepción, [...] lo dirige a un estado irregular de conocimiento (ASK [anomalous state of knowledege]) reconocido, el cual más adelante [...] se convierte en un requerimiento para el sistema de IR [Information Retrieval-Recuperación de Información]. (Belkin, 1980: 135) 
La interrelación entre el generador (autor) y el usuario está mediada por transformaciones producidas por aspectos lingüísticos y pragmáticos. Este modelo enfatiza el papel del usuario y sus necesidades, y las considera más importantes que los textos para diseñar SRI.

Profundiza en esta idea y declara que el concepto de información debe estar directamente relacionado con las necesidades de información de los sujetos, como representación de una situación problemática identificada por el sujeto. Este individuo identifica que carece del conocimiento para resolverla; lo irregular se refiere a brechas o carencias cognitivas, a incertidumbres e incoherencias.

El modelo arriba explicado se basa en el conocimiento de varios aspectos del usuario:

1. El estado del usuario en el proceso del tratamiento del problema.

2. El tópico y el tipo de problema que el usuario está enfrentando.

3. El estado de conocimiento del usuario acerca del problema.

4. Las metas, intenciones y antecedentes del usuario.

5. Qué tan bien interactúa con el sistema para obtener conocimiento. (Belkin, 1984: 117)

Idea con la que se está totalmente de acuerdo, y que ha llevado a crear folksonomías y maneras nuevas de recuperar información en las redes sociales digitales.

De los autores anteriores, se retoman y modifican algunos elementos para definir a la información como un conjunto de datos organizados que representan contenidos y transforman las estructuras de conocimiento de los sujetos al conferirles significado. 
El sentido de la información: un enfoque centrado en el usuario

a) Características:

- Contiene significado para un determinado usuario o comunidad de usuarios. En su aspecto lingüístico, el receptor percibe y acomoda en sus estructuras de conocimiento el contenido de la información.

- Promueve la interpretación. Toda vez que el sujeto concede significado a la información, la interpreta, asimila y acomoda en su estructura de conocimientos.

b) Funciones. La función más genérica es transformar el estado de conocimientos de un sujeto. Sin embargo, cabe aclarar que esta transformación depende de los objetivos que dichos sujetos persiguen al buscarla, recuperarla y eventualmente utilizarla, por lo que las funciones serán tantas como problemas o actividades existan.

c) Tipos de información. Igual que en el apartado anterior, es posible crearlas de acuerdo con el contexto de la investigación.

\section{Sense-making o dar sentido}

Brenda Dervin sigue también el enfoque cognitivo — no declarado cabalmente por ella- y desarrolla un modelo que denomina sense-making. Este modelo ha servido para estudiar diversos aspectos de la relación entre los sujetos y la información, sus necesidades de información, el comportamiento en la búsqueda y recuperación y el uso. La base teórica de su modelo es la comunicación de las brechas que existen entre un estado de conocimiento y otro, ubicados en el tiempo y el espacio; un sujeto varía de un momento a otro de acuerdo con su actividad cognitiva. 
El sense-making estudia desde una perspectiva holística y compleja el proceso de comunicación de los usuarios con la información; cómo éstos conceptualizan sus movimientos a través del tiempo y espacio y los puentes que crean para acercarse a ella; lo que predicen para darle o no sentido. Cuestiona sobre todo el proceso para cubrir sus brechas de conocimiento (se identifican como la desestabilización del acervo cognitivo del sujeto): pasos, sentimientos, resultados, o micro-momentos específicos, y dudas. Registra el proceso desde cualquier perspectiva humana, no "sólo la cognitiva", afirmación que de acuerdo con la neurociencia no tiene fundamento, puesto que lo cognitivo produce lo emocional y sentimental. El trabajo atiende tres premisas: "1) humanos y realidad algunas veces son ordenados y otras caóticos; 2) existe una necesidad humana para crear significado, y el conocimiento es algo que siempre está entre la mediación y la disputa; y que 3) existen diferencias humanas en la experiencia y en la observación”. (Dervin, 2003: 7)

Está conformado por tres elementos principales: la situación, que incluye las experiencias e historias de los sujetos, atiende al pasado, se retrotrae al presente y se proyecta al futuro; la brecha reflejada en preguntas, confusiones y angustia; y los resultados, entendidos como horizontes futuros, consecuencias, efectos e impactos. La intención es acompañar al sujeto en todo el camino desde que se plantea una situación problemática hasta que logra las metas planteadas para resolverla.

En las múltiples explicaciones que se encuentran sobre el sense-making siempre aparece la importancia de la información. Sin embargo, no se establece una delimitación conceptual como tal; va de entenderse como proceso a percibirla como el producto del proceso; lo que importa es el sentido dinámico que tiene; se concibe como un verbo, una 
acción, no como sustantivo estático; es un término en constante movimiento, un continuum de significados imposible de asir como un concepto estático.

Es posible afirmar que cualquier modelo consolidado debiera definir los términos que se manejan para explicarlo; se hace necesario comprometerse con un significado para que nuestro hacer en la investigación sea consistente y podamos generar una suerte de marco teórico o conceptual que defina nuestra disciplina. Es difícil obtener resultados en un escenario pantanoso terminológicamente hablando.

Una de las características del sense-making que lo hace propicio para abonar en la idea de significación e interpretación de la información, es la técnica de recogida de datos; se hace siempre con entrevistas a profundidad, promueven que el sujeto se exprese ampliamente desde su perspectiva y visión del mundo para dar sentido a los problemas que enfrenta y cómo los resuelve con el apoyo de la información, desde que tiene la necesidad de buscar y recuperar información, las barreras que encuentra y cómo las derriba, mediante la consideración de las experiencias y tomas de decisiones pasadas, es decir, el conocimiento previo. Importan las formas (los cómo) más que la causas (por qué) o los objetivos (para qué), los procesos y las acciones que realiza un sujeto para enfrentarse ante la información.

El análisis de las entrevistas se hace desde la semántica; otorga figuras semánticas a las palabras expresadas por los entrevistados que le permiten hacer un análisis más profundo, generar patrones y múltiples conectividades para entender la relación entre un sujeto y la información. Resalta la interpretación de las situaciones, no existe una realidad absoluta, depende de la percepción y significación que los individuos les dan, siempre dentro de un plano temporal, por lo que retoma el pasado, el presente y el futuro del 
sujeto en circunstancia, actúa así ahora por el ayer y para prever el futuro.

Concede gran importancia a darle sentido a dicha información dentro de un contexto determinado. Si bien trae y lleva el término contexto, no es posible identificar en sus textos una definición puntual; lo vuelve subjetivo y lo ubica como algo cambiante de acuerdo con el tiempo y el espacio en el que se mueva el sujeto. Incluso, lo refiere como un elemento que tiene implicaciones en la metodología para investigar y generar nuevo conocimiento, el investigador dentro de un contexto de interpretación de lo recogido.

Construye un conjunto de categorías que representan la forma en la que los sujetos enfrentan la situación, basados en los conceptos tiempo, espacio, movimiento, brecha, represión. Codifica los movimientos del usuario en un momento en el tiempo-espacio como parada:

1. Dos o más caminos aparecen al frente (decisión).

2. Algo bloquea el camino (barrera).

3. El camino ha desaparecido (derrumbado).

4. Alguien o algo está empujando al usuario bajo el camino (problemática).

5. El camino tuerce en espiral y no tiene dirección (prolongación).

6. El usuario lo reprimió (hizo un alto).

Dependiendo de las formas de mirar y enfrentar una situación, los usuarios se moverán de diferente manera. De esas categorías, los sujetos evalúan la interacción con los sistemas de información (Dervin, 1998). 
- 1. Encuentran los caminos o dirección.

- 2. Permiten tener una nueva manera de mirar las cosas.

- 3. Obtienen conexión con la información.

- 4. Obtienen compañía y soporte.

- 5. Logran evitar un mal lugar.

- 6. Obtienen placer y júbilo.

- 7. Llegan al lugar que querían.

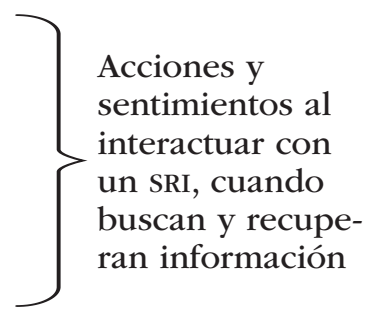

El acto de dar o no dar sentido varía si el usuario trabaja solo o en forma colaborativa, si está relacionado:

1. Con él mismo.

2. Con otro.

3. Con una colectividad.

4. En una colectividad relacionado con otro.

5. En una colectividad relacionado con otra colectividad.

Es posible apreciar que el sense-making no da respuestas; promueve la búsqueda de las mismas, de las interacciones de sujetos e información, el sentido de la información deviene del sentido que le dan a sus vidas y actividades cotidianas, es por eso que se considera como una metodología. Si bien Dervin apunta que su modelo es una metateoría, su análisis puntual arroja que es un proceso heurístico (para profundizar en el tema revisar Rendón Rojas y Hernández Salazar, 2010).

También podemos percibir, de acuerdo con las propias categorías que se expresaron, que este modelo es propicio para entender la generación y expresión de necesidades de información, y el comportamiento que siguen para cubrirlas, no así para identificar el uso de la información, aunque esté expresado puntualmente por la propia autora. La justificación es que en toda su obra no delimita lo que entiende por 
uso de la información, y circunscribe sus estudios a lo que pasa en el sujeto cuando se enfrenta al proceso de resolver un problema relacionado con la información, cómo hace para darle sentido al proceso que realizó para encontrar lo buscado, los puentes que crea para enfrentar las barreras o las brechas que la realidad le impone para buscar y encontrar información. Por lo que no se retoma en el apartado relacionado con el uso de la información como fenómeno clave para dar significado e interpretar a la información.

Con el análisis de las aportaciones de Brookes, Belkin y Dervin, es posible afirmar que sus ideas adelantan las investigaciones sobre el uso de la información, el sujeto aprehende, asimila y transforma la información en relación con su estructura cognitiva y el objetivo que le cubrirá, es decir, la significa e interpreta.

\section{Toma de decisiones}

Una de las perspectivas que han surgido para definir la información es la relacionada con la toma de decisiones. Yovits y Foulk (1985) realizan una serie de experimentos para validar el supuesto de que cada sujeto crea un modelo mental de toma de decisiones que se va perfeccionando conforme encadena las mejores decisiones o cursos de acción (COA, por sus siglas en inglés: Course of Action) de los resultados. Es evidente que su referente teórico es el enfoque cognitivo, ya que el estado de conocimiento del sujeto sobre un problema le permitirá ser un Tomador de Decisiones.

Consideran el término incertidumbre para representar la toma de decisiones como matrices de probabilidad; su intención fue crear y validar un modelo conceptual del flujo de información y su relación con la toma de decisiones. Concretamente afirman: 
La palabra "información" tiene una variedad de significados, la mayoría de ellos imprecisos, depende del contexto en el que se use. Nuestra aproximación relaciona a la información con su efectividad es decir su uso y valor [...] la manera en que la información, toda vez que es transmitida y recibida, es utilizada por un tomador de decisiones. Específicamente, tratamos a la información como datos de valor en la toma de decisiones. (Yovitz \& Foulk, 1985: 63)

Es posible apreciar que la información es un conjunto de datos que pretendidamente serán transformados en parámetros y variables para ser medidos, y así establecer el valor que los sujetos le dan de acuerdo con la toma de decisiones. Idea que fue presentada por Belkin en 1975 y que desafortunadamente en este texto no es referida.

\section{EL USO DE LA INFORMACIÓN COMO BASE PARA GENERAR SIGNIFICADOS E INTERPRETACIONES}

Para la bibliotecología la idea uso de la información generalmente ha estado relacionada con el manejo de recursos secundarios (catálogos, índices, resúmenes, bibliografías y bases de datos), herramientas que permiten la búsqueda y recuperación de información.

En la década de los noventa surgió la inquietud de delimitar puntualmente el sentido del uso de la información. Este fenómeno se ha abordado desde diversas perspectivas, y aquí lo examinaremos en relación con los significados e interpretaciones que el sujeto le da a la información, primero como ente individual y, enseguida, como ente social, y dentro de éstas las tendencias teóricas que se han seguido. 
Significados e interpretaciones de la información desde el usuario

\section{El sujeto como ente individual}

En este apartado se aborda el uso de la información a partir de un solo sujeto, quien le da sentido a la información, la generación de constructos cognitivos, significados e interpretaciones se mira como un proceso individual.

\section{Enfoque cognitivo}

El sujeto percibe y acomoda la nueva información de acuerdo con la representación mental que tiene del mundo. Estos procesos de percepción y acomodo llevan al uso cabal de la información, ¿cómo se entiende este uso? Para una adecuada delimitación, partiremos de lo que no es:

- Búsqueda y recuperación de datos en recursos secundarios acerca de los recursos primarios que resuelven una necesidad de información.

- Recuperación física de recursos primarios.

Uno de los autores que inicia con el estudio formal del uso de la información es Ross J. Todd (1996, 1999a, y 1999b). Cabe aclarar que T. D. Wilson, en la década anterior, hizo alusión al procesamiento y uso de la información como parte de su modelo de comportamiento informativo, sin abundar en él por considerarlo muy subjetivo.

Todd analiza el fenómeno desde el enfoque cognitivo y toma como base las ideas de Brookes y Belkin antes expuestas; habla del cambio de paradigma del orientado en el sistema al orientado en el usuario; aunque él le adjudica este cambio a Dervin \& Nilan (1986), en realidad (como se expuso en el primer apartado), el precursor del cambio de paradigma fue Belkin, con el establecimiento del marco teó- 
rico construido a partir del concepto de información desde la década de los setenta, y que se consolida con su modelo del Estado Irregular de Conocimiento (EIC - ASK, por sus siglas en inglés: Anomalous State of Knowledge).

Inicia con la explicación de la Ecuación Fundamental de Brookes, con el fin de delimitar conceptualmente el fenómeno, establece nueve proposiciones en las que se percibe la importancia del significado e interpretación de la información para un sujeto:

(a) La información tiene el potencial de hacer una diferencia, y los individuos involucrados en la utilización de la información tendrían que actuar o pensar en forma diferente ante la ausencia de información;

(b) La información necesita ser conocida para ser utilizada y esto implica un proceso de comunicación;

(c) La utilización de la información es interpretativa, interpretada por varios interesados en el tema de acuerdo con sus propios marcos de referencia;

(d) La utilización de la información está socialmente limitada por marcos de referencia y las realidades situadas que generan;

(e) La utilización de la información es sistemática, raramente separable en partes discretas;

(f) La utilización de la información es transactiva, más que intercambiable o transmisible en su totalidad;

(g) La utilización de la información implica cogniciones y comportamientos en relación con la información que resulta en efectos cognitivos como preludios de resolución al problema o necesidad de información;

(h)La información no siempre evoca una respuesta discernible; dar la información disponible no es suficiente para asegurar su utilización. (Todd, 1996: 355-356)

La declaración de estas suposiciones le requirió establecer los conceptos de información, conocimiento, cognición, y estructura de conocimiento, los cuales deriva de Brookes, dado que información y conocimiento ya fueron abordados en el apartado de este autor, no se requiere regresar a 
ellos. Por lo que vamos directo a la cognición. De acuerdo con Brookes, "[...] es la conciencia mental de cualquier signo recibido y lo resultante de la interpretación subjetiva de estos signos." (Todd, 1996: 357) En cuanto a la estructura de conocimientos es definida como la relación entre conocimientos. Cohesiona todos estos elementos y se pregunta:

- ¿cómo pueden medirse las estructuras de conocimiento?

- ¿qué se conoce sobre la relación entre las estructuras de información y conocimiento?

- ¿cuáles son los efectos de la exposición a la información?

- ¿cómo cambia las estructura de conocimiento a diferentes exposiciones? (Todd, 1996: 356)

Al dar respuesta a estas interrogantes, genera su marco teórico sobre la utilización de la información. Como punto de partida, contesta la primera pregunta y establece las formas en las que se ha entendido y medido el uso de la información; destaca básicamente tres: instrumental, simbólica, y conceptual. (Todd, 1999a)

Ubica la instrumental en un ambiente organizacional, en el que se miden los resultados, impactos, estados-finales y cambios físicos dentro de la práctica y los procesos de la organización. Los sujetos que pertenecen a determinada entidad producen elementos observables con los que se generan indicadores para valorar la utilización de la información. Es posible inferir que esta acepción se refiere a estudios métricos de la información, análisis de citas, cienciometría y otros campos que no están centrados en el sujeto que usa, sino en la información usada. Se privilegia la información por sobre el individuo, y es aplicable en la generación de perfiles de necesidades y comportamiento en la búsqueda de información.

La información se utiliza de manera simbólica cuando la intención es "[...] legitimar o sostener posiciones prede- 
terminadas, tales como elegir información selectivamente o tergiversarla para justificar acciones realizadas por otras razones" (Todd, 1999a: 855), permite generar argumentos que sostengan cualquier idea preconcebida y que se requiere sostenerla o justificarla.

Por su parte, la utilización conceptual la entiende como "[...] lo que está pasando en las mentes de la gente cuando hace algo con la información [...]: actividad en la que uno procesa información, la construye y razona [...] sedimentación gradual de introspecciones, teorías, conceptos y formas de mirar el mundo" (Todd, 1999a: 854). Son "[...] procesos cognitivos y cambio; [...] procesos mentales transformativos y formativos en los que la información es incorporada al acervo de conocimientos de una persona, en éste es traducida y entonces aplicada a una situación de trabajo [...]" (Todd, 1999a: 854).

De la utilización conceptual derivan varios atributos que le servirán de base para generar su definición. Estos atributos se pueden resumir de la siguiente manera: se enfoca en lo que gente piensa activamente; es interna, cognitiva y se relaciona con el conocimiento que las personas poseen. Concretamente, define el uso de la información como "[...] un proceso holístico a lo largo del tiempo que involucra procesos cognitivos y transformaciones que ocurren dentro de la mente del individuo cuando trabaja con la información." (Todd, 1999a: 856) Las transformaciones cognitivas que él establece para percibir el uso de la información se basan en los efectos que tiene la información en la imagen que cada sujeto posee de un tema en particular, y las declara de la siguiente manera: (1) obtener una imagen completa; (2) obtener un cambio en la imagen; (3) obtener una imagen más clara; (4) obtener una imagen verificada, y (5) obtener una posición sobre la imagen. (Todd, 1999a: 866) 
Estos efectos responden a las tres preguntas restantes. Relaciona esas categorías y las hace más específicas, en un estudio sobre el uso de información sobre heroína por adolescentes del género femenino (Todd, 1999b).

Es posible apreciar que la utilización de la información implica procesos mentales de lectura, comprensión, análisis, síntesis, aprehensión, asimilación y acomodo de la nueva información en la cadena de conocimientos de un sujeto. Este proceso inicia y termina con la delimitación de significados de lo que se lee y se acomoda.

Estos atributos retoman mucho de las ciencias cognitivas y del cognoscitivismo propuesto por Ausubel para la psicología del aprendizaje: una nueva información tendrá sentido para un sujeto si y sólo si es acomodada en el acervo de conocimientos que ya posee de forma significativa y no arbitrariamente.

De lo expuesto en los párrafos anteriores, podemos desprender las siguientes afirmaciones:

- Existe un vínculo entre los términos información-individuo-cognición-interpretación-utilización.

- La cognición se refiere a la transformación por procesos de pensamiento.

- Si un sujeto desconoce la existencia de ciertos recursos de información no los buscará y utilizará, por lo que alguien debe comunicarle que existen.

- Hay un nexo entre utilización e interpretación por un sujeto específico.

- La interpretación requiere procesos de pensamiento previos, como la percepción, significación y asimilación.

- La utilización-interpretación depende de los marcos de referencia y realidades del sujeto/sujetos, es decir, del contexto. 
En la línea de investigación, del uso de la información desde una perspectiva cognitiva, Jarkko (2007) retoma a Todd y propone una nueva forma de abordar el tema al entenderlo como resultados de la información en los sujetos. Enfatiza la confusión que existe en el concepto de uso de la información, al considerarla como búsqueda de información. Critica a los estudiosos que incluyen elementos afectivos para dar nuevos significados a la información.

Para enmarcar el estudio de los resultados del uso de la información, parte de entenderlo como proceso y efecto. La utilidad que se obtiene con dicho proceso define los resultados de la información como "[...] un constructo analítico que sintetiza los diferentes significados del uso de la información." (Disponible en: http://www.informationr.net/ ir/12-2/paper292.html p. 1) Para Jarkko la información, más que un sustantivo, es un verbo/acción o proceso continuo (a la manera de Dervin), pues sólo de esta manera "[...] el 'resultado de la información' se convierte en un término lo suficientemente legítimo y preciso" (p. 3). En realidad, esta percepción es contradictoria; si es proceso no puede ser resultado. Incluso concluye que el uso de la información "[...] es lo que pasa después que la persona ha convertido una entidad de información en conocimiento [...]" (Jarkko, 2007: 3) y lo lleva hasta verlo como "un resultado activo de la información” (Jarkko, 2007: 4). En el más puro estilo de análisis lógico de este discurso, podríamos apuntar que lo que está pasando no puede ser, y lo que es ya pasó.

Por otro lado, considera que existen dos categorías del uso de información, la mental y la física, y las explica de forma separada. Idea difícil de sostener, puesto que sintéticamente lo que sucede en el cerebro, que sería el aspecto mental, determina el hacer físico. Todas las órdenes para que un órgano funcione vienen del cerebro, es decir, ningu- 
na actividad fisiológica se realiza si no es mediante los procesos neurológicos o de orden superior. El cerebro genera una serie de tipologías de uso de la información que se empatan con todos los procesos cognitivos que se realizan, por ejemplo, analizar, responder, evitar, aclarar, consolidar, decidir, entre otros; equipara estos procesos con los resultados del uso de la información, lo que nos regresa a lo planteado por Brookes, Belkin y Todd en cuanto al enfoque cognitivo. El resultado del uso de la información es la transformación de la misma por el sujeto de acuerdo con su acervo de conocimientos.

Otro autor que ha trabajado sobre este tema es Reijo Savolainen, y lo ha hecho desde varias perspectivas, una de las cuales fue considerar el modelo del sense-making para delimitar el concepto de uso de información (2006). Como se comentó en párrafos anteriores, este modelo se acerca al sujeto mediante la metáfora de crear puentes para cubrir brechas. El autor aclara que si bien este modelo no se genera para estudiar cabalmente el uso de la información - afirmación con la que se está de acuerdo_-, él lo retoma para completarlo.

La dificultad de la aplicación radica en qué está pensado para entender la generación de necesidades de información y el comportamiento que realizan los sujetos para cubrirlas, paso a paso; incluso, el uso de información es concebido como "los pasos que los seres humanos emprenden para construir sentido a sus mundos" (Dervin, 1992: 65, citado por Savolainen, 2006: 1122) no al sentido que se le ha dado al proceso, como la transformación cognitiva toda vez que los sujetos han recuperado, leído y aprehendido la información. La base argumentativa de Savolainen es que el modelo refiere al contexto, argumento que tampoco se sostiene, puesto que, como ya quedó asentado, el sense-making en- 
tiende el contexto como la experiencia o trayectoria de una persona y no su entorno.

\section{Uso como conocimiento/acción}

En otro trabajo, Savolainen realizó el análisis de las conceptualizaciones del uso de la información desde el conocimiento y el conocer, sólo que los une directamente a la acción. Retoma los trabajos de estudiosos que establecen que el uso de la información es la construcción y reconstrucción de lo cognoscible en un espacio de acción.

Concretamente alude al uso de información "[...] como un proceso que está contextualizado en acción o práctica" (Savolainen, 2009: 3, disponible en: http://files.eric.ed.gov/ fulltext/EJ837279.pdf)

Desde la filosofía esto resulta paradójico, pues conocer lo cognoscible o el conocimiento no son aspectos que se puedan acomodar dentro de una acción. Vamos directamente al sentido de ambos términos. Según la teoría del conocimiento o epistemología (de aquí seguramente el título del artículo del autor), conocer es: “[...] 'aprehender', es decir, el acto por el cual un sujeto aprehende un objeto. El objeto debe ser, pues, por lo menos gnoseológicamente, trascendente al sujeto, pues de lo contrario no habría 'aprehensión' de algo exterior". (Ferrater Mora, 2001: 658)

Esta autor abunda y nos dice que "Hay acuerdo hoy en que conocer no es aunque así se la siga llamando una actividad" (Ferrater Mora, 2001: 656), o una acción es más un proceso neurofisiológico.

Por su parte: “[...] se tiende a emplear 'acción' en estrecha relación con 'acto', 'actividad', 'operación', 'producción', 'práctica', etc.; en todo caso, se suele restringir la noción de acción a la operación de un agente”. (Ferrater Mora, 2001: 41) 
El concepto de uso como proceso/acción/práctica resulta totalmente ecléctico. Ferrater inicia hablando del conocer, saber y conocimiento como términos filosóficos que nos refieren a un sujeto (ser cognoscente) que aprehende o hace suyo un objeto (de conocimiento), más cercano a la tendencia gnoseológica de aprehensión del objeto cognoscible para insertarlo en la cadena de conocimientos de un sujeto. Finalmente, aterriza el uso de la información como una práctica, actividad o acción, con un producto específico. No se percibe el enfoque cognitivo en el cual la utilización es un proceso de transformación. Esta propuesta se acerca al sentido instrumental.

Es posible apreciar que existen análisis y aseveraciones acerca del uso de la información poco sólidos. La creación epistemológica no es un asunto sencillo que se deba tomar a la ligera.

\section{El sujeto como ente social}

El entendimiento del sentido que le da el individuo a la información como parte de una práctica social nos implica situar al sujeto dentro de un contexto o entorno específico: mirarlo como un ente en relación con otros sujetos. Acomodarlo como parte de una comunidad específica, lo que precisa establecer si esta pertenencia modifica sus apreciaciones de la información, si existe un cambio al transitar de un plano individual a uno social, y de un contexto a otro.

Para esta tendencia, el aspecto individual cognitivo se traslada a uno social. Las construcciones mentales parten no sólo del sujeto sino del sujeto entre otros, que comparten visiones del mundo semejantes y que a partir de esta compartición le dan significado e interpretan la información de manera diferente. Este entendimiento va acompañado 
siempre de los contextos dentro de los que los sujetos hacen elecciones acerca de la utilidad de la información. Aparecen reiteradamente términos como: contexto o entorno, y comunidad.

El contexto para este trabajo se refiere a los factores que rodean al sujeto: históricos, sociales y cultuales; todos los hechos y fenómenos dentro de los que actúa, lo que permite entender su relación con la información.

\section{Construccionismo social}

Este enfoque teórico nace en la sociología del conocimiento, y se refiere en esencia a que "la realidad se construye socialmente" (Berger y Luckman, 1966: 11). Depende de la unión de varias ideas compartidas dentro de un contexto social hasta consolidarse como un constructo compartido por varios sujetos. La realidad no se produce en la mente del sujeto, sino en la percepción de la mente del sujeto como parte de una comunidad o colectividad.

Interviene la realidad de la vida cotidiana. En la vida cotidiana nos enfrentamos a sujetos, a colectivos. De ahí la importancia, para la teoría sociológica del conocimiento, el nosotros, el varios. Para forjar un entendimiento común de los fenómenos que conforman la vida cotidiana, varía la aprehensión de éstos, pues pareciera que existen sin que el sujeto los perciba y aprehenda. El primer contacto para construir el conocimiento y la realidad de la vida cotidiana es cara a cara con otros; lo que dice el otro me permite integrarlo a una categoría de sujeto.

El lenguaje aparece como el vínculo para percibir, aprehender, y construir la realidad/conocimiento de los otros para conmigo y de mí para los otros, importa lo que se dice, lo que se lee; el intercambio de signos, símbolos y significa- 
dos, se acomoda a los sujetos en categorías, tipos o estereotipos. Se generan los llamados "roles" sociales, entendidos como los tipos de actuación que realizan los sujetos dentro de un contexto determinado, y pueden generarse por escalas económicas, sociales, culturales y religiosas. Se refieren a representaciones de estatus sociales, la mayoría de las veces establecidas por instituciones $\mathrm{u}$ organizaciones sociales, más que por comunidades. La precisión de roles depende de la forma en como los individuos se relacionan con la colectividad dentro de la comunidad y el contexto en el que transcurre su vida cotidiana.

El construccionismo social no es la suma de las percepciones individuales. Existe cuando el individuo asume o se asume como parte de un colectivo, comprende el mundo que le rodea y lo hace suyo; su percepción de la realidad/ mundo es como la de los otros. Asumirse como parte de una sociedad no se da de facto; el sujeto no pertenece a una sociedad porque le sea cercana o haya nacido dentro de ella, sino por la predisposición a pertenecer a la misma.

Los autores que han trabajado el uso de la información tomando como base el construccionismo social son (entre otros) Kimmo Tuominen y Reijo Savolainen (1996). Ellos no establecen el antecedente del construccionismo social con Berger y Luckman, lo relacionan con el análisis del discurso y generan la idea de construccionismo discursivo, aunque lo denominan construccionismo social entendido como:

[...] la naturaleza constructiva del uso del lenguaje. Cuando hablamos y escribimos, producimos y organizamos nuestra realidad social. Aquí, el lenguaje no es concebido como una ventana a través de la cual el mundo se muestra ni como un espejo que refleje directamente nuestras observaciones.

Porque el construccionismo social enfatiza el proceso de negociación de significados, la atención primaria está puesta en la 
El sentido de la información: un enfoque centrado en el usuario

construcción de la realidad mediante el discurso. (Tuominen y Savolainen, 1996: 82)

Comprenden el fenómeno uso de la información como una acción discursiva organizada "sobre qué pasa 'entre', no 'dentro' de los hablantes" (Tuominen y Savolanen, 1996: 87), el vínculo de los sujetos se establece por lo que se dice y se interpreta de manera colectiva.

Desde esta perspectiva, la información es un constructo que se forma a partir de un acto comunicativo dentro de un contexto social. Este contexto determina la interacción y la argumentación entre los hablantes; por consiguiente, el uso de información "[...] es visto como una acción constructiva que puede ser estudiada como un fenómeno del mundo real más que una abstracción teórica" (Tuominen y Savolanen, 1996: 92).

Regresamos a entender la utilización como una acción perfectamente delimitada y perceptible a primera vista. Es notoria la crítica tácita que hacen a la concepción del uso como un proceso cognitivo de transformación para dar significado e interpretar la información, ya que aparecen frases como "fenómeno del mundo real y no una abstracción teórica". Este proceso es tan real, que permite entender lo expresado en la información, interpretarlo, generar nuevo conocimiento y plasmarlo en un recurso informativo (si fuera el caso).

Enfoque instrumental de la utilización de la información

Si bien los autores que se examinan a continuación no le llaman de esta manera a la perspectiva que siguen, se consideró conveniente retomarla y encuadrarlos aquí, puesto que circunscriben sus modelos a los resultados del uso de 
la información y los ubican en entornos organizacionales; miden los efectos y productos de dicho uso en las personas adscritas a ciertas entidades o pertenecientes a diversas comunidades para generar sus perfiles.

Un concepto ampliamente desarrollado en la década de los noventa es el de los entornos o ambientes de información. El precursor de esta tendencia fue R. S. Taylor (1991), que parte del principio de Dervin para caracterizar la información. La asocia con una función de utilidad para el sujeto dentro de un contexto de problemas o preocupaciones. La información que a él le interesa es la formal, entendida como aquella que resuelve un problema, la asocia al sujeto y conceptualiza el vínculo entre ambos a partir de "lo que la información hace para o por el receptor y para su problema o situación" (Taylor, 1991: 221), y no lo que el sujeto hace con la información, es decir, la importancia recae en la información y no en el sujeto.

Taylor crea la frase ambientes de uso de la información (IUE, por sus siglas en inglés de Information Use Environments), y los define como "[...] el conjunto de aquellos elementos que (a) afectan el flujo y uso de los mensajes de información hacia adentro, dentro, y fuera de cualquier entidad definible; y (b) determinan los criterios por los cuales el valor de los mensajes de información serán juzgados". (Taylor, 1986, citado por Taylor, 1991: 218)

Aclara que para realizar los estudios de usuarios, las comunidades que le interesan son "[...] aquellos grupos o clases de personas que son usuarios de información activos, experimentados y críticos." (Taylor, 1991: 219) Su objetivo es encontrar semejanzas y diferencias entre las comunidades para diseñar sistemas de información útiles. Sostiene que la información y el sujeto sólo pueden estar vinculados dentro de un contexto inmediato y limitado a la informa- 
ción, llamado contexto informativo: ¿cómo es la información? ¿En qué recurso está contenida? ¿Cómo se tiene acceso a ella? ¿Cómo se mueve el usuario dentro de este contexto informativo?

En sentido estricto, podría entenderse como el sistema de información, su procesamiento, organización, almacenamiento, formas de búsqueda y recuperación. Esto es el Entorno Informativo; de ahí que el uso se circunscriba al comportamiento en la búsqueda y recuperación de información en herramientas secundarias, más que la utilización. Si lo esquematizamos queda de la siguiente manera:

Sujeto - necesidades de información - sistemas de información - recursos secundarios de información - instituciones que proveen recursos o servicios de información

Este esquema representa el contexto informativo del sujeto y no el contexto social en el que se inserta y que genera, eventualmente, las necesidades de información y el modo como las resuelve.

El paradigma sigue centrado en la información, aunque afirme que es en el sujeto. Pareciera que el contenido de la información tiene sentido en sí mismo, y no a partir de que algún sujeto la lea, asimile, aprehenda, le dé un significado e interprete, que es el núcleo central de nuestra tesis.

Lamb, King y Kling (2003) retoman los ambientes informativos dentro de las organizaciones para analizar el uso de información en línea. De acuerdo con estos autores, existen tres causas por las que las organizaciones reúnen información: "[...] el deseo de reducir la incertidumbre, la necesidad de aumentar el conocimiento nuclear, y el deseo de disminuir la ansiedad acerca de las decisiones hechas bajo incertidumbre”. (Lamb, King y Kling, 2003: 98) 
Es fácil identificar que estas causas en realidad son de los sujetos que trabajan en una organización. Esto hace que sea casi imposible delimitar el momento en que pasa de hablarse de una perspectiva individual a una social. Se plantean estas causales como organizacionales, y en realidad son de categorías de usuarios (profesionales, administradores y tomadores de decisiones).Tal vez la variación sea el tipo de información que requieren, en términos del origen de la misma, interna (producida por la propia organización) y externa. Lo que evidencia este documento es que, al interior de las organizaciones, generalmente no se utiliza la información impresa o electrónica que ofrecen los proveedores o las unidades de información (si es que las hubiere) o se usa en una baja proporción. La toma de decisiones se hace con base en la experiencia y en la consulta con compañeros de trabajo o mandos superiores.

Si bien los autores expresan que será un estudio sobre el uso de la información en tres organizaciones (leyes, bienes raíces, y biotecnología/farmacéutica), en realidad corresponde a uno sobre el comportamiento en la búsqueda y recuperación de información (prácticas de recogida de información) aplicado a tres comunidades, para determinar "[...] si los ambientes industriales constituyen medios informativos que influyan en las infraestructuras y prácticas informativas" (Lamb, King y Kling, 2003: 100) de las organizaciones. La muestra estuvo conformada por individuos que respondieron como tales y no como representantes de organizaciones que hablaran como entidad: gerentes; miembros del staff; corredores de bolsa o de bienes raíces; agentes comerciales, entre otros.

El enlace se hizo al relacionar las preferencias individuales y sostener que existen interacciones interorganizacionales, las cuales se encaminan, más que a trabajar conjuntamente, 
a recoger paquetes de información para generar perfiles sobre las agencias que podrían ser la competencia, los nichos de mercado o los futuros socios. Cabe enfatizar que el uso no crea interacción entre organizaciones; cada organización utiliza lo que requiere - siempre desde un sujeto que escala para toma de decisiones dentro de una entidad- para identificar las características de alguna otra y establecer (o no) relaciones con ellas.

Regresamos al lugar común de confundir el uso de información con los perfiles de necesidades de información o comportamientos en la búsqueda de información que pueden ser coincidentes de acuerdo con dichos perfiles. El uso se circunscribe a la explotación de herramientas secundarias y los servicios de información. En este caso las soportadas en Internet o recursos en línea, y no a la transformación cognitiva que hemos considerado como la verdadera utilización de la información.

El ambiente informativo está conformado por dos dimensiones, institucional y técnica, y las variables que interesan son: utilidades, relación con instituciones o agencias bancarias, escuelas, iglesias, hospitales y clientes.

Otra definición de uso de información desde una perspectiva instrumental y organizacional es la que generan Choo, Bergeron, Detlor y Heaton (2008). Ellos estudian el vínculo entre la cultura de información y el uso de la información, con la intención de establecer que la primera afecta a la segunda. A la cultura de información la delimitan como "[...] aquellos elementos de la cultura de una organización que influyen en su administración y en el uso de información. Así, la cultura de la información se manifiesta en los valores, normas y prácticas e impactan en cómo es percibida, creada y utilizada la información”. (Choo, Bergeron, Detlor y Heaton, 2008: 793) 
Esto permite que la institución sea una basada en el conocimiento. El uso de la información representa "[...] los resultados de aplicar y trabajar con la información tal como es percibida y experimentada por los miembros de una organización." (Choo, Bergeron, Detlor y Heaton, 2008: 792) Este uso permite construir nuevo conocimiento y nuevos significados, tomar decisiones, intercambiar ideas e influir en los sujetos que trabajan dentro de una organización. El logro de una cultura de información en una organización requiere infraestructura tecnológica, prácticas de administración de información y comportamientos con valores positivos hacia la información.

De acuerdo con lo anterior, es claro determinar que existe una relación directa y que no era necesario hacer un estudio para probar dicha idea. La aportación es que identifican la falta de cultura informativa en las organizaciones, lo que redunda en pérdida de ganancias o productos deficientes.

En términos generales, el uso de la información es un proceso individual, y la suma de las interpretaciones podría considerarse como uno social. Sólo el construccionismo social promueve una idea de construcción social de significados.

\section{CONCLUSIONES}

Las definiciones de información se han enmarcado por diversas tendencias. La que se reconoce como válida es el enfoque centrado en el usuario, la información vinculada directamente al sujeto. Esta base permite delimitarla de varias formas:

- Entidad de la misma clase que el conocimiento; es una parte del conocimiento (Brookes). 
- Datos estructurados que actúan en la transformación del estado de conocimientos de un sujeto (Belkin).

- En un sentido dinámico verbo, acción, proceso y producto (Dervin).

- Se relaciona con su efectividad, su uso y valor para tomar decisiones (Yovits y Foulk).

- Conjunto de datos organizados, que representan contenidos y transforman las estructuras de conocimiento de los sujetos al conferirles significado (propia).

El enfoque centrado en el usuario permite afirmar que el sentido de la información se percibe cabalmente en el proceso, uso o utilización de la información. Este fenómeno se ha estudiado a partir de la década de los noventa, y se define como un proceso holístico que ocurre dentro de la mente de un sujeto cuando hace algo con la información. Es una transformación cognitiva mediante la cual se da significado e interpretación a la información. La información se convierte en el insumo y producto de este proceso; al exponer a un sujeto a ella, la imagen que tiene de un tema o situación cambia.

Los términos y frases que aparecen como constantes en el análisis de los documentos son: procesos cognitivos, transformaciones, percepciones del mundo (personales y compartidas con otros sujetos), contexto, entorno informativo, comunicación, intercambio, construcción de significados, e interpretación.

Todos estos elementos conforman el sentido de la información, como definición y como constructo mental a partir de los sujetos que la utilizan. 
Significados e interpretaciones de la información desde el usuario

\section{BIBLIOGRAFÍA}

Ausubel, D. P. (1983). Psicologia educativa: Un punto de vista cognoscitivo. México: Ed. Trillas.

Belkin, N. J. (1975). Towards a definition of information for informatics. En: V. Horsnell (Ed.), Informatics 2 : proceedings of a conference held by ASLIB Co-ordinate Indexing Group on 25-27 March 1974 at New College Oxford (pp. 50-56). London: Aslib.

. (1977). Lingüistic and cognitive models of information and state of knowledge: Final Report arising from a Study Visit Overseas made to the USA 21 September - 20 October 1976. S. L.: Centre for Information Science.

. (1978). Information concepts for Information Science. The Journal of Documentation, 34(1), 55-85.

. (1980). Anomalous States of Knowledge as a Basis for Information Retrieval. The Canadian Journal of Information Science, 5, 133-143.

(1984). Cognitive models and information transfer. Social Science Information Studies, 4(2-3), 111-129.

Belkin, N. J., Oddy, R. N., y Brookes, H. M. (1982). Ask for information retrieval. Part I: Background and theory; Part II: Results of a design study. Journal of Information Science, 38(2 y 3), $61-71 ; 145-164$.

Berger, P. L., y Luckman, T. (1966). La construcción social de la realidad. Buenos Aires: Amorrurtu.

Brookes, B.C. (1980). The foundations of information science. Part I: philosophical aspects: classes of things and the challenge of human individuality. Journal of Information Science, 2, 125133. 
El sentido de la información: un enfoque centrado en el usuario

Choo, C. W., Bergeron, P., Detlor, B., y Heaton, L. (2008). Information culture and information use: an exploratory study of three organizations. Journal of the American Society for Information Science and Technology, 59(5), 792-804.

Dervin, B. (1998). Sense-Making theory and practice: An overview of user interests in knowledge seeking and use. Journal of Knowledge Management, 2(2), 36-46.

Dervin, B., y Foreman-Wernet, L. (2003). Sense-making methodology reader: selected writings of Brenda Dervin. Cresskill, New Jersey: Hampton Press.

Dervin, B., y Nilan, M. (1986). Information needs and uses. Annual Review of Information Science and Technology, 21, 3-33.

Ferrater Mora, J. (2001). Diccionario de filosofía. Barcelona: Editorial Ariel. 4 t.

Hernández Salazar, P. (2013). Transformación de la metodología para estudiar a los usuarios de la información. En Jaime Ríos Ortega y César Augusto Ramírez Velázquez (Coord.), Naturaleza y método de la investigación bibliotecológica y de la información (pp. 209-252). México: UNAM / Centro Universitario de Investigaciones Bibliotecológicas.

Jarkko, K. (2007). Conceptualizing the personal outcomes of information. iRinformation research, 12(2). Disponible en: http:// www.informationr.net/ir/12-2/paper292.html

Lamb, R., King, J. L., \& Kling, R. (2003). Informational Environments: organizational contexts of online information use. Journal of the American Society for Information Science and Technology, 54(2), 1116-1125.

Rendón Rojas, M. A; y Hernández Salazar, P. (2010). Sense-making: ¿metateoría, metodología o heurística? Investigación Bibliotecológica, 24(50), 61-81. 
Savolainen, R. (2006). Information Use as Gap-Bridging: The Viewpoint of Sense-Making Methodology. Journal of the American Society for Information Science and Technology, 57(8), 97-114.

Savolainen, R. (2009). Epistemic work and knowing in practice as conceptualizations of information use. iRinformation research, 14(1). Disponible en: http://files.eric.ed.gov/fulltext/ EJ837279.pdf

Taylor, R. S. (1991). Information Use Environments. En Dervin, B. (Ed.) Progress in Communications Sciences, 10 (pp. 217-225). Norwood, N. J.: Ablex.

Todd, R. J. (1996). Information Utilization: A Cognitive Analysis of how Girls Utilise Drug Information Based on Brookes' Fundamental Equation $[\mathrm{K}[\mathrm{S}]+\Delta \mathrm{I}=\mathrm{K}[\mathrm{S}+\Delta \mathrm{S}]$. En: P. Vakkari; R. Savolainen, y B. Dervin, Information seeking in context: proceedings of an International Conference on research in information needs, seeking and use in different context 14-16 August, 1996, Tampere, Finland (pp. 351-370). London: Taylor Graham.

(1999a). Back to our beginnings: information utilization, Bertram Brookes and the fundamental equation of information science. Information Processing and Management, 35, 851870.

. (1999b). Utilization of Heroin Information by Adolescent Girls in Australia: A Cognitive Analysis. Journal of the American Society for Information Science, 50(1), 10-23.

Tuominen, K., y Savolainen, R. (1996). A Social Constructionist approach to the study of information use as discursive action. En P. Vakkari; R. Savolainen, y B. Dervin, B. Information seeking in context: proceedings of an International Conference on research in information needs, seeking and use in different context 14-16 August, 1996, Tampere, Finland (pp.81-96). London: Taylor Graham. 
El sentido de la información: un enfoque centrado en el usuario

Vygotskii, L. S. (1996). Pensamiento y lenguaje: teoría del desarrollo cultural de las funciones psíquicas. México: Quinto Sol.

Wilson, T. D. (2000). Human information behavior. Information Science, 3(2), 49-55.

Yovits, M. C., y Foulk, C. R. (1985). Experiments and analysis of information use and value in a decision-making context. Journal of the American Society for Information Science, 36(2), 63-81. 


\title{
La información desde la perspectiva de las comunidades indígenas
}

\author{
CÉSAR Augusto Ramírez VelázQuez \\ Universidad Nacional Autónoma de México
}

\begin{abstract}
D las comunidades indígenas la información entre los sujetos ha sido uno de los principales factores de integración, comunicación, socialización y desarrollo, amén de la creación de conocimiento y conciencia sobre los elementos que los rodean.

Jaime Ríos indica que existen para la palabra información ocho significados que le otorga el Diccionario de la Lengua Española, de los cuales, para fines de este trabajo, se mencionan los siguientes:
\end{abstract}

[...] en quinto lugar se le entiende como adquisición o comunicación de conocimientos que permiten ampliar o precisar los que se poseen sobre una materia determinada; en sexto lugar se le denomina información a los conocimientos así comunicados o adquiridos; [...] en octavo lugar se designa a la información como educación e instrucción. (2014: 145-146)

Por lo tanto, las comunidades indígenas conciben la información como una serie de datos que, unidos entre sí, dan respuesta, la mayoría de las veces, a las diversas interrogantes que a lo largo de su vida le surgen a un individuo en los diversos escenarios en que se desarrolla y convive. 
La información obliga al sujeto a analizar y sintetizar los conocimientos recibidos, con el fin de esclarecer dudas y problemas derivados del entorno social, económico, religioso y de su vida, entre otros, lo cual da como resultado la generación de diversos supuestos que pretenden esclarecer su pertinencia, estadía y pertenencia al mundo que lo rodea.

La información, entonces, da lugar a diversas formas de concebir la vida, de entenderla y de transformarla, de acuerdo a la interpretación que se le dé a través de la comprensión de las manifestaciones generadas por el medio ambiente, creando su propia cosmovisión, experimentando con plantas, hierbas y animales, observando los cambios climáticos y prodigios de la naturaleza, así como las expresiones, estados y comportamientos de sus congéneres. Ivis Goñi indica que:

La información y su industria se han convertido en un factor esencial para el accionar humano en la sociedad moderna y que la diversidad de definiciones puede deberse a factores como el que ser humano al desarrollar sus ideas, teorías y conceptos, está bajo la influencia de su experiencia personal en el campo del saber donde incursiona $y$, por tanto presenta puntos de vista diferentes. (2000: 202)

Situación que no es ajena a las comunidades indígenas en su andar cotidiano.

Por lo tanto, la información, conforme pasa el tiempo, se vuelve más compleja, conduce al individuo a asimilarla, seleccionarla y jerarquizarla de acuerdo a sus inquietudes y expectativas, lo cual da lugar a diversos niveles de información que se expresan a continuación: mínimo, intermedio y significativo. El primero se define como aquel que cubre necesidades informativas de primer orden: sustento, abrigo y comunicación oral; el segundo, como aquel que permite la interacción con otros sujetos: relación, integra- 
ción y socialización; el tercer nivel implica el desarrollo de nuevas formas de comunicación, de percepción del mundo y la generación de nuevo conocimiento: escritura, pintura, cosmovisión y establecimiento de respuestas a través de la observación y experimentación.

Sobre esta base, las comunidades indígenas han visto la información como una forma de salvaguardar sus conocimientos milenarios, sus tradiciones y costumbres; en una palabra: su cultura. Simplemente, en las comunidades indígenas de México se observa a primera vista la gran disparidad que existe entre ellas en cuanto al uso de Tecnologías de Información y Comunicación (TIC) y recursos e infraestructura para poder acceder a medios masivos de comunicación, que en un momento dado podrían ampliar sus conocimientos en temas de toda índole.

Lo anterior implica que existe una brecha digital entre comunidades indígenas, donde algunas cuentan con medios tales como la radio, la televisión e internet, con lo cual han ampliado el espectro de la información al que pueden acceder; en el lado opuesto, se encuentran comunidades que, por diversas razones que van desde la miseria, la marginación y el hambre, hasta la falta de infraestructura eléctrica, electrónica y digital, no han tenido oportunidad de contar con información distinta a la que han generado y compartido por años al interior de sus propias comunidades.

La información también es concebida por las comunidades indígenas como aquellos datos que se han podido conjuntar a través de los tiempos para preservar la cultura a partir de varias formas de comunicación:

- Comunicación oral. Es decir, los relatos que por tiempos inmemoriales se han transmitido de generación en generación, de ancianos a jóvenes, por medio de relatos 
orales en forma de cuentos, mitología y fábulas, entre otras formas de dar a conocer aspectos importantes de un pasado histórico y expresar pensamientos y sentimientos respecto a todo lo circundante.

- Comunicación visual. Utiliza dibujos, imágenes y glifos en paredes de cavernas, acantilados, montañas, pirámides y códices, entre otros.

- Comunicación escrita. Por medio de textos escritos; emplea algún tipo de alfabeto.

Con base en lo anterior, consideran la información como un baluarte que les ha ayudado a no perder su identidad, a incrementar su acervo cultural, a conocer sus orígenes, a defender su autonomía, su libertad y sus derechos, a mantener su integridad y a luchar contra la desigualdad y la discriminación.

De igual forma, reconocen que la información es un instrumento que bien encauzado puede serles útil para auxiliarles en diversas plazas y ante diferentes instancias, tanto sociales como gubernamentales, para solicitar y exigir respeto a su pertenencia territorial, mejores oportunidades de desarrollo comunitario e individual, mejores condiciones laborales y económicas, ampliación de los servicios médicos y de salud en general, mayores ofertas educativas y de recreación lúdica y deportiva, mayores oportunidades de participación ciudadana en políticas que afecten sus intereses, así como para defender el derecho irrestricto de la libre determinación para planear su futuro.

Es necesario mencionar que los sujetos indígenas reconocen que la información por sí misma carece de sentido como apoyo, si antes no es ubicada en el contexto para el cual es requerida y por lo tanto organizada. Las comunidades deben, por tanto, realizar un trabajo arduo de búsque- 
da, localización, recuperación, organización y análisis, con el fin de darle el lugar y la preponderancia que tiene como auxiliar en la toma de decisiones ante situaciones y problemas de cualquier índole.

En este sentido, es necesario ratificar que las comunidades indígenas, de acuerdo a sus particulares condiciones, deberán manejar la información de acuerdo a las necesidades que tengan, a los recursos (ya sea tecnológicos, o no) con que dispongan para obtener dicha información, al enfoque que pretendan darle a la información y a los objetivos que se intenten alcanzar.

A través de los años, las comunidades indígenas de Latinoamérica se han visto inmersas en distintos escenarios, desde aquellos en los que vivían sin influencias externas; es decir, de civilizaciones de otros continentes, en la época colombina, en la era de los movimientos independentistas y revolucionarios, en los periodos dictatoriales y los tiempos actuales en los que la economía ha resultado ser el eje motor del desarrollo del mundo y en el cual han sido ignoradas y desplazadas.

A partir de lo anterior, Beatriz Casa indica que en estos tiempos de diversidad cultural, la información debe entenderse:

[...] como aquella información destinada a los individuos que se insertan en culturas diferentes a las propias, y que está destinada a que conozcan las características, ventajas y problemas que tiene el nuevo grupo social en el que se integran, pero también sirve para proporcionarles materiales acerca de su país o región de origen, con el objeto de mitigar el drama del desarraigo y, no pocas veces, las vivencias de un rechazo inicial en la nueva situación.

La otra vertiente, no menos importante, es la que se dirige a la comunidad que pertenece al lugar, con el objeto de que abra su espíritu a la presencia de otras personas con una cultura distinta, diversa, la cual debe ser respetada de la misma manera que los 
inmigrantes lo deben ser como personas y como miembros de la comunidad. (2007: 6)

En consecuencia, la información ha sido (como ya se mencionó anteriormente) el eje motor de varias comunidades indígenas, para su desarrollo económico y social; ejemplos de esta situación son los siguientes:

- Comunidad mixteca. La información que mantienen a través de la comunicación con la gente que ha partido a otras latitudes ha generado una migración muy alta entre los mixtecos; de acuerdo a reportes recientes se calcula que 100,000 de ellos viven en Estados Unidos y tienen asentamientos en la Ciudad de México, Sonora, Sinaloa y Baja California.

- Comunidad triqui. Sus reivindicaciones sociales los han erigido como líderes de las comunidades indígenas de Oaxaca; han utilizado la información y los medios de comunicación para organizarse, política y socialmente, con el fin de hacer frente a las entidades que atentan en su contra.

- Comunidad huave. Se dedican principalmente a la pesca de camarón en las lagunas marinas del golfo de Tehuantepec; los hombres lo pescan y las mujeres lo venden. Los montang ombas, "los que tienen el cuerpo grande", son el grupo de ancianos y personas distinguidas que manejan la información al interior de su comunidad y, por lo tanto, tienen un importante peso en las decisiones de la misma.

- Comunidad amuzga. El Consejo de Ancianos ha sido siempre el gobierno de los amuzgos. Los ancianos son la guía del Pueblo puesto que son los que manejan la información más verídica, son la autoridad tradicional, municipal y de las congregaciones. 
- Comunidad yaqui. Aprovechando la información obtenida para organizar una cooperativa pesquera promovida por el gobierno, 150 individuos de Pótam y Belem se trasladaron al nuevo pueblo de Guásimas. Actualmente los pescadores yaquis están organizados en grupos de trabajo de 15 hombres que dependen del consejo de la administración cooperativa. El aprovechamiento de la información sobre el tema de la ganadería les ha dado una de las mejores posibilidades de crecimiento de la economía yaqui. Actualmente, el ganado dispone de un área de pastizal de por lo menos 15000 ha, y hay una docena de sociedades ganaderas en la sierra. Otras actividades remuneradas y complementarias que se han podido desarrollar gracias a la información obtenida son: el corte de madera, mezquite y carrizo para lo que sólo se necesita el permiso de las autoridades tradicionales; asimismo, se trabajan las grandes salinas. Por otra parte, el aprovechamiento de la información ha apoyado la migración en dos niveles: los yoremes se van de braceros a Estados Unidos durante las épocas de cosecha o siembra, pero siempre vuelven a su territorio y en la migración interna, durante la temporada de zafra del camarón entre agosto y octubre, hacia la Bahía de Lobos y Guásimas.

- La comunidad maya y otras más, a lo largo del país, aprovechan la información para crear diversos espacios turísticos donde se promueve el deporte ecológico, como el escalamiento, el rapel, la tirolesa, la navegación en ríos rápidos, el campismo, el buceo, la pesca, etcétera.

- La comunidad huichol. Es un grupo étnico que aprovecha los medios de comunicación para dar a conocer su cultura y, a partir de la información sobre cooperativas y empresas, venden de manera comunitaria productos 
artesanales tales como su colorida indumentaria, prendas de manta bordadas, sombreros coronados de plumas, así como pulseras, anillos y collares de cuentas de cristal en las que también plasman su visión del cosmos.

- Comunidad cora. Al igual que los huicholes, son reconocidos por su arte en cerámica, así como por sus originales y coloridas artesanías: colibríes de estambre que vuelan entre cielos de intensos amarillos, de alucinantes violetas; felinos que toman forma en brillantes cuentas de cristal.

- Comunidad tepehuana. Conviven en el mismo territorio de las otras etnias; entre los productos artesanales que elaboran se encuentran morrales de estambre, sombreros, equipales y ollas de barro.

- Comunidad de mexicaneros. Como las anteriores comunidades del estado de Nayarit, entre sus actividades se encuentra el fabricar canastas, cestos y chiquigüites de otate, piezas de madera, redes de ixtle y morrales de estambre.

Como se pudo observar en los ejemplos anteriores, la información ha sido utilizada por las comunidades indígenas para incrementar su interacción con las sociedades que las rodean, para generar organismos que resulten en empresas y negocios de venta de sus productos artesanales y evitar a los intermediarios que se apropiaban de una parte considerable de sus ganancias.

Otra forma de aprovechar la información que obtienen es utilizándola para dar una mejor educación y preparación a sus hijos, con el fin de darles la oportunidad de emprender una vida mejor al amparo de la preservación de su cultura, incluyendo su idioma, sus costumbres y sus tradiciones. 
También la información les sirve para ampliar sus oportunidades de una vida sana y longeva al amparo de la obtención de mejores servicios de salud, los cuales se sumarán a la medicina tradicional que practican sus curanderos $o$ chamanes.

El uso de la información por parte de las comunidades indígenas tiene, como dice Hugo Figueroa: "[...] una función eminentemente social, comunitaria y permite generar complejos vínculos de identidad, [...] unión, localización, solidaridad y gestión." (2008: 43)

No se puede soslayar que la información ha sido un instrumento que les ha permitido, a través de los medios de comunicación masivos, luchar públicamente, interactuar con otras comunidades y elevar la voz para defender sus derechos humanos y civiles.

Para las comunidades indígenas no ha pasado inadvertido que la información es el mejor legado y el más importante que le pueden dejar a las siguientes generaciones, como una herramienta eficaz que les permitirá consolidarse en un mundo cada vez más impersonal, superpoblado y, por lo tanto, menos humanitario.

\section{BIBLIOGRAFÍA}

Casa Tirao, B. (2007). Bibliotecas e información en la diversidad cultural. En Estela Morales Campos (Coord.), El multiculturalismo y los servicios de información (pp. 1-8). México: UNAM / CUIB.

Figueroa Alcántara, H. A. (2008). Usos sociales de Internet y acceso a la información por parte de comunidades migrantes. En Estela Morales Campos (Coord.), Diversidad cultural y acceso a la información (pp. 19-48). México: UNAM / CUIB. 
Significados e interpretaciones de la información desde el usuario

Goñi Camejo, I. (2000). Contribuciones breves: Algunas reflexiones sobre el concepto de información y sus implicaciones para el desarrollo de las ciencias de la información. ACIMED, 8(3), 201-207.

Martínez Aguirre, E. (2006). Sobre la noción de información: aportes y alcances de una definición. En La trama de la comunicación (Anuario del Departamento de Ciencias de la Comunicación. Facultad de Ciencia Politica y Relaciones Internacionales. Universidad Nacional de Rosario, Rosario Argentina), 11, 221229.

Ríos Ortega, J. (2014). El Concepto de información: dimensiones bibliotecológica, sociológica y cognoscitiva. Investigación bibliotecológica, 28(62), ene-abr., 143-179. 


\section{El papel de la alfabetización informativa en la interpretación de la información}

ANDRÉS FERNÁNDEZ RAMOS

Universidad Nacional Autónoma de México

INTRODUCCIÓN

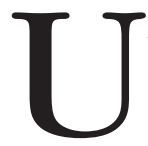

Tna correcta planificación de bibliotecas y centros de documentación pasa necesariamente por conocer a sus usuarios, puesto que la función principal de este tipo de instituciones es satisfacer sus necesidades de información. Sin embargo, durante muchos años, las labores de planificación no los tenían en cuenta, centrándose mucho más en la calidad de las colecciones o en las instalaciones. El interés por conocerlos e incorporarlos a los modelos de gestión y planificación no se manifestó hasta mediados del siglo pasado, dando lugar a una disciplina dentro de la bibliotecología y las ciencias de la información denominada "estudios de usuarios" (Wilson, 1999: 250).

En un primer momento el objetivo fundamental de esta disciplina era conocer las necesidades, hábitos y satisfacción de los usuarios de las bibliotecas para poder adaptar sus colecciones y servicios a sus requerimientos y así mejorar su rendimiento. Esto se tradujo en que, en sus orígenes, los es- 
tudios de usuarios estuvieran muy orientados hacia el sistema de información y los modelos utilizados para analizarlos partían de la formulación de una necesidad de información, analizaban cómo se llevaba a cabo la búsqueda y se valoraba la satisfacción con la información recuperada. Desde un punto de vista práctico, esto servía para evaluar el sistema de información (biblioteca, archivo, centro de documentación, etcétera) en función de su capacidad de responder satisfactoriamente a las necesidades de información planteadas.

Con el paso del tiempo, estos estudios fueron evolucionando con el fin de profundizar en el conocimiento de los usuarios y adaptarse a un nuevo contexto, marcado por las nuevas formas de acceder a la información. Los modelos teóricos centrados en el sistema, predominantes hasta los años ochenta, presentaban bastantes limitaciones a la hora de comprender y caracterizar a los usuarios, puesto que no tenían en cuenta sus motivaciones, contexto, ni otros factores de tipo cognitivo. Básicamente trataban de averiguar quién utilizaba el sistema y cómo lo hacía (Wilson, 2008: 457). Numerosos autores, como Wilson (1994) o Bates (2010), señalan el trabajo de Dervin y Nilan (1986) como el inicio de una nueva etapa, en la que el centro de atención pasó a ser el usuario y se empezaron a considerar sus propias características personales y sus procesos mentales como elementos fundamentales para comprender su comportamiento informacional. Este enfoque, marcadamente cognitivista, sigue vigente en la actualidad, aunque ha sido criticado por ser demasiado individualista y dejar fuera el contexto sociocultural o los aspectos afectivos de la persona (Pettigrew, Fidel, y Bruce, 2001). Así, han surgido diferentes modelos y teorías que amplían y complementan este enfoque, haciendo uso de las aportaciones del constructivismo o las técnicas etnográficas (Talja, Tuominen, y Savolainen, 
2005) y considerando también los aspectos emocionales (Kuhlthau, 1991) o los sociológicos y contextuales (Savolainen, 2007).

Por otro lado, de la misma manera que en la bibliotecología el objeto de estudio ha pasado de ser la biblioteca a ser la información, los estudios de usuarios han evolucionado para pasar de estar centrados en los usuarios de las bibliotecas a centrarse en los usuarios de información. Como señala Olsson (2009: 27), la investigación sobre usuarios de información debe ir más allá de la biblioteca y de la evaluación de sistemas de información. La hegemonía que tuvieron las bibliotecas y centros de documentación a la hora de proporcionar acceso a la información se ha visto desplazada en favor de nuevos canales, que han aparecido de la mano de los avances en las tecnologías de la información y la comunicación, que cada vez son más populares y que también deben ser tenidos en cuenta para poder comprender las relaciones de las personas con la información. Los estudios de usuarios tradicionalmente han prestado poca atención a ciertos colectivos y prácticas informativas y han privilegiado determinados perfiles de usuarios y comportamientos informativos muy concretos, como la búsqueda de información que hacen los investigadores, médicos o profesores en el ejercicio de su actividad laboral o académica (Julien, 1999). En la actualidad, cada vez se abordan más perfiles de usuarios y de comportamientos informativos y los estudios se han enriquecido de una multidisciplinariedad cada vez mayor, favorecida por el hecho de que los usuarios de información también son objeto de estudio de otras disciplinas, como la sociología, la psicología, la comunicación o el marketing (Wilson, 1997).

En definitiva, hoy en día, los estudios de usuarios han ampliado su marco de actuación e investigación para abor- 
dar la relación de las personas con la información desde una perspectiva más global y sin centrarse exclusivamente en la biblioteca. Ahora, el centro de atención no son únicamente los usuarios de bibliotecas y su satisfacción con el sistema, sino, desde una perspectiva más amplia, los usuarios de información y todos los procesos y factores implicados en su comportamiento informativo.

\section{ALFABETIZACIÓN INFORMATIVA Y USUARIOS DE INFORMACIÓN}

Los usuarios de información, "[...] aquellos individuos que necesitan información para el desarrollo continuo de sus actividades, ya sean profesionales o privadas, y que como tal utilizan un servicio o hacen uso de un producto informativo" (Izquierdo Alonso, 1999: 116), son estudiados, como hemos visto, por la bibliotecología y otras disciplinas, con el fin de comprender cómo actúan y por qué. Sin embargo, este interés no es sólo teórico, sino que tiene importantes aplicaciones de carácter práctico, como por ejemplo para dirigir campañas de marketing en la web o adoptar diferentes estrategias de comunicación por parte de empresas o instituciones. En nuestro ámbito, además de para evaluar y adaptar a sus necesidades colecciones y servicios de información, tiene especial importancia para poder cumplir con la labor formativa de las bibliotecas, orientada en la actualidad al desarrollo de competencias informativas a través de la alfabetización informativa (en adelante, AI).

La AI se ha definido a menudo de forma indirecta, esto es, caracterizando al individuo alfabetizado en información en vez de definiendo el proceso. Así, una de las definiciones más utilizadas es la que propuso la American Library Asso- 
El papel de la alfabetización informativa en la interpretación...

ciation (1989), según la cual una persona alfabetizada en información es aquella que es capaz de reconocer una necesidad de información y tiene las habilidades para localizarla, evaluarla y utilizarla de forma efectiva. Sin embargo, por obvio que resulte, es importante recordar que el individuo no nace alfabetizado, sino que para llegar a serlo va a necesitar de un proceso de aprendizaje que le capacite como tal. Ésa es precisamente la finalidad y la naturaleza de la AI, capacitar a las personas para que lleguen a ser individuos alfabetizados en información, debiendo entenderse por tanto como la acción formativa encaminada a que las personas adquieran las competencias y habilidades necesarias para el adecuado manejo de la información. En este sentido, resulta más precisa la definición de AI propuesta por Hernández Salazar (2012: 12):

[...] acción educativa sistematizada destinada a proveer a los sujetos de un conjunto de habilidades, procesos de pensamiento, como el pensamiento crítico, y actitudes que le permitan acceder, evaluar y usar efectivamente la información, para cubrir una necesidad dada. Esta acción deberá promover que aprendan a aprender y generar aprendizajes para toda la vida [...]

Lo cual incide, entre otros aspectos, en que la AI es un proceso de carácter educativo y que se orienta al aprendizaje a lo largo de la vida.

Capacitar a la gente para que sea competente en habilidades de información es una de las metas básicas y fundamentales de la bibliotecología (Reichel, 1991) y se ha convertido en las últimas décadas en una de las principales labores que llevan a cabo las bibliotecas, especialmente las universitarias (Chen y Lin, 2011), y en uno de los temas de investigación más abordados en la literatura científica del área de la bibliotecología y las ciencias de la información 
(Pinto, Cordón, y Díaz, 2010). Este auge cada vez mayor de la AI se explica, entre otros, por los siguientes motivos:

- La cantidad de información a la que los usuarios tienen acceso es cada vez mayor y es más heterogénea, tanto en lo referente a formatos y a canales de difusión como a su calidad. La aparición de internet y su uso generalizado por parte de la sociedad ha supuesto una trasformación importante en el panorama informativo actual, que lo hace mucho más complejo y que obliga a un aprendizaje y actualización constantes sobre las nuevas formas de expresión, difusión, gestión, localización, acceso y uso de la información (Saunders, 2009).

- Los usuarios son cada vez más autónomos. Las bibliotecas en los últimos años han visto cómo perdían su hegemonía como intermediarias entre los usuarios y la información. Hoy en día las personas pueden acceder a una ingente cantidad de información en la red y los motores de búsqueda, cada vez más potentes y fáciles de manejar, les brindan la oportunidad de buscar la información por su cuenta sin necesidad de utilizar los catálogos, bases de datos y otras herramientas y servicios que las bibliotecas también ponen a su alcance (Fernández-Ramos, 2014: 118).

- En el ámbito educativo, especialmente en el de la educación superior, se está pasando de un modelo centrado en el aprendizaje memorístico a otro basado en los postulados constructivistas, en el que se hace hincapié en el desarrollo de competencias y habilidades, favoreciendo así el aprendizaje activo por parte de los alumnos (Fernández-Ramos, 2015: 127).

- La importancia creciente que se da al aprendizaje a lo largo de la vida en la sociedad actual. La necesidad de 
El papel de la alfabetización informativa en la interpretación...

adaptación a un entorno en constante transformación, no sólo en lo que se refiere a la información, sino también en lo social, económico y laboral, supone que los individuos deben vivir aprendiendo continuamente. Este aprendizaje, para que sea efectivo, requiere de una actitud proactiva, de un hábito y de haber aprendido a aprender (Gómez Hernández y Licea de Arenas, 2005). Una persona alfabetizada en información estará en condiciones óptimas para aprender, puesto que sabrá cómo se organiza el conocimiento, cómo encontrar la información que necesita y cómo usarla de forma efectiva.

Distintas asociaciones bibliotecarias y colegios profesionales han propuesto una serie de normas y modelos de AI, que establecen un marco de actuación y pretenden determinar exactamente qué competencias y habilidades son necesarias para estar alfabetizado en información. Aunque en su gran mayoría están orientadas al ámbito de la educación superior, pueden aplicarse a otros niveles formativos y a otros entornos no necesariamente académicos. Las más conocidas internacionalmente son las propuestas por la Association of College \& Research Libraries (ALA/ACRL, 2000), Society of College, National and University Libraries (SCONUL, 2011), Australian and New Zealand Institute for Information Literacy / Council of Australian University Librarians (ANZIIL/ CAUL, 2004), o la International Federation of Library Associations and Institutions (Lau, 2006). Aunque existen pequeñas diferencias entre ellas a la hora de enunciar y agrupar las competencias y habilidades, todas ellas inciden en las siguientes: el reconocimiento de la necesidad de información; su búsqueda y recuperación; su evaluación y análisis; su organización; su utilización; y la compresión de los aspectos éticos, legales y sociales de la información (Gráfico 1). 
Significados e interpretaciones de la información desde el usuario

Gráfico 1.

Competencias y conocimientos en Al

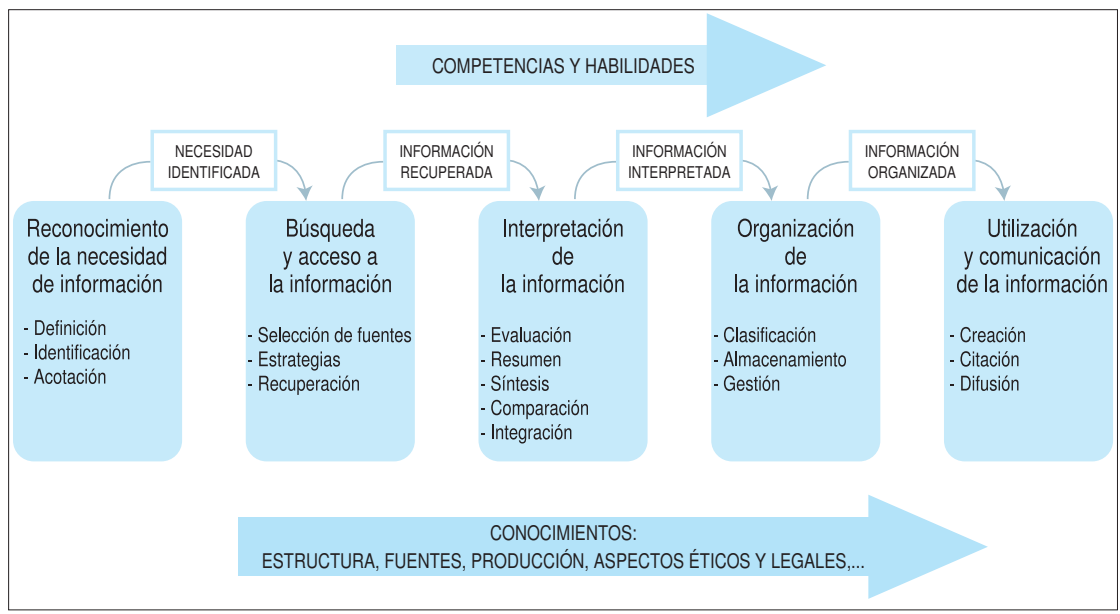

Fuente: elaboración propia.

La secuencia planteada en este gráfico sigue un orden lógico basado en las normas de la ALA (1999), que se corresponde muy bien con la mayor parte de los distintos modelos de comportamiento informativo, pero no es la única secuencia posible, sobre todo teniendo en cuenta que muchos procesos pueden darse de forma simultánea o en varios momentos. En la Tabla 1 puede observarse, a modo de ejemplo, la comparación de algunas de estas normas y cómo el orden de las competencias varía de unas a otras. 
Tabla 1.

Competencias y habilidades recogidas en normas de alfabetización informativa

\begin{tabular}{|c|c|c|}
\hline ACRL (2000) & SCONUL (2011) & III Encuentro DHI (2002) \\
\hline \multirow[t]{2}{*}{$\begin{array}{l}\text { Es capaz de determinar la naturaleza y } \\
\text { nivel de la información que necesita }\end{array}$} & $\begin{array}{l}\text { Es capaz de identificar una necesidad } \\
\text { personal de información }\end{array}$ & \multirow{2}{*}{$\begin{array}{l}\text { Habilidad para determinar la } \\
\text { naturaleza de una necesidad } \\
\text { informativa }\end{array}$} \\
\hline & $\begin{array}{l}\text { Puede evaluar el conocimiento actual } \\
\text { e identificar las lagunas }\end{array}$ & \\
\hline \multirow[t]{2}{*}{$\begin{array}{l}\text { Accede a la información requerida de } \\
\text { manera eficaz y eficiente }\end{array}$} & $\begin{array}{l}\text { Puede construir estrategias para } \\
\text { localizar información y datos }\end{array}$ & $\begin{array}{l}\text { Habilidad para plantear estrategias } \\
\text { efectivas para buscar y encontrar } \\
\text { información }\end{array}$ \\
\hline & $\begin{array}{l}\text { Puede localizar y acceder a la informa- } \\
\text { ción y datos que necesita }\end{array}$ & $\begin{array}{l}\text { Habilidad para recuperar infor- } \\
\text { mación }\end{array}$ \\
\hline $\begin{array}{l}\text { Evalúa la información y sus fuentes de } \\
\text { forma crítica e incorpora la información } \\
\text { seleccionada a su propia base de cono- } \\
\text { cimientos y a su sistema de valores }\end{array}$ & $\begin{array}{l}\text { Puede revisar el proceso de } \\
\text { investigación y comparar y evaluar la } \\
\text { información y los datos }\end{array}$ & $\begin{array}{l}\text { Habilidad para analizar y evaluar } \\
\text { información }\end{array}$ \\
\hline \multirow{2}{*}{$\begin{array}{l}\text { A título individual o como miembro de un } \\
\text { grupo, utiliza la información eficazmente } \\
\text { para cumplir un propósito específico }\end{array}$} & \multirow{2}{*}{$\begin{array}{l}\text { Puede aplicar el conocimiento adqui- } \\
\text { rido: presentando los resultados de } \\
\text { su investigación, sintetizando nueva } \\
\text { y vieja información y datos para crear } \\
\text { nuevo conocimiento y difundiéndolo de } \\
\text { formas variadas }\end{array}$} & $\begin{array}{l}\text { Habilidad para integrar, sintetizar y } \\
\text { utilizar la información }\end{array}$ \\
\hline & & $\begin{array}{l}\text { Habilidad para presentar los resul- } \\
\text { tados de la información obtenida }\end{array}$ \\
\hline \multirow{2}{*}{$\begin{array}{l}\text { Comprende muchos de los problemas y } \\
\text { cuestiones económicas, legales y socia- } \\
\text { les que rodean al uso de la información, } \\
\text { y accede y utiliza la información de } \\
\text { forma ética y legal. }\end{array}$} & \multirow[t]{2}{*}{$\begin{array}{l}\text { Puede organizar la información } \\
\text { profesional y éticamente }\end{array}$} & $\begin{array}{l}\text { Comprensión de la estructura del } \\
\text { conocimiento y la información }\end{array}$ \\
\hline & & $\begin{array}{l}\text { Respeto a la propiedad intelectual } \\
\text { y a los derechos de autor }\end{array}$ \\
\hline
\end{tabular}

Fuente: elaboración propia.

Según hemos visto, existe una relación obvia entre AI y usuarios de información, puesto que estas competencias y habilidades informativas están enfocadas en los individuos en su condición de usuarios de información y pretenden mejorar su comportamiento informativo. Por otro lado, también existe una notable relación entre AI y estudios de usuarios, que puede precisarse en dos aspectos fundamentales que, tal y como se afirmaba al comienzo del epígrafe, resaltan la importancia del conocimiento de los usuarios de información en la formación en competencias informativas.

En primer lugar, las competencias informativas que se pretenden desarrollar a través de la AI deben tener en cuenta 
y abordar los procesos incluidos en los modelos de comportamiento informativo (Limberg y Sundin, 2006), así como, más específicamente, los subprocesos o procesos propios de los modelos de búsqueda, recuperación y uso de la información. ${ }^{1}$ Los procesos generales, comunes en los diferentes modelos (Niedźwiedzka, 2003; Wilson, 1981; Wilson, 1997, 1999), son la identificación de la necesidad de información, su búsqueda y recuperación y su uso. Por tanto, los contenidos específicos a impartir deben estar orientados a capacitar a los usuarios para saber identificar correctamente sus necesidades de información, saber buscar y acceder a la información que necesitan (conocimiento de fuentes, estrategias, etcétera) y saber usarla (organizarla, sintetizarla, comunicarla, etcétera). Como puede verse en la Tabla 1, todos estos procesos aparecen reflejados en las normas de AI como competencias fundamentales, y posteriormente son desarrollados en profundidad en habilidades concretas.

En segundo lugar, la formación en competencias informativas debe tener en cuenta los factores o variables que van a condicionar el comportamiento informativo de las personas y que han sido también recogidos en diferentes modelos de comportamiento informativo (Allen y Kim, 2001; Courtright, 2007; Kuhlthau, 1991; Wilson, 1997). Estos factores son de diversa naturaleza y engloban: las características personales, bien sean demográficas, emocionales, cognitivas o educativas, como son la edad, conocimientos, habilidades, preferencias, etcétera; condicionantes de tipo social o cultural, como los roles en los diversos trabajos o la situación económica; y factores relativos al contexto, como son el motivo por el que se necesita información o el tiempo del que se dispone. Además, en la literatura científi-

1 Se ha considerado, de acuerdo con Wilson (2000), que el comportamiento informacional engloba los comportamientos de búsqueda, de recuperación y de uso de la información 
El papel de la alfabetización informativa en la interpretación...

ca podemos encontrar numerosos estudios de usuarios que analizan cómo influyen esos factores en el comportamiento informativo, por ejemplo, los rasgos de la personalidad -neuroticismo, extraversión, apertura a la experiencia, la amabilidad y la escrupulosidad- (Heinström, 2003; Tidwell y Sias, 2005), la motivación y la inteligencia emocional (Matteson, 2014) o los distintos estilos de aprendizaje - convergentes, divergentes, asimiladores y acomodadores- (Bawden y Robinson, 2011; Ford, Wilson, Foster, Ellis, y Spink, 2002; Onwuegbuzie y Jiao, 1998).

Toda esta información que nos proporcionan los modelos y estudios de usuarios puede y debe tenerse en cuenta a la hora de impartir formación en competencias informativas. Puesto que no todos los individuos tienen las mismas características y que los contextos pueden variar en cada caso, es necesario que la enseñanza de competencias informativas esté enfocada en los usuarios concretos que van a recibir esa formación, lo que se traduce en que hay que conocer a los alumnos y ser capaces de ajustar los contenidos al contexto y a sus particularidades. Como señala Uribe-Tirado (2012: 88), es necesario incluir los modelos de comportamiento informacional en el diseño instruccional de programas de AI, ya que permiten identificar aspectos clave para la enseñanza de AI, como que existen diferentes formas de buscar y usar la información y que están determinadas por distintos factores.

USO, INTERPRETACIÓN DE LA INFORMACIÓN Y ALFABETIZACIÓN INFORMATIVA

Definir y acotar lo que entendemos por uso de la información es una tarea compleja, ya que en la literatura especia- 
lizada se ha conceptualizado de formas muy distintas (Kari, 2010): como práctica informativa a nivel general (cualquier interacción del individuo con la información), como búsqueda y recuperación de información, como procesamiento de la misma (incorporarla a su conocimiento, interiorizarla), como construcción de conocimiento, como producción de información, como aplicación de la información y como el resultado o efecto de la información. Aunque todas ellas tienen su justificación, coincidimos con el análisis de Savolainen (2009), en el que indica que, en los principales modelos teóricos, el uso de la información comienza cuando ésta ya ha sido recuperada y empieza a ser procesada por el individuo. Desde este punto de vista, como parte de un modelo genérico de comportamiento informativo, el uso de la información sería una etapa posterior a la búsqueda y recuperación de información.

Partiendo de esta base, que el uso de la información sigue a la búsqueda y recuperación, podemos abordarlo, de acuerdo con Savolainen (2006), desde dos perspectivas principales compatibles entre sí: como proceso y como resultado. En la primera de estas perspectivas estaría la definición de comportamiento en el uso de la información que propone Wilson (2000: 50):

[...] las actividades físicas y mentales involucradas en la incorporación de la información recuperada en la base de conocimiento del individuo. Pueden incluir, por tanto, las acciones físicas, como marcar una sección de un texto para resaltar su importancia o significado, como las mentales, por ejemplo, comparar la nueva información con el conocimiento previo que se tenía.

El uso de la información, desde esta perspectiva, englobaría todos los procesos y actividades que se llevan a cabo con la información recuperada hasta que se integran en la base de conocimientos y sistema de valores del indivi- 
duo. Desde la perspectiva de los resultados, se referiría a las consecuencias o a los efectos que derivarían del uso de la información (Savolainen, 2006: 1120) y abarcarían desde acciones o comportamientos hasta sentimientos o conocimientos, resultado de la incorporación de la información al conocimiento del individuo. Una de las principales utilidades de esta perspectiva es que estos resultados serían más fácilmente observables y analizables que los procesos empleados.

Las actividades mentales que se llevan a cabo para la que la información recuperada se incorpore a la base de conocimiento de un individuo son numerosas, complejas y en muchos casos se dan de forma simultánea. Según Pappas y Tepe (1997), todas ellas formarían parte de una etapa del procesamiento de la información, denominada interpretación de la información, que permiten dar un significado a la información recuperada. Algunas de las que recogen estos autores serían el análisis, evaluación, comprensión, síntesis, clasificación o comparación. Estas actividades estarían enmarcadas en un proceso constante de valoración y evaluación, que, a su vez, estaría condicionado por una serie de factores contextuales (laborales, temporales, sociales, etcétera) y personales (creencias, valores, educación, habilidades, conocimientos...), que determinarán la forma en que se lleven a cabo.

La AI no puede intervenir en todos estos factores para que el individuo pueda mejorar su comportamiento informativo, pero sí y de forma muy significativa en dos de ellos: en los conocimientos y en las habilidades. Si analizamos las diferentes normas de AI, podemos observar que se recoge una serie de conocimientos y habilidades directamente relacionadas con la interpretación de la información recupe- 
rada. A continuación se comentan las que consideramos de mayor utilidad al respecto. ${ }^{2}$

\section{EVALUACIÓN DE LA INFORMACIÓN}

Determinar el valor y la utilidad de la información recuperada es la primera y una de las más importantes labores a la hora de procesarla, puesto que mediante la evaluación establecemos un primer filtro que servirá para seleccionar aquella información que posteriormente será analizada y utilizada. Debido al ingente volumen de información que tenemos a nuestro alcance y a que no toda tiene la misma calidad ni utilidad, sobre todo en internet, es necesario distinguir aquella que nos es relevante de la que no, puesto que el uso de información sesgada, desactualizada o incompleta puede llevarnos a conclusiones erróneas y a no satisfacer adecuadamente nuestras necesidades.

Aunque la evaluación de la información es un proceso subjetivo, que va a estar condicionado por el contexto en el que se produzca y por la necesidad de información concreta del individuo (Mai, 2013), existe una serie de conocimientos, técnicas y pautas que pueden enseñarse en los programas de formación de competencias informativas y que nos ayudarán a determinar el valor de la información, como pueden ser el conocimiento de las características de las distintas fuentes de información o sus parámetros de calidad (actualidad, autoridad, consistencia, etcétera).

2 Aunque en la organización de la información y en su comunicación también se da una cierta interpretación de la información, a efectos de este trabajo sólo se han considerado aquellas habilidades que tienen que ver directamente con la incorporación de la información a la base de conocimientos y sistema de valores del individuo. 
En las normas de AI de la ALA y ANZIIL/CAUL, indicador 3.2, se menciona de forma explícita que el individuo alfabetizado en información "articula y aplica criterios de evaluación de las fuentes y de los textos”. Mientras, las normas de scoNUL, en el quinto pilar de la AI, indican que "[...] es capaz de revisar el proceso de investigación y de comparar y evaluar la información y los datos”. Según estas normas, para poder evaluar correctamente la información, el individuo deberá ser capaz de llevar a cabo las siguientes acciones (Tabla 2):

Tabla 2.

Evaluación de la información

\begin{tabular}{|l|l|l|}
\hline \multicolumn{1}{|c|}{ ALA } & \multicolumn{1}{|c|}{ ANZIIL/CAUL } & \multicolumn{1}{c|}{ SCONUL } \\
\hline $\begin{array}{l}\text { Examinar y comparar la información } \\
\text { de varias fuentes para valorar su fiabi- } \\
\text { lidad, validez, adecuación, autoridad, } \\
\text { oportunidad y punto de vista o sesgo. } \\
\text { (3.2.a) }\end{array}$ & $\begin{array}{l}\text { Examinar y comparar la información } \\
\text { de varias fuentes para valorar su fiabi- } \\
\text { lidad, validez, adecuación, autoridad, } \\
\text { oportunidad y punto de vista o sesgo. } \\
\text { (3.2.1) }\end{array}$ & $\begin{array}{l}\text { Evaluar la calidad, adecuación, } \\
\text { relevancia, sesgo, reputación y credi- } \\
\text { bilidad de la información encontrada. } \\
\text { (5.3) }\end{array}$ \\
\hline $\begin{array}{l}\text { Analizar la estructura y la lógica de sus } \\
\text { argumentos o métodos. (3.2.b) }\end{array}$ & $\begin{array}{l}\text { Analizar la estructura y la lógica de sus } \\
\text { argumentos o métodos. (3.2.2) }\end{array}$ & $\begin{array}{l}\text { Distinguir las diferentes fuentes de } \\
\text { información y su aportación. (5.1) }\end{array}$ \\
\hline $\begin{array}{l}\text { Reconocer prejuicios, engaños o } \\
\text { manipulación. (3.2.c) }\end{array}$ & $\begin{array}{l}\text { Reconocer prejuicios, engaños o } \\
\text { manipulación. (3.2.3) }\end{array}$ & $\begin{array}{l}\text { Evaluar la credibilidad de los datos. } \\
\text { (5.4) }\end{array}$ \\
\hline $\begin{array}{l}\text { Reconocer el contexto cultural, físico } \\
\text { o de otro tipo dentro del cual se creó } \\
\text { la información, y comprender el } \\
\text { impacto del contexto al interpretar la } \\
\text { información. (3.2.d) }\end{array}$ & $\begin{array}{l}\text { Reconocer el contexto cultural, físico } \\
\text { o de otro tipo dentro del cual se creó } \\
\text { la información, y comprender el } \\
\text { impacto del contexto al interpretar la } \\
\text { información. (3.2.4) }\end{array}$ & \\
\cline { 2 - 2 } & $\begin{array}{l}\text { Reconocer y ser consciente de sus } \\
\text { propios sesgos y contexto cultural. } \\
\text { (3.2.5) }\end{array}$ & \\
\hline
\end{tabular}

Fuente: elaboración propia.

\section{RESUMEN DE LA INFORMACIÓN}

La información útil que ha sido seleccionada tras el proceso de evaluación debe ser comprendida para que pueda integrarse adecuadamente en la base de conocimientos del indi- 
viduo. Para poder comprenderla, además de conocimientos de tipo general (idioma, vocabulario, temática), es necesaria una serie de habilidades relacionadas con la capacidad de resumir. En primer lugar es necesario conocer la estructura, características y finalidad de los diferentes tipos de documentos (Koltay, 2009; Pinto, Fernández-Ramos, y Doucet, 2008). Después, es necesario identificar y extraer sus ideas principales, diferenciándolas de las ideas secundarias, contextualizadoras, ejemplos, etcétera (Harris y Sipa, 1980; Winograd, 1984). Posteriormente, las ideas extraídas deber ser organizadas, reflejando la relación que existe entre ellas, y finalmente deben ser expresadas de forma lógica y con las propias palabras del individuo, demostrando que se ha comprendido el documento. Según Koltay (2009), resumir se basa en pensamiento crítico y puede ser un proceso complementario al de selección en la medida en que una mejor comprensión de la información ayudará a determinar su utilidad y, por tanto, podría servir de segundo filtro (el primero sería el basado en la autoridad, actualidad, etcétera).

En las normas de la ALA, indicador 3.1., se especifica que el alumno competente en información "resume las ideas principales de la información recuperada" y especifica que, en consecuencia, será capaz de llevar a cabo las actividades que figuran en la Tabla 3. En las normas de ANZIIL/CAUL y SCONUL no se hace tanto hincapié en esta habilidad, pero sí que aparece al menos mencionada. 
El papel de la alfabetización informativa en la interpretación...

Tabla 3.

Resumen de la información

\begin{tabular}{|l|l|l|}
\hline \multicolumn{1}{|c|}{ ALA } & \multicolumn{1}{|c|}{ ANZIIL/CAUL } & \multicolumn{1}{c|}{ SCONUL } \\
\hline $\begin{array}{l}\text { Lee el texto y selecciona las ideas } \\
\text { principales. (3.1.a) }\end{array}$ & $\begin{array}{l}\text { Selecciona información que proporcio- } \\
\text { ne evidencia sobre un tema y resumen } \\
\text { las principales ideas. (5.1.3) }\end{array}$ & $\begin{array}{l}\text { Lee de forma crítica, identificando } \\
\text { puntos clave y argumentos. (5.5) }\end{array}$ \\
\cline { 2 - 3 } $\begin{array}{l}\text { Redacta los conceptos textuales con } \\
\text { sus propias palabras y selecciona con } \\
\text { propiedad los datos. (3.1.b) }\end{array}$ & $\begin{array}{l}\text { Resume documentos e informes } \\
\text { verbalmente y por escrito. (7.2) }\end{array}$ \\
\hline $\begin{array}{l}\text { Identifica fragmentos que después } \\
\text { pueden ser citados textualmente. } \\
\text { (3.1.c) }\end{array}$ & & \\
\hline
\end{tabular}

Fuente: elaboración propia.

SÍNTESIS DE LA INFORMACIÓN

La síntesis guarda estrecha relación con el resumen, ya que en ambos casos se trata de condensar información, pero hay ciertos matices que permiten diferenciar estas dos actividades, en particular en el contexto de las normas de AI. Así como el resumen está orientado al contenido de un documento o de un texto y en general refleja su estructura, la síntesis se orienta a la relación entre las ideas y conceptos de uno o varios documentos. Se trataría por tanto de una habilidad que implica un alto grado de abstracción, ya que es el individuo el que tiene que construir o adecuar una estructura para plasmar la interrelación de esas ideas. Esto es más evidente en el caso de la síntesis de información de varias fuentes, puesto que habrá que buscar patrones comunes a todas ellas en función de una serie de criterios que permitan obtener una visión de conjunto.

Al igual que en el caso anterior, son las normas de la ALA las que mayor atención prestan a esta habilidad, señalando en su indicador 3.3 que una persona alfabetizada en información es capaz de sintetizar ideas principales para 
construir nuevos conceptos. No obstante, como se observa en la Tabla 4, también aparece mencionada en las otras dos normas de AI.

Tabla 4.

Síntesis de la información

\begin{tabular}{|l|l|l|}
\hline \multicolumn{1}{|c|}{ ALA } & \multicolumn{1}{|c|}{ ANZIIL/CAUL } & \multicolumn{1}{c|}{ SCONUL } \\
\hline $\begin{array}{l}\text { Reconoce la interrelación entre } \\
\text { conceptos y los combina en nuevos } \\
\text { enunciados primarios potencialmente } \\
\text { útiles con el apoyo de las evidencias } \\
\text { correspondientes. }\end{array}$ & $\begin{array}{l}\text { Reconoce la interrelación entre con- } \\
\text { ceptos y obtiene conclusiones basadas } \\
\text { en la información recogida. (5.1.2) }\end{array}$ & $\begin{array}{l}\text { Sintetiza y valora nueva y compleja } \\
\text { información de diferentes fuentes. } \\
\text { (7.5.) }\end{array}$ \\
\hline $\begin{array}{l}\text { Extiende, cuando sea posible, la } \\
\text { síntesis inicial hacia un nivel mayor } \\
\text { de abstracción para construir nuevas } \\
\text { hipótesis que puedan requerir informa- } \\
\text { ción adicional }\end{array}$ & $\begin{array}{l}\text { Extiende la síntesis inicial hacia un } \\
\text { nivel mayor de abstracción para } \\
\text { construir nuevas hipótesis. (5.1.5) }\end{array}$ & \\
\hline $\begin{array}{l}\text { Utiliza los computadores y otras tecno- } \\
\text { logías para estudiar la interacción de } \\
\text { las ideas y otros fenómenos. }\end{array}$ & & \\
\hline
\end{tabular}

Fuente: elaboración propia.

\section{COMPARACIÓN E INTEGRACIÓN DE LA INFORMACIÓN}

Una vez seleccionada y comprendida la información recuperada, es necesario compararla con aquella de la que se disponía y valorar en qué medida ésta contradice, confirma o cubre lagunas en nuestro conocimiento previo para su posterior integración en nuestra base de conocimiento. Este es un proceso complejo, en la medida en que requiere de un análisis profundo y una sistematización de las diferencias entre ambos conocimientos (el nuevo y el previo). Una vez hecha esta comparación, la nueva información puede integrarse a la base de conocimientos y sistema de valores del individuo, en función de factores contextuales y personales como las actitudes o las creencias. No obstante, de- 
terminadas acciones como la comprobación de las distintas informaciones o la reflexión profunda, que pueden dar lugar a nuevas demandas informativas, servirán de gran ayuda al individuo a la hora de tomar decisiones fundadas al respecto y determinar si la necesidad de información inicial ha sido satisfecha.

Las normas de la ALA inciden especialmente en estas habilidades finales del proceso de interpretación de la información y las recogen en varios indicadores que después desglosan en capacidades concretas. Las normas de ANZIIL/ CAUL y SCONUL también las recogen, pero, como puede verse en la Tabla 5, de una forma mucho menos detallada.

Tabla 5.

Comparación e integración de la información

\begin{tabular}{|l|l|l|}
\hline \multicolumn{1}{|c|}{ ALA } & \multicolumn{1}{|c|}{ ANZIIL/CAUL } & \multicolumn{1}{c|}{ SCONUL } \\
\hline $\begin{array}{l}\text { Compara el nuevo conocimiento con el } \\
\text { anterior para determinar el valor aña- } \\
\text { dido, contradicciones o características } \\
\text { únicas de la información. (3.4) }\end{array}$ & $\begin{array}{l}\text { Determina si la información obtenida } \\
\text { satisface las necesidades de la } \\
\text { investigación o de información, o si } \\
\text { la información contradice o verifica la } \\
\text { información utilizada de otras fuentes. }\end{array}$ & $\begin{array}{l}\text { Sintetiza y valora nueva y compleja } \\
\text { información de diferentes fuentes. } \\
(7.5 .)\end{array}$ \\
\cline { 1 - 2 } $\begin{array}{l}\text { Determina si el nuevo conocimiento } \\
\text { tiene un impacto sobre el sistema } \\
\text { de valores del individuo y toma las } \\
\text { medidas adecuadas para reconciliar } \\
\text { las diferencias. (3.5) }\end{array}$ & $\begin{array}{l}\text { Integra la nueva información con la } \\
\text { información o el conocimiento previo. }\end{array}$ \\
\cline { 1 - 2 } $\begin{array}{l}\text { Valida la comprensión e interpreta- } \\
\text { ción de la información por medio de } \\
\text { intercambio de opiniones con otros } \\
\text { estudiantes, expertos en el tema y } \\
\text { profesionales en ejercicio. (3.6) }\end{array}$ & $\begin{array}{l}\text { Selecciona la información que aporta } \\
\text { evidencias sobre el tema y resume } \\
\text { las principales ideas extraídas de la } \\
\text { información reunida. (5.1.3) }\end{array}$ & \\
\hline $\begin{array}{l}\text { Determina si la formulación inicial de la } \\
\text { pregunta debe ser revisada. (3.7) }\end{array}$ & & \\
\hline
\end{tabular}

Fuente: elaboración propia. 
FORMACIÓN EN HABILIDADES RELACIONADAS CON LA INTERPRETACIÓN DE LA INFORMACIÓN

La AI ha evolucionado notablemente desde sus orígenes hasta la actualidad, pasando de un enfoque orientado al manejo de determinadas herramientas y recursos a otro mucho más complejo, en el que cobran importancia los procesos cognitivos y el pensamiento crítico (Beherens, 1994). Este último concepto, el pensamiento crítico, está presente en las normas de AI y engloba la conceptualización, el análisis, la síntesis, la evaluación y la aplicación de la información, de forma que el individuo pueda sacar conclusiones o formarse una opinión a partir de la nueva información en combinación con el conocimiento previo que tenía (Allen, 2008).

En la práctica, sin embargo, los programas de formación en AI no siempre abarcan la totalidad de competencias que recogen las normas, y es habitual que éstos se centren en algunas de ellas, como la búsqueda de información o su uso ético (Knievel, 2008). Esta circunstancia no se debe a una infravaloración de las otras competencias, sino a las limitaciones temporales que suelen ser frecuentes en estas actividades formativas y que obligan a escoger entre ellas las que puedan impartirse más fácilmente en un corto periodo de tiempo (Albitz, 2007; Reece, 2005). Hay que tener en cuenta que, por ejemplo, sintetizar información de diferentes fuentes es más complejo de enseñar y requiere de un nivel de abstracción mayor al que se necesita para manejar los operadores booleanos en una base de datos, algo que es difícil de enseñar en sesiones de un par de horas.

A continuación se muestran varias propuestas de formación y ejemplos representativos de acciones formativas en AI que sí contemplan las competencias y habilidades relacionadas con la interpretación de la información, bien sea 
El papel de la alfabetización informativa en la interpretación...

en programas generales que abarcan todas las competencias o bien en módulos o cursos específicos, prestándose especial atención a los contenidos y a las técnicas didácticas empleadas.

La evaluación de la información es posiblemente la habilidad relacionada con su interpretación que más presente está en los programas de AI y en los últimos años se ha orientado principalmente a los recursos disponibles en internet. Su didáctica suele consistir en explicar qué aspectos se deben tener en cuenta para determinar su calidad, así como qué criterios se deben valorar y cómo, siendo habitual que se recurra a algún tipo de cuestionario o checklist para facilitar la esta tarea. Algunos ejemplos de buenas prácticas serían los tutoriales diseñados por la biblioteca de la Universidad Virginia Tech $^{3}$ o por la Universidad Johns Hopkins ${ }^{4}$, que, además de especificar los criterios a tener en cuenta para evaluar un recurso de internet, incluyen una explicación de la importancia y utilidad de cada aspecto a analizar y ofrecen claves sobre dónde hay que fijarse para encontrar la información necesaria para su evaluación (Fernández-Ramos, 2014).

A pesar de la utilidad de la explicación de criterios a valorar y de los checklists para una primera aproximación el tema, conseguir un dominio profundo de esta habilidad requiere un abordaje más complejo y un aprendizaje activo, puesto que el modelo basado en checklists es difícil de implementar en la práctica, dada la heterogeneidad de los recursos en la web, y adolece de un excesivo mecanicismo, que puede dar lugar a una infravaloración del pensamiento crítico y la reflexión (Meola, 2004). Existen pues otras propuestas de formación en evaluación de la información más

3 http://www.lib.vt.edu/instruct/evaluate/index.html

4 http://guides.library.jhu.edu/evaluatinginformation 
rigurosas y complejas que intentar recoger la complejidad de esta labor y que se basan en modelos contextuales mediante el "uso de la información para evaluar información". Su didáctica estaría basada en el examen de recursos que ya han sido evaluados por profesionales, la comparación de estos recursos con otros y la corroboración con otras fuentes. En esta línea formativa estarían las propuestas de Mandalios (2013), Meola (2004), Ostenson (2014) o Metzger (2007).

La enseñanza de habilidades relacionadas con el resumen y la síntesis de información, aunque se menciona en todas las normas, no es muy frecuente en programas de AI, debido a su complejidad y a la necesidad de bastante práctica para su dominio, siendo considerada en algunos casos como una habilidad de alto nivel (Ondrusek, Thiele, y Yang, 2014). Las pautas para resumir documentos pueden encontrarse en cualquier manual sobre resumen documental (por ejemplo, Izquierdo Alonso y Moreno Fernández, 2009; Lancaster, 2003; Pinto, 1992), pero por lo general son prolijas y están muy enfocadas al resumidor profesional o a los estudiantes de bibliotecología y ciencias de la información, que requieren de un conocimiento profundo sobre su elaboración. Es por este motivo que en la formación sobre resumen en los programas de AI se tienda a simplificar el proceso y a dar pautas sencillas de seguir y aplicar. Por ejemplo, Huerta y McMillan (2004), en un curso de competencias informativas impartido a estudiantes de ciencias, les enseñan a diferenciar la estructura de un texto científico y sus secciones (introducción, objetivos, metodología, resultados y conclusiones) y les piden que extraigan las frases más representativas de cada sección, las organicen de forma lógica y las redacten con sus propias palabras. Otras propuestas sencillas pero más rigurosas para enseñar esta habilidad, como 
El papel de la alfabetización informativa en la interpretación...

las recogidas en el portal e-COMs 5 o las utilizadas por Porter (2005) en un curso a estudiantes de biología, contemplan al menos una explicación somera de las principales etapas del resumen: identificación del tipo de texto y su estructura, selección de las ideas principales, síntesis y organización de las ideas y redacción de acuerdo a una serie de normas.

A un nivel más avanzado, el desarrollo de la competencia resumidora requiere de una formación más completa, que implicaría el desarrollo de la capacidad de lectura crítica (Koltay, 2009), que supone aprender, entre otras cosas, a detectar el propósito de un documento, su tema principal y secundarios, la intención del autor, la audiencia a la que va dirigido, el tipo de documento y de argumentación o los posibles sesgos. En la propuesta de Pinto, Doucet y Fernández-Ramos (2008) se detallan una serie de procedimientos y actividades didácticas para su formación, agrupadas en cinco etapas: comprensión, análisis, síntesis, organización y redacción. Estas actividades, que pueden ser grupales o individuales, incluyen, entre otras, la clasificación de tipos textuales, el uso del método Lasswell para (1985) para detectar la intención del autor, el método SQ5R (Thomas y Robinson, 1979) y el análisis de los marcadores textuales para detectar las ideas principales y el uso de esquemas para representar la relación entre ideas. Existen otras propuestas más específicas para reforzar el aprendizaje o mejorar alguna de las etapas del resumen, como por ejemplo la enseñanza basada en ejemplos de resúmenes profesionales (Ondrusek y otros, 2014), el uso de mapas conceptuales para organizar ideas y conceptos (Pinto, Doucet, y Fernández-Ramos, 2010) o ejercicios de paráfrasis para sintetizar las ideas principales de un documento (Bronshteyn y Baladad, 2006).

5 http://www.mariapinto.es/e-coms/or_con_elect.htm 
La síntesis de información proveniente de diferentes documentos también es una tarea compleja y difícil de explicar, que no suele incluirse en los programas de AI. De acuerdo con Spatt (1983: 266), se trataría de un proceso que implica el análisis de los diferentes puntos de vista y conceptos sobre un tema, tomados de diferentes fuentes de información, con la idea de condensar las diferentes opiniones en un nuevo texto. De entre las pocas propuestas para la enseñanza de esta habilidad en el ámbito de la bibliotecología, se podría mencionar la de Megwalu (2013), que consiste en identificar los temas principales que abordan las diferentes fuentes de información, observar sus diferencias y similitudes en cuanto a puntos de vista, resultados y metodologías, sistematizar esas diferencias y similitudes (por ejemplo mediante tablas o gráficos) y expresarlas de forma lógica. Curiosamente, esta habilidad está muy valorada en determinados ámbitos de la ciencia, como es el caso de la medicina basada en la evidencia o en otras ciencias que utilicen las revisiones sistemáticas como método de generación de evidencia, y existen numerosos trabajos sobre cómo enseñar y aprender a sintetizar información (Foster, 2013; Goldschmidt, 1986; Marcus, Grover, y Revicki, 1987) que podrían utilizarse como base para la enseñanza de esta habilidad en programas de AI.

La comparación e integración de la nueva información con la que se disponía se basaría en los procesos anteriores y consistiría sobre todo en sintetizar la nueva información con la que ya se tenía, ver diferencias y similitudes entre ambas y profundizar en la evaluación de la información (la nueva y la que ya se tenía) para determinar el grado de fiabilidad de cada una de ellas. Esto implicaría no sólo conocer las pautas anteriormente mencionadas de evaluación de la información, sino profundizar en aspectos como el contexto 
en que fue producida la información, los posibles sesgos o el grado de evidencia que la sustenta. En esta etapa habrá que valorar en qué medida se ha satisfecho la necesidad de información planteada en un origen y en muchos casos supondrá la generación de una nueva necesidad de información y el comienzo de un nuevo ciclo para satisfacerla.

En la práctica, la formación en competencias y habilidades que puedan ayudar a una mejor comparación e integración de la información requiere de una importante disponibilidad de tiempo, ya que es algo que no se puede aprender en un par de horas, y sólo los programas avanzados de AI pueden abordar estas cuestiones. Además, para que sea exitosa esa formación es muy recomendable el uso de técnicas de aprendizaje activo y que esté integrada en el currículum de una titulación o vinculada a alguna asignatura o temática (Warmkessel y McCade, 1997; Grafstein, 2002), puesto que los conceptos a explicar son bastante abstractos y se aprenden mejor si existe un conocimiento previo y se percibe la utilidad de desarrollar estas competencias. Algunos ejemplos de buenas prácticas los podemos encontrar en las iniciativas de Swanson (2004) y Johnston y otros (2008), en las que la instrucción estaba integrada en asignaturas concretas relacionadas con la investigación y abarcaba las diferentes etapas del proceso de investigación.

\section{CONCLUSIONES}

Las habilidades y competencias informativas cada vez son más necesarias para desenvolverse en la sociedad de la información y del conocimiento, siendo su dominio un requisito imprescindible para poder aprovechar todo su potencial. La formación en este tipo de habilidades a través 
de programas de AI es una labor fundamental de las bibliotecas, que deben esforzarse en ofrecer una formación de calidad adecuada a las necesidades y características de sus usuarios. Para ello, es necesario conocer a los usuarios, tanto desde el punto de vista de los modelos teóricos que explican su comportamiento informativo, como desde un punto de vista práctico, mediante la realización de estudios de usuarios.

En las normas de AI se señalan una serie de competencias que debe tener un individuo para que sea considerado alfabetizado en información, que incluyen el reconocimiento de sus necesidades de información, su búsqueda, análisis, organización y uso ético y efectivo. La AI, por tanto, no consistiría únicamente en el aprendizaje del manejo de una serie de herramientas (catálogos, bases de datos, etcétera), sino que comprende también habilidades de tipo cognitivo (Scales, Matthews, y Johnson, 2005). No es suficiente saber buscar información, además hay que evaluarla, procesarla, comprenderla, interpretarla e incorporarla a nuestra base de conocimientos. Estas habilidades son más complejas de aprender y de enseñar, puesto que requieren un nivel de abstracción y reflexión elevado, pero en la literatura científica se pueden encontrar pautas y guías que pueden ayudar a conseguirlo.

En la práctica, la mayoría de los programas de AI se ha centrado en las habilidades relacionadas con la búsqueda de información y el uso de citas y referencias bibliográficas, pero no se ha profundizado lo suficiente en las de carácter cognitivo, como las relacionadas con la interpretación y el procesamiento de la información. Enseñar este tipo de habilidades y conseguir que los individuos estén realmente alfabetizados en información es posible y existe suficiente bagaje para hacerlo, pero aún es un gran reto para las bi- 
El papel de la alfabetización informativa en la interpretación...

bliotecas, que deberán buscar las fórmulas más adecuadas para conseguir incluir este tipo de formación en sus programas de AI. Las principales barreras para conseguirlo son la falta de tiempo, la escasa colaboración con los profesores y en muchos casos la falta de respaldo institucional, pero, como muestran varias experiencias y casos de éxito, son superables.

\section{BIBLIOGRAFÍA}

ALA (1989). Presidential Committee on Information Literacy: Final Report. Chicago: American Library Association. Recuperado de http://www.ala.org/acrl/publications/whitepapers/presidential

ALA/ACRL (2000). Information Literacy Competency Standards for Higher Education. Recuperado de: http://www.ala.org/acrl/ standards/informationliteracycompetency

Albitz, R. S. (2007). The what and who of information literacy and critical thinking in higher education. portal: Libraries and the Academy, 7(1), 97-109.

Allen, B., y Kim, K. S. (2001). Person and context in information seeking: Interactions between cognitive and task variables. The New Review of Information Behaviour Research, 2, 1-16.

Allen, M. (2008). Promoting critical thinking skills in online information literacy instruction using a constructivist approach. College \& Undergraduate Libraries, 15(1/2), 21-38.

ANZIIL/CAUL (2004). Australian and New Zealand Information Literacy Framework ( $2^{\circ}$ ed.). Recuperado de: http://www.caul. edu.au/content/upload/files/info-literacy/InfoLiteracyFramework.pdf 
Bates, M. J. (2010). Information behavior. En Encyclopedia of Library and Information Sciences (3a ed, pp. 2381-2391). New York: CRC.

Bawden, D., y Robinson, L. (2011). Individual differences in information-related behaviour: what do we know about information styles? En A. Spink y J. Heinström (ed.), New directions in information behaviour (Vol. 1, pp. 127-158). Emerald.

Behrens, S. J. (1994). A conceptual analysis and historical overview of information literacy. College \& Research Libraries, 55(4), 309-322.

Bronshteyn, K., y Baladad, R. (2006). Perspectives on ... librarians as writing instructors: using paraphrasing exercises to teach beginning information literacy students. The Journal of Academic Librarianship, 32(5), 533-536.

Chen, K., y Lin, P. (2011). Information literacy in university library user education. Aslib Proceedings, 63(4), 399-418.

Courtright, C. (2007). Context in information behavior research. Annual Review of Information Science and Technology, 41(1), 273-306.

Dervin, B., y Nilan, M. (1986). Information needs and uses. Annual Review of Information Science and Technology, 21, 3-33.

Fernández-Ramos. (2015). Alfabetización informativa a través de tutoriales electrónicos: nuevo reto para las bibliotecas universitarias. En La información y sus contextos en el cambio social (pp. 127-153). México: UNAM, IIBI.

Fernández-Ramos, A. (2014). El papel de las bibliotecas en el acceso a recursos web de calidad. Perspectivas em Ciência da Informação, 19(1), 115-129.

Ford, N., Wilson, T. D., Foster, A., Ellis, D., y Spink, A. (2002). Information seeking and mediated searching. Part 4. Cognitive styles in information seeking. Journal of the American Society for Information Science and Technology, 53(9), 728-735. 
El papel de la alfabetización informativa en la interpretación...

Foster, R. L. (2013). Extracting and synthesizing information from a literature review. Journal for Specialists in Pediatric Nursing, 18(2), 85-88.

Goldschmidt, P. G. (1986). Information synthesis: a practical guide. Health Services Research, 21(2), 215-237.

Gómez Hernández, J. A., y Licea de Arenas, J. (2005). El compromiso de las bibliotecas con el aprendizaje permanente. La alfabetización informacional. En Información, conocimiento y bibliotecas en el marco de la globalización neoliberal (pp. 145-179). Gijón: Trea.

Grafstein, A. (2002). A discipline-based approach to information literacy. The Journal of Academic Librarianship, 28(4), 197-204.

Harris, A. J. y Sipa, E. R. (1980). How to increase reading ability: a guide to developmental and remedial methods. New York: Longman.

Heinström, J. (2003). Five personality dimensions and their influence on information behaviour. Information Research, 9(1). Recuperado de: http://www.informationr.net/ir/9-1/paper165. html

Hernández Salazar, P. (2012). Contexto teórico de la alfabetización informativa. En Tendencias de la alfabetización informativa en Iberoamérica (pp. 3-46). México: UNAM, CUIB.

Huerta, D., y McMillan, V. (2004). Reflections on collaborative teaching of science information literacy and science writing. Resource Sharing \& Information Networks, 17(1-2), 19-28.

Izquierdo Alonso, M. (1999). Una aproximación interdisciplinar al estudio del usuario de información: bases conceptuales y metodológicas. Investigación Bibliotecológica, 13(26), 112-134.

Izquierdo Alonso, M., y Moreno Fernández, L. M. (2009). El resumen documental: un reto didáctico. Madrid: FESABID. 
Johnson, C. M., Lindsay, E. B., y Walter, S. (2008). Learning more about how they think: information literacy instruction in a campus-wide critical thinking project. College \& Undergraduate Libraries, 15(1-2), 231-254.

Julien, H. (1999). Where to from here? Results of an empirical study and user-centered implications for system design. En T. D. Wilson y D. K. Allen (Eds.), Exploring the contexts of information behaviour (pp. 586-596). London: Taylor Graham.

Kari, J. (2010). Diversity in the conceptions of information use. Information Research, 15(3). Recuperado de http://www.informationr.net/ir/15-3/colis7/colis709.html

Knievel, J. E. (2008). Instruction to faculty and graduate students: a tutorial to teach publication strategies. portal: Libraries $\&$ the Academy, 8(2), 175-186.

Koltay, T. (2009). Abstracting: information literacy on a professional level. Journal of Documentation, 65(5), 841-855.

Kuhlthau, C. C. (1991). Inside the search process: Information seeking from the user's perspective. Journal of the American Society for Information Science, 42(5), 361-371.

Lancaster, F. W. (2003). Indexing and abstracting in theory and practice. Londres: Facet.

Lasswell, H. D. (1985). Estructura y función de la comunicación en la sociedad. En M. Moragas (ed.), Sociología de la comunicación de masas, II, estructura, funciones y efectos (pp. 50-68). Barcelona: Gustavo Pili.

Lau, J. (2006). Guidelines on information literacy for lifelong learning. Recuperado de http://archive.ifla.org/VII/s42/pub/ILGuidelines2006.pdf

Limberg, L. y Sundin, O. (2006). Teaching information seeking: relating information literacy education to theories of information behaviour. Information Research 12(1). Recuperado de http:// www.informationr.net/ir/12-1/paper280.html 
El papel de la alfabetización informativa en la interpretación...

Mai, J. E. (2013). The quality and qualities of information. Journal of the American Society for Information Science and Technology, 64(4), 675-688.

Mandalios, J. (2013). RADAR: An approach for helping students evaluate internet sources. Journal of Information Science, 39(4), 470-478.

Marcus, S. H., Grover, P. L., y Revicki, D. A. (1987). The method of information synthesis and its use in the assessment of health care technology. International Journal of Technology Assessment in Health Care, 3(4), 497-508.

Matteson, M. L. (2014). The whole student: cognition, emotion, and information literacy. College \& Research Libraries, 75(6), 862877.

Megwalu, A. (2013). Undergraduate Research, Part II. A Technique for Synthesizing Information. The Reference Librarian, 54(4), 349-352.

Meola, M. (2004). Chucking the checklist: a contextual approach to teaching undergraduates web-site evaluation. portal: Libraries E the Academy, 4(3), 331-344.

Metzger, M. J. (2007). Making sense of credibility on the Web: Models for evaluating online information and recommendations for future research. Journal of the American Society for Information Science and Technology, 58(13), 2078-2091.

Niedźwiedzka, B. (2003). A proposed general model of information behaviour. Information Research, 9(1). Recuperado de http:// www.informationr.net/ir/9-1/paper164.html

Olsson, M. R. (2009). Re-Thinking our concept of users. Australian Academic \& Research Libraries, 4O(1), 22-35.

Ondrusek, A. L., Thiele, H. E., y Yang, C. (2014). Writing abstracts for MLIS research proposals using worked examples: an Innovative approach to teaching the elements of research design. College \& Research Libraries, 75(6), 822-841. 
Onwuegbuzie, A. J., y Jiao, Q. G. (1998). The relationship between library anxiety and learning styles among graduate students: Implications for library instruction. Library \& Information Science Research, 20(3), 235-249.

Ostenson, J. (2014). Reconsidering the checklist in teaching internet Source Evaluation. portal: Libraries and the Academy, 14(1), 33-50.

Pappas, M. L., y Tepe, A. E. (1997). Pathways to knowledge: Follett's information skills model. Kit. McHenry, IL: Follett Software Company. Recuperado de http://www.intime.uni.edu/model/ information/proc.html

Pettigrew, K. E., Fidel, R., y Bruce, H. (2001). Conceptual frameworks in information behavior. Annual Review of Information Science and Technology, 35, 43-78.

Pinto, M. (1992). El resumen documental: principios y métodos. Madrid: Pirámide.

Pinto, M., Cordón, J. A., y Díaz, R. G. (2010). Thirty years of information literacy (1977-2007): a terminological, conceptual and statistical analysis. Journal of Librarianship and Information Science, 42(1), 3-19.

Pinto, M., Doucet, A. V., y Fernández-Ramos, A. (2008). The role of information competencies and skills in learning to abstract. Journal of Information Science, 34(6), 799-815.

Pinto, M., Doucet, A. V., y Fernández-Ramos, A. (2010). Measuring students' information skills through concept mapping. Journal of Information Science, 36(4), 464-480.

Pinto, M., Fernández-Ramos, A., y Doucet, A. V. (2008). Measuring students' information literacy skills through abstracting: case study from a Library \& Information Science perspective. College \& Research Libraries, 69(2), 132-154. 
El papel de la alfabetización informativa en la interpretación...

Porter, J. R. (2005). Information literacy in biology education: an example from an advanced cell biology course. Cell Biology Education, 4(4), 335-343.

Reece, G. J. (2005). Critical thinking and cognitive transfer: Implications for the development of online information literacy tutorials. Research strategies, 20(4), 482-493.

Reichel, M. (1991). Library literacy. Reference Quarterly, 31(1), 25.

Saunders, L. (2009). The future of information literacy in academic libraries: a delphi study. portal: Libraries and the Academy, 9(1), 99-114.

Savolainen, R. (2006). Information use as gap-bridging: the viewpoint of sense-making methodology. Journal of the American Society for Information Science and Technology, 57(8), 11161125.

Savolainen, R. (2007). Information behavior and information practice: reviewing the «umbrella concepts» of information seeking studies. The Library Quarterly, 77(2), 109-132.

Savolainen, R. (2009). Information use and information processing. Journal of Documentation, 65(2), 187-207.

Scales, J., Matthews, G., y Johnson, C. M. (2005). Compliance, cooperation, collaboration and information literacy. The Journal of Academic Librarianship, 31(3), 229-235.

SCONUL (2011). Seven pillars of information literacy. Core model for Higher Education. Recuperado de: http://www.sconul.ac.uk/ sites/default/files/documents/coremodel.pdf

Spatt, B. (1983). Writing from sources. New York: St. Martin's Press.

Swanson, T. A. (2004). A radical step: Implementing a critical information literacy model. portal: Libraries and the Academy, 4(2), 259-273. 
Talja, S., Tuominen, K., y Savolainen, R. (2005). "Isms» in information science: constructivism, collectivism and constructionism. Journal of Documentation, 61(1), 79-101.

Thomas, E. L. y Robinson, H. A. (1982). Improving reading in every class: a sourcebook for teachers. Boston: Allyn \& Bacon.

Tidwell, M., y Sias, P. (2005). Personality and information seeking understanding how traits influence information-seeking behaviors. Journal of Business Communication, 42(1), 51-77.

Uribe Tirado, A. (2012). El aprendizaje y la enseñanza de competencias informacionales: dos sistemas interconectados desde la teoría de la actividad y los modelos de comportamiento informacional. Pensando Psicología, 8(15), 74-92.

Warmkessel, M. M. y McCade, J. M. (1997). Integrating information literacy into the curriculum, Research Strategies, 15(2), 80-88.

Wilson, T. D. (1981). On user studies and information needs. Journal of Documentation, 37(1), 3-15.

Wilson, T. D. (1994). Information needs and uses: fifty years of progress. En Fifty years of information progress: A Journal of Documentation review (pp. 15-51). Londres: Aslib.

Wilson, T. D. (1997). Information behaviour: An interdisciplinary perspective. Information Processing \& Management, 33(4), 551-572.

Wilson, T. D. (1999). Models in information behaviour research. Journal of Documentation, 55(3), 249-270.

Wilson, T. D. (2000). Human information behavior. Informing science, 3(2), 49-56.

Wilson, T. D. (2008). The information user: past, present and future. Journal of Information Science, 34(4), 457-464.

Winograd, P. N. (1984). Strategic difficulties in summarizing texts. Reading Research Quarterly, 19(4) 404-425. 
Significados e interpretaciones de la información desde el usuario. La edición consta de 100 ejemplares. Coordinación editorial, Carlos Ceballos Sosa; revisión especializada, Francisco Xavier González y Ortíz; formación editorial, cotejo y revisión de pruebas, Mercedes Torres Serratos. Instituto de Investigaciones Bibliotecológicas y de la Información/UNAM. Fue impreso en papel cultural de $90 \mathrm{~g}$. Se terminó de imprimir en el mes de junio de 2017 en AGYS Alevin S. C., Retorno de Amores No. 14, colonia Del Valle, c.p. 03100, delegación Benito Juárez, México, CDMX. 